\title{
WestVirginiaUniversity
}

THE RESEARCH REPOSITORY @ WVU

Graduate Theses, Dissertations, and Problem Reports

2020

\section{Health Outcomes Associated with Gulf War Illness}

Shannon K. Barth

West Virginia University, skb0015@mix.wvu.edu

Follow this and additional works at: https://researchrepository.wvu.edu/etd

Part of the Epidemiology Commons

\section{Recommended Citation}

Barth, Shannon K., "Health Outcomes Associated with Gulf War Illness" (2020). Graduate Theses,

Dissertations, and Problem Reports. 7936.

https://researchrepository.wvu.edu/etd/7936

This Dissertation is protected by copyright and/or related rights. It has been brought to you by the The Research Repository @ WVU with permission from the rights-holder(s). You are free to use this Dissertation in any way that is permitted by the copyright and related rights legislation that applies to your use. For other uses you must obtain permission from the rights-holder(s) directly, unless additional rights are indicated by a Creative Commons license in the record and/ or on the work itself. This Dissertation has been accepted for inclusion in WVU Graduate Theses, Dissertations, and Problem Reports collection by an authorized administrator of The Research Repository @ WVU.

For more information, please contact researchrepository@mail.wvu.edu. 


\title{
Health Outcomes Associated with Gulf War Illness
}

\author{
Shannon Kathleen Barth, MPH \\ Dissertation submitted to the School of Public Health \\ at West Virginia University \\ In partial fulfillment of the requirements for the degree of \\ Doctor of Philosophy in \\ Public Health Sciences - Epidemiology \\ Robert M. Bossarte, Ph.D., Committee Chair \\ Thomas C. Hulsey, Sc.D. \\ Kim E. Innes, Ph.D. \\ Ronald C. Kessler, Ph.D. \\ Department of Epidemiology \\ Morgantown, West Virginia \\ 2020
}

Keywords: veterans, Gulf War Illness, mortality, chronic diseases, women's health, predictors, Veterans Health Administration

Copyright: 2020 Shannon Kathleen Barth 


\title{
ABSTRACT \\ Health Outcomes Associated with Gulf War Illness
}

\author{
Shannon K. Barth
}

\section{Background and objectives:}

Nearly thirty years after the 1990-1991 Persian Gulf War there is still no definitive case definition for Gulf War Illness (GWI), a syndromic disorder reported by large number of servicemembers deployed in support of the war. Currently accepted case definitions define GWI with different groups of medical conditions including pain, fatigue, cognitive, respiratory, dermatologic, and gastrointestinal disorders; however, these case definitions have not been validated or replicated and their reliability has not been determined. Due to the array of symptoms reported by Gulf War veterans, there is considerable overlap among these current GWI definitions and existing syndromic disorders, such as chronic fatigue syndrome, irritable bowel syndrome, and fibromyalgia. The objective of this dissertation is to explore health outcomes associated with GWI using currently accepted classifications in order to better understand and define the disorder by examining pre-war medical conditions as predictors of probable GWI, mortality outcomes of veterans with probable GWI, and female-specific medical conditions among women with probable GWI. Additionally, we develop and utilize an alternative GWI case definition conforming to recommendations from a systematic review of GWI studies.

\section{Methods:}

Data come from the Department of Veterans Affairs (VA) 1995 National Health Survey of Persian Gulf War Era Veterans, a population-based survey of 30,000 deployed and nondeployed Gulf War era veterans (70\% response rate). We classified respondents as meeting the criteria for the two currently accepted definitions of GWI. For Aim One, we examined pre-war medical conditions as predictors for probable GWI using the two currently accepted classifications in addition to our new definition. For Aim Two, we matched social security numbers of survey respondents to the Joint Department of Defense/VA Mortality Data Repository for years 2000-2014 to determine vital status and cause-specific mortality risk among those with and without probable GWI. For Aim Three, we matched female survey respondents to VA electronic medical records for years 2000-2017 and analyzed risk for femalespecific medical conditions among those with and without probable GWI.

\section{Results:}

Aim One: All pre-war medical condition predictor group variables (pain, dermatologic, genitourinary, gastrointestinal, neurological, cardiac, respiratory, and inflammation) included in the respective logistic regression models were significantly associated with the 3-domain and $\mathrm{CDC} /$ Kansas measures of GWI. Results from this study suggest pre-war factors are associated with increased risk for meeting criteria for GWI following deployment to the Persian Gulf War. Aim Two: Deployed veterans meeting criteria for GWI in 1995-1997 were at increased risk for cause-specific mortality due to malignant neoplasms, circulatory system disorders, and 
digestive system disorders, and had greater risk for overall mortality compared to deployed veterans who did not meet criteria for GWI. However, when compared to non-deployed veterans with probable GWI, deployed veterans with probable GWI had decreased overall mortality risk and decreased risk for mortality due to diseases of the circulatory system. Aim Three: Deployed women meeting criteria for either the CDC or Kansas definition of GWI in 1995 were at increased risk for disorders of the breast and female genital tract compared to non-deployed women who did not meet GWI criteria. Within the deployed group, women meeting criteria for GWI had increased risk for disorders of the female genital tract compared to those not meeting GWI criteria.

\section{Conclusion:}

Our findings add to the GWI literature by presenting results for previously unexplored aspects of the disorder. We were able to identify an association between pre-war medical conditions and post-war probable GWI, indicating that some veterans may have had a pre-existing vulnerability for developing GWI-related conditions. Additionally, we demonstrate use of an alternative case definition for GWI, which was also associated with pre-war predictors. Our mortality results indicate that deployed veterans meeting criteria for GWI in 1995 had some increased risk for GWI-related causes of death, plus mortality due to malignant neoplasms. Finally, we found some evidence of increased risk for female-specific medical conditions among deployed women with GWI symptoms, though we are unable to determine if the findings are related to GWI domains, deployment conditions, or pre-war factors. Our findings support the ongoing need to prioritize GWI research and continued development of a validated and reliable measure for classification of GWI. 


\section{DEDICATION}

I dedicate this dissertation to:

My family, particularly my children, Sullivan and Alister, my greatest loves, who graciously sacrificed so much for this opportunity. They motivate me to continue to grow as a person, ask tough questions, and contribute to society.

My parents, Ken and Bonnie, for their constant support and encouragement to continue my educational journey; from Governor's School for the Arts to William and Mary, they taught me that I could pursue and achieve anything with honest, hard work. Thank you for planting the PhD seed at my MPH graduation 15 years ago.

My brother, Travis, for inspiring me with his successful balance of creativity, thoughtfulness, adventure, and integrity.

My girlfriends, new and old, who are like family - my daily cheerleaders in all aspects of life. I'm incredibly fortunate to be surrounded by accomplished, empowered, and kind women. 


\section{ACKNOWLEDGEMENTS}

This dissertation was completed as part of a larger study, Follow-Up Study of a National Cohort of Gulf War and Gulf Era Veterans. I would like to recognize Dr. Erin Dursa at the Department of Veterans Affairs for providing the survey data used for this study and her tireless efforts towards improving veterans' health. Thanks to Dr. Aaron Schneiderman, also at the Department of Veterans Affairs, who graciously approved this dissertation research.

At West Virginia University, Bob Hoover was instrumental in helping with SQL coding and sample matching. Maria Martik kindly assisted with SAS coding questions. I am thankful for the rest of the team at the WVU Injury Control Research Center for their support.

Though this dissertation research did not involve direct contact with the U.S. military veteran community, I acknowledge and appreciate their service to our country. I am aware of the suffering and frustration among those living with Gulf War Illness, their time dedicated to the research studies used in this dissertation, and the crucial need for answers to this complicated disorder.

I am greatly appreciative to my dissertation committee members, Dr. Thomas Hulsey, Dr. Kim Innes, and Dr. Ronald Kessler, for their expertise, advice, and interest in this study.

Lastly, I am grateful to Dr. Robert Bossarte, my committee chair and mentor, for his continual encouragement during this dissertation process and throughout my PhD program. Particularly with this study, he has challenged me to question the status quo, take a fresh look at the problem of Gulf War Illness, and ultimately grow as an epidemiologist. 


\section{TABLE OF CONTENTS}

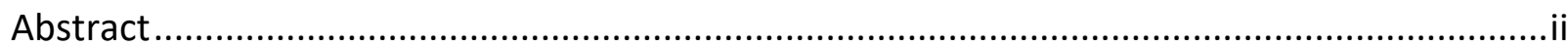

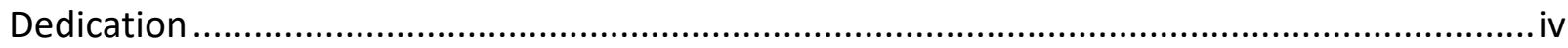

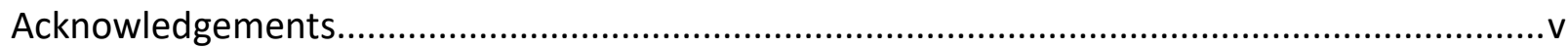

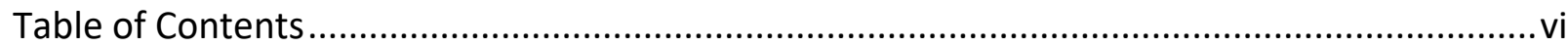

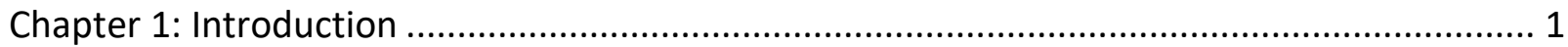

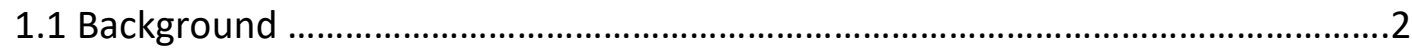

1.1.1 History of Gulf War and Gulf War Illness .................................................. 2

1.1.2 Definitions of Gulf War Illness ........................................................................... 3

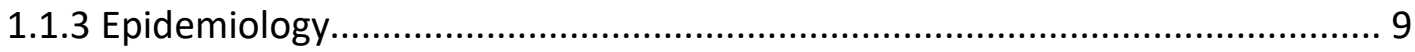

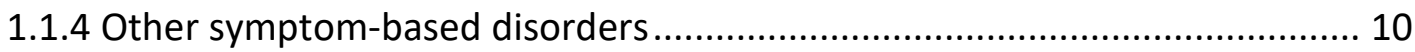

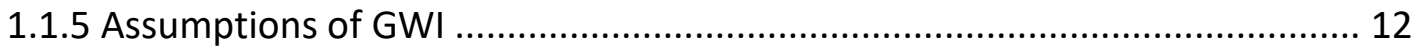

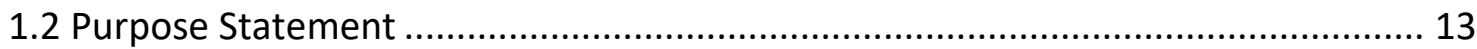

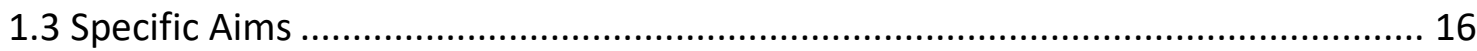

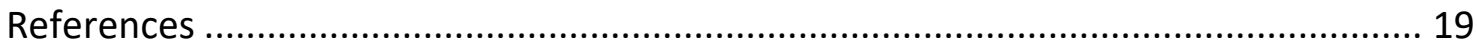

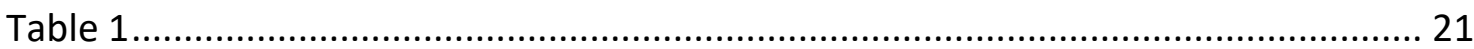

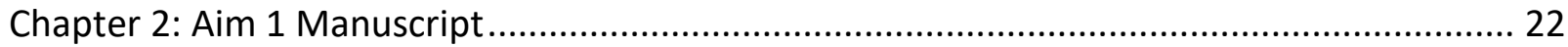

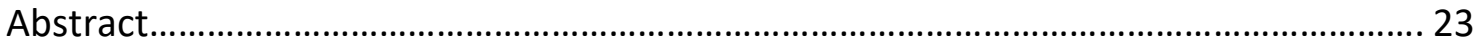

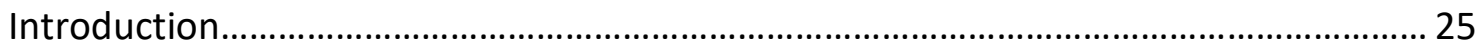

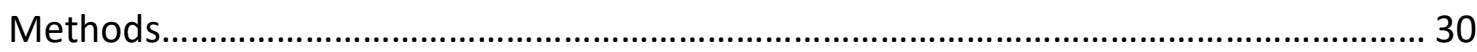

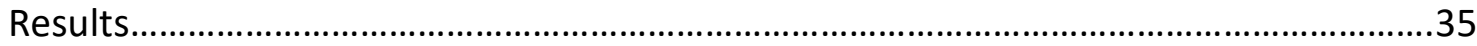

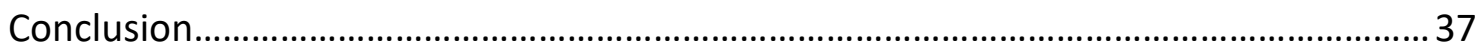

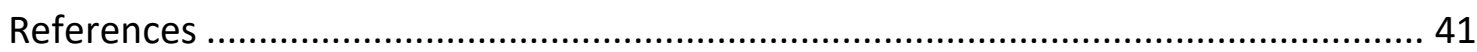

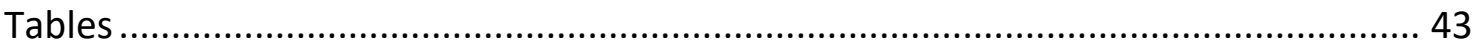

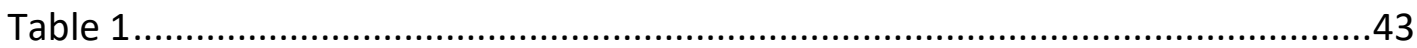

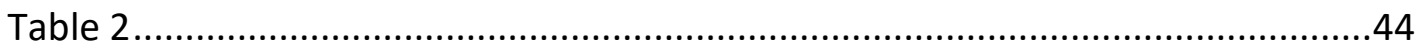

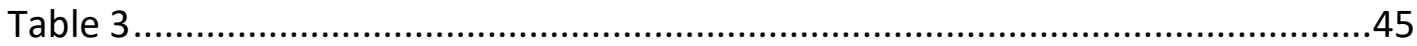

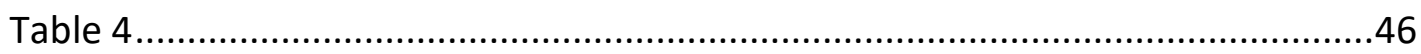

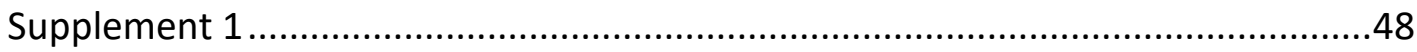

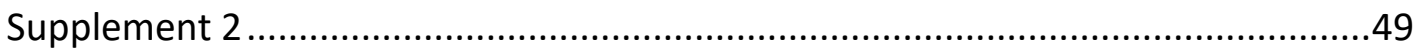

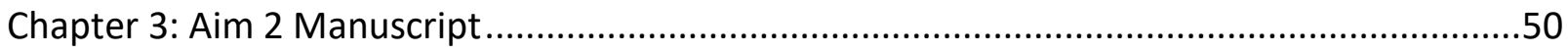

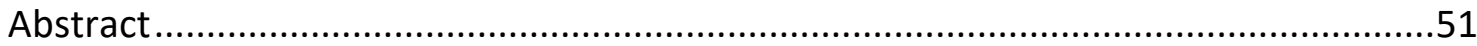

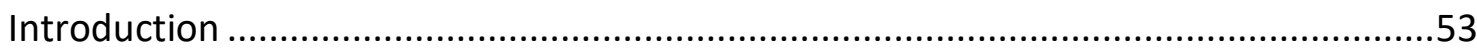

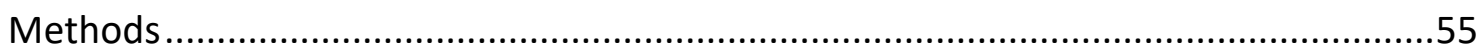

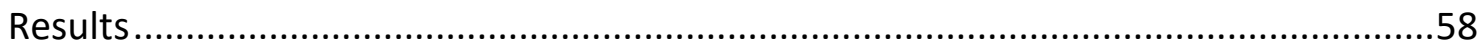

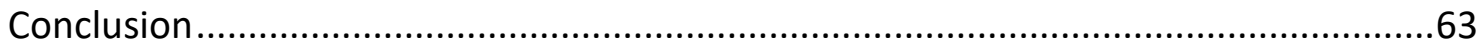

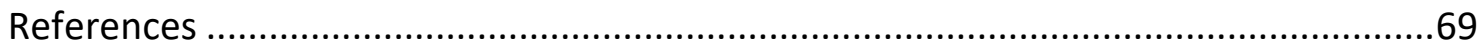

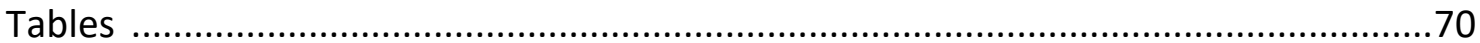

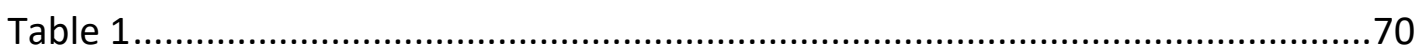

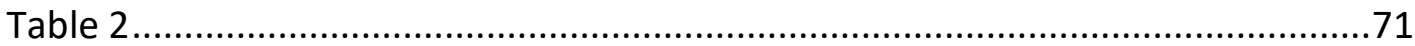

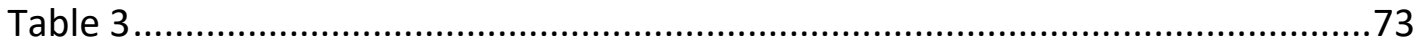

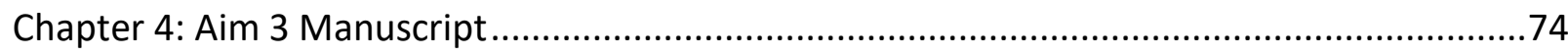

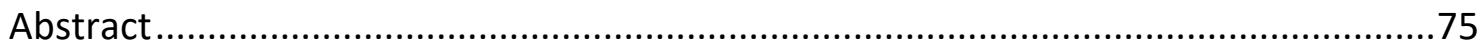




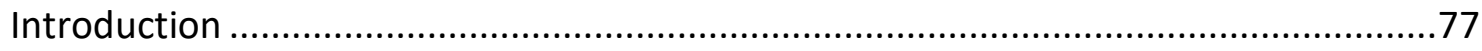

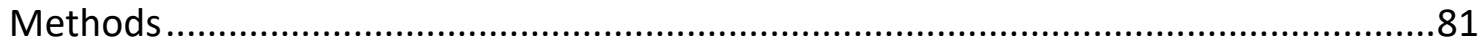

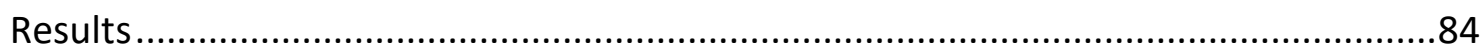

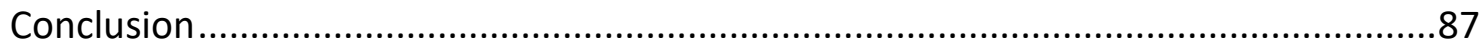

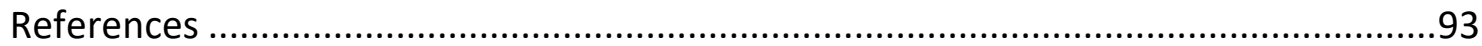

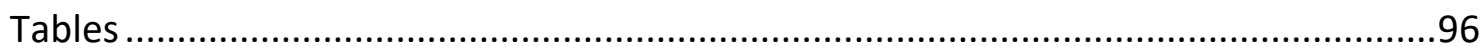

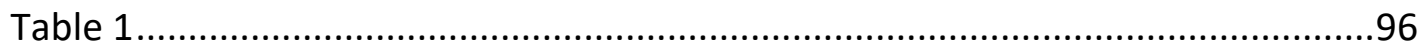

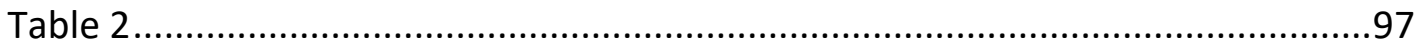

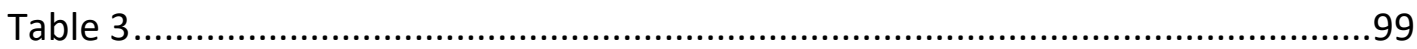

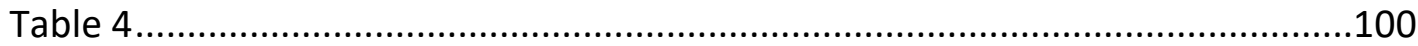

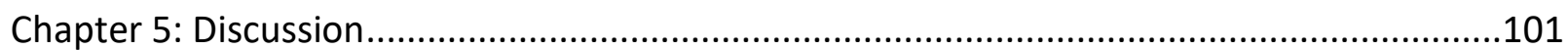

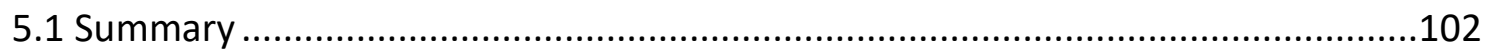

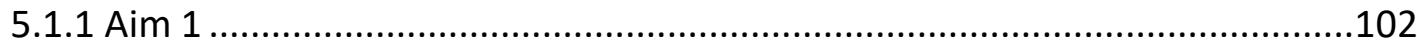

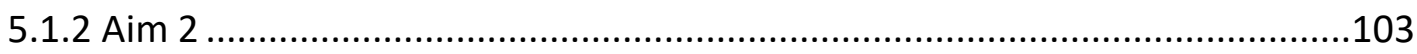

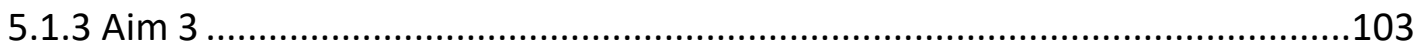

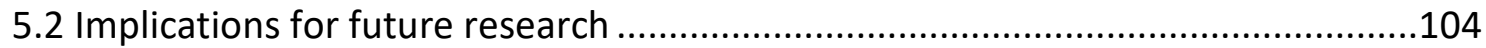

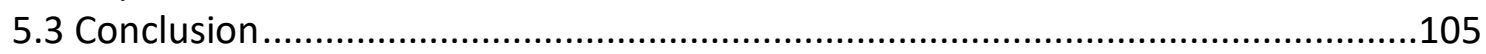

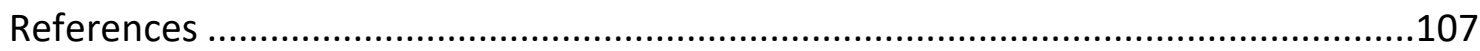


Chapter 1

Introduction 


\section{Chapter 1: Introduction}

\subsection{Background}

\subsubsection{History of Gulf War and Gulf War Illness}

Beginning on August 8, 1990, the United States (U.S.) deployed 697,000 troops to Saudi Arabia in support of Kuwait after an Iraqi invasion led by Saddam Hussein known as Operation Desert Shield. Iraq refused to withdraw from Kuwait and the conflict developed into a massive U.S.-led airstrike beginning on January 17, 1991, known as Operation Desert Storm, which progressed to a ground war in mid-February and ended in a cease-fire on February 28, 1991 [1]. While this was considered a relatively short conflict in comparison to other U.S.-involved wars, many of those who deployed in support of the war have been impacted by persistent negative health outcomes assumed to be linked to deployment or related exposures of war.

Soon after their return from the Gulf War, military servicemembers and veterans began reporting multiple, varying, and difficult to diagnose clusters of health problems, such a pain, fatigue, respiratory problems, cognitive issues, and gastrointestinal illnesses. Utilizing samples of various military and veteran cohorts, researchers conducted epidemiological studies to investigate these symptoms in an effort to explore clustering of highly prevalent symptoms and define the disorder, which became known first as Gulf War Syndrome, then chronic multisymptom illness, and finally Gulf War Illness (GWI), the signature disease of the Gulf War era. However, 29 years after the Gulf War, the fundamental task of defining GWI is still ongoing; no definitive, validated case definition has ever been developed [2], which has led to a quarter 
century of complications and delays in treatment research and frustrated veterans who are still suffering.

\subsubsection{Definitions of Gulf War Illness}

At least 40 studies have been published attempting to describe and group symptoms of GWI or develop case definitions using Gulf War deployed and non-deployed cohorts from the U.S. and Europe, military unit-specific subsets of deployed and non-deployed Gulf War veterans or servicemembers, and Gulf War registries [2] (Appendix 1). The range of symptoms reported and lack of details about onset, duration, and severity in many studies has made it difficult to use symptom-based research to develop a case definition for GWI [2]. Five studies attempted to define a case definition for GWI, which are referred to as the Haley, CDC, Portland, Kansas, and Kang definitions of GWI.

Haley

In 1995 and 1996, using a small cohort $(n=249)$ of Gulf War deployed servicemembers and veterans from a Naval Reserve Unit, a group of researchers [3] conducted a survey and analyzed data using a two-stage factor-analysis approach to determine syndromes. Based on their analyses, they reported discovery of six syndromes: impaired cognition, confusion-ataxia, arthro-myo-neuropathy, phobia-apraxia, fever-adenopathy, weakness-incontinence. Syndromes one through three had strongly clustered symptoms, while syndromes four through six were weakly clustered, with strong overlap with syndromes two and three. This study was small and lacked a comparison group. Haley, et al conducted a validity study in 1996 through 
1997 using a group of 335 Active Duty U.S. Army servicemembers living in Texas [4]. Results of this validation study indicated three syndromes based on factor analysis of symptoms from the previous study: impaired cognition, confusion-ataxia, and central pain. The Haley, et al studies present the most statistically robust attempts at defining $\mathrm{GWI}$, though this research is limited by small sample sizes and lack of generalizability in both publications.

$C D C$

Fukuda, et al conducted a clinical examination and survey study with a sample of approximately 3,700 U.S. Air Force veterans in 1995 in an attempt to define GWI [5] using two methodologiesconfirmatory factor analysis and symptom-category approach. Ultimately, their case definition was based on the symptom-category method due to the ease of use in a clinical setting. They defined GWI as having one or more symptoms for 6 months or more in at least two of the following categories: fatigue, mood and cognition (feeling depressed, difficulty remembering or concentrating, moody, anxious, trouble finding words, sleep problems), and musculoskeletal (joint pain or stiffness, muscle pain). Cases were considered severe if all symptoms reported were severe. Based on this definition of GWI, which is referred to as the CDC definition, $39 \%$ of their surveyed deployed Gulf War veterans met the criteria for mild-moderate GWI compared to $14 \%$ of the non-deployed veterans met the criteria. This study is limited by its use of a specific geographical cohort of U.S. Air Force veterans. Additionally, no studies have validated the case definition developed by this research. 


\section{Portland}

VA researchers and collaborators from Portland, Oregon conducted a two-phase case-control study of Gulf War veterans in the Northwestern area of the U.S. in November 1995 through January 1998. Phase I involved a survey of deployed Gulf War veterans ( $n=1,119$ respondents) followed by Phase II, a clinical follow-up study $(n=357)$ [6]. Based on factor analysis performed using survey data and analysis of the case-control study data, the definition of GWI developed by this group required at least one symptom occurring for at least one month in the previous three months in the follow categories: fatigue, cognitive and psychological, and musculoskeletal. For the fatigue group of symptoms, the following criteria must be met: unexplained fatigue must be accompanied by at least four additional symptoms: fever/chills, new headaches, unrefreshing sleep, tender glands, memory problems or difficulty concentrating, sore throat, painful joints, unexplained muscle weakness, muscle aches, feeling ill for a day or more after exercising. Results from this study are limited due to small sample sizes and lack of generalizability to the greater Gulf War deployed cohort.

Kansas

In 1998, a survey of approximately 3,000 Gulf War veterans living in Kansas was conducted to investigate increased burden of health issues among deployed Gulf War veterans [7]. This study resulted in what is commonly referred to as the Kansas definition of GWI. Based on correlations of symptom scores and comparison of symptom groups between deployed and non-deployed veterans in the study, five groups were identified: fatigue/sleep problems, pain symptoms, neurologic/cognitive/mood symptoms, gastrointestinal symptoms, and respiratory symptoms. 
A sixth group, skin symptoms, was added based on one skin related question on the survey. Exclusionary criteria included serious psychiatric illness and a list of chronic diseases including heart disease, cancer, diabetes, chronic infectious diseases, problems resulting from postwar injuries, liver disease, lupus, multiple sclerosis, or stroke. To be classified as a GWI case according to this definition, the veteran must have reported one moderately severe symptom or two or more symptoms in a group in at least three of the six symptom categories, with no exclusion criteria. According to this definition, $34 \%$ of deployed veterans and $8 \%$ of nondeployed veterans met the criteria for GWI. This study also applied the CDC criteria for GWI to their respondents and reported $3.26 \%$ of deployed and $1 \%$ of non-deployed met criteria for GWI.

Kang

A survey conducted by Kang, et al, at the Department of Veterans Affairs (VA) in 2005 as a 10year follow up to the 1995 National Health Survey of Persian Gulf War Era Veterans (NHS) [8] defined GWI (referred to as unexplained multi-symptom illness) as "having several different symptoms together that persist for 6 months or longer and are not adequately explained by conventional medical or psychiatric diagnoses." Symptoms included in this definition are fatigue, headaches, joint and muscle pain, and respiratory problems. The description of the definition used for this study is vague and specific criteria are not listed, making it difficult to deem this a new or revised definition of GWI. Regardless, the authors reported that $36 \%$ of Gulf War deployed respondents and $11 \%$ of non-deployed responses met criteria for multi-symptom illness. Recently, errors were discovered in the 2005 survey data, making this publication an 
unreliable source (unpublished; personal communications with VA). The IOM considers this publication an attempt at a case definition for GWI, though considering the lack of a description of methodology and no specific criteria for classification, in addition to the survey data errors, published results from this study may not be reliable.

In 2014 the Institute of Medicine (IOM) published a systematic review of the GWI literature, which concluded that three symptom domains occur consistently across all published studies (fatigue, pain, and neurocognitive disorders), and three additional domains occur in all symptom-based publications (respiratory, gastrointestinal, and dermatologic disorders). Based on these findings, the IOM determined that no existing case definition fully captured the findings from the systematic review, and most are additionally missing important components of case definitions, including details regarding laboratory findings, onset, duration, frequency, and severity of symptoms. IOM ultimately recommended continued research towards a definitive case definition for GWI; however, they stated that the CDC [5] and Kansas [7] case definitions could be used to identify veterans with GWI until an ideal case definition is developed.

The IOM stated that the CDC definition of GWI identified the three most common domains occurring in symptomatic Gulf War veterans, however, this is not entirely accurate. While the CDC definition includes fatigue as a domain, the other two domains representing pain and neurocognitive disorders are more limited in scope than what was summarized by the IOM as occurring in all publications. In the CDC definition, pain is represented by "musculoskeletal symptoms," specifically referring to joint and muscle pain [5]. Neurocognitive disorders are 
represented by a "mood and cognition" domain, which includes depressive symptoms and anxiety, two commonly occurring mental health disorders that often co-occur with physical health issues but excludes additional and potentially important neurocognitive disorders such as chronic headaches and migraines. The IOM rationalized the use of the Kansas definition for GWI due to the inclusion of a version of all six of the domains found in their systematic review of the literature. While their pain, neurocognition, and fatigue domains seem fitting, the inclusion of the three additional domains (gastrointestinal, respiratory, and skin symptoms) that were only found in some GWI publications may mean that this definition is identifying a large number of false positives. Additionally, it is important to note that the Kansas definition criteria includes exclusionary criteria for severe psychiatric disorders and several chronic diseases (heart disease, cancer, diabetes, chronic infectious diseases, problems resulting from postwar injuries, liver disease, lupus, multiple sclerosis, or stroke) [7].

Using the CDC and Kansas definitions of GWI could result in misclassification of cases due to decreased sensitivity and specificity; although no studies have demonstrated validity of either of these definitions. Additionally, both of these definitions were conducted on relatively small samples in very specific, non-generalizable populations (approximately 2,000 Kansas Gulf War veterans included in the Kansas study and approximately 3,700 U.S. Air Force veterans from 4 units who served in the Gulf War in the CDC study) $[5,7]$. Considering the many subsequent studies that have proceeded with research on GWI using cases defined by the CDC and/or Kansas definitions, the IOM may have done the Gulf War research community and veterans a disservice with this endorsement. 
Support for a definitive disorder unique from other known syndromes responsible for the increase in symptom reporting among Gulf War veterans was not universal among those conducting research in this area. Some researchers concluded that their studies did not support of evidence of a unique GWI [9-11]. A review study by Ismail and Lewis [11] stated that there is no evidence for a unique GWI and that the symptoms experienced by Gulf War veterans are similar to medically unexplained syndromes experienced among civilians.

\subsubsection{Epidemiology}

According to various studies, an estimated $25-50 \%$ of veterans who served during the 1990 1991 Gulf War report symptoms consistent with various definitions of (GWI) [12] [7, 13]. A primary reason for the broad range of GWI prevalence estimates is lack of a universally accepted and validated case definition. Without knowing how to define a case, it is nearly impossible to understand the magnitude of the problem from an epidemiological standpoint.

One recent paper looking at the demographic characteristics reported that GWI is prevalent among women, Hispanics, African Americans, and veterans who served in the Army, Reserves, and National Guard [12]. One study reported increased symptom reporting among a cohort of Gulf War veterans 20 years after the war, though the increase in symptoms was similar in both deployed and non-deployed groups [14]. To our knowledge, no researchers have investigated mortality among veterans who met the criteria for GWI. 


\subsubsection{Other symptom-based disorders}

There are several other syndrome-based disorders for which case definitions have been developed, such a chronic fatigue syndrome (CFS), irritable bowel syndrome (IBS), and fibromyalgia, which occur in the general population. Due to the large number of and varied symptoms involved in GWI, currently defined symptom-based disorders do not completely explain the common clusters of symptoms seen in this group of veterans [2]. Previous research studies have demonstrated overlap between GWI and some of these disorders [11], making it likely that some proportion of the general population experiences symptom patterns of GWI, though to our knowledge this has not been investigated. For example, it is highly plausible that a proportion of the general U.S. civilian population, in the same age range as Gulf War veterans, experience symptoms consistent with the CDC definition of GWI, meeting criteria by experiencing conditions in two of the three domains of fatigue, mood and cognition, and musculoskeletal conditions [5]. Studies have demonstrated that non-deployed veterans of the Gulf War era also experience symptoms consistent with the symptoms included in definitions of GWI [12].

Chronic fatigue syndrome, also known as myalgic encephalomyelitis, is a difficult to diagnosis and treat syndromic disorder comprised of symptoms that overlap considerably with GWI symptoms, such as fatigue, muscle pain, headaches, cognitive dysfunction, and gastrointestinal issues [15]. Similar to GWI, it took over 30 years to develop an accepted case definition for CFS [16]. Women are more than twice as likely as men to experience CFS, and the disease often has a substantial negative impact on quality of life [17]. The currently accepted case definition for 
CFS requires new onset fatigue, post-exertional malaise, and unrefreshing sleep plus either cognitive impairment or orthostatic intolerance [16]. Research has shown that many patients with CFS also meet criteria for other syndromic disorders including IBS and fibromyalgia [16].

Fibromyalgia is also described as a difficult to diagnose disorder characterized by widespread and often migratory pain, frequently accompanied by fatigue, sleep problems, memory issues, and mood disturbances [18]. These secondary symptoms often subside with pain relief. Fibromyalgia affects $2 \%$ to $8 \%$ of the general population and women are more likely to be affected than men [18]. Again, there is commonality between some definitions of GWI and the symptoms included in fibromyalgia.

Irritable bowel syndrome (IBS) is another syndromic disorder characterized by symptom clusters such as constipation, abdominal cramping, and bloating, which are often dynamic and associated with specific food intake [19]. IBS is estimated to occur in $7 \%$ to $21 \%$ of the general population [19], causes decreased quality of life, and co-occurs often with other syndromic disorders such as CFS and fibromyalgia [20]. The ROME III criteria is currently used to diagnose IBS, requiring recurrent abdominal pain or discomfort for at least three days per month for at least three months, with exclusion of organic disease [19]. Given the inclusion of the gastrointestinal domain for the Kansas definition for GWI, it seems plausible that some patients meeting the criteria for GWI would also meet criteria for IBS. 


\subsubsection{Assumptions of GWI}

There are several assumptions inherent in our current understanding of GWI that have yet to be elucidated. First, it is assumed that GWI is a unique illness due to its proposed domain construct, meaning that it is meaningfully different from other syndromic disorders and related combination of domains. There is little evidence to support this statement. In fact, it is likely that the domains shown to be highly prevalent in deployed Gulf War veterans often occur together in the general, civilian population as well. However, to our knowledge no studies have been conducted to apply either of the accepted case definitions to a cohort of the general population to test this hypothesis. No studies have conclusively demonstrated that GWI is a uniquely occurring set of symptoms.

Secondly, it is assumed that GWI is an illness that is meaningfully distinct from other syndromebased disorders that have occurred in other military cohorts. One argument for this distinction has been the prevalence of symptoms among those deployed in support of the Gulf War. The prevalence of symptoms has been shown to be greater in Gulf War deployed veterans compared to non-deployed veterans who served during the same time period [2]. In order to demonstrate that this is a unique disorder to those veterans deployed to the Gulf War, we would need evidence that GWI rarely occurs in non-deployed cohorts and that this is different from health outcomes in other military cohorts. Studies have shown that non-deployed veterans who served during the Gulf War era do experience the combinations of symptoms used to identify GWI in ample numbers [12]. The various symptoms reported in the GWI literature do not differ greatly from disorders prevalent in previous military conflicts [21, 22]. 
Additionally, veterans returning from the recent conflicts of Operation Iraqi

Freedom/Operation Enduring Freedom have met the criteria for GWI [23, 24].

These leads to the next assumption of GWI, which is that GWI was caused by some unknown exposure or exposures during the Gulf War. Studies attempting to address this hypothesis have not demonstrated correlations between GWI and various exposures including vaccinations, oil well fire smoke, sarin gas, and depleted uranium $[11,25]$.

There is an assumption that GWI is independent of underlying vulnerabilities that may interact with subsequent exposures or otherwise increase risk for GWI following deployment. The CDC definition for GWI does not include any exclusion criteria, while the Kansas definition does exclude based on psychiatric and chronic disease history [5, 7]. If GWI is an independently occurring disorder that is not related to an individual's underlying health status, then it seems counterintuitive to apply exclusion criteria to these case definitions. Use of such a definition could erroneously exclude individuals from research studies and treatment regimens.

Finally, there is an assumption that the latency period between exposure and symptom onset is boundless; veterans are still eligible for meeting GWI criteria even 30 years after the war, when symptom causation is increasingly complicated due to the aging population.

\subsection{Purpose Statement}

The overarching purpose of this dissertation is to explore health outcomes associated with GWI among Gulf War veterans in order to aid in our understanding of the disorder. Our null 
hypothesis is that there is no evidence that GWI is a disorder unique to veterans of the 19901991 Gulf War.

Nearly 30 years after the war there is still no clear understanding regarding the causes of GWI or the long-term outcomes among those who have symptoms consistent with the disorder [2]. While numerous studies have researched GWI as a function of military service, significant gaps exist in our understanding of baseline risk, longer-term outcomes or differences across demographic groups. Results from this dissertation will address important questions related to baseline risk for diseases and other disorders associated with GWI. This research provides a unique opportunity to explore health outcomes and pre-service characteristics among veterans with symptoms consistent with GWI soon after the end of the war, using data from a population-based survey, mortality records, and electronic medical records.

To date, there has not been a single analysis that has assessed the possibility that GWI may not be completely a function of exposures during military service. To our knowledge, only one previous study of veterans with GWI has considered pre-enlistment factors as predictors of GWI [26]. This work has important consequences for policies related to federal compensation for GWI and potential exposures or other characteristics related to this disorder. Similarly, there has been no research to date that has investigated differences in either all-cause or causespecific mortality potentially associated with GWI. Differences in patterns of mortality associated with a positive screen for GWI have not been explored. Drawing on a unique data set collected shortly after the Gulf War, the research included in this project has the potential to identify differences in patterns of mortality that may shed light on potential exposures or 
previously unrecognized burden of illness. Finally, despite evidence of differential impact of GWI on women, there has been little research focused on gender-specific diseases or disorders related to GWI. This dissertation will directly contribute to the existing literature by carefully considering outcomes unique to a proportionately smaller but clinically important segment of the veteran population.

\section{Data sources}

Data used to address our objectives come from a population-based retrospective case-control study and VA mortality and electronic medical records. Survey data come from the 1995-1997 National Health Survey of Persian Gulf War Era Veterans (NHS), the largest population-based cohort study of Gulf War and Gulf War Era veterans conducted to date. A stratified random sample of 15,000 deployed and 15,000 non-deployed veterans was drawn from DoD records of all 693,826 troops deployed between September 1990 and May 1991 and 800,680 nondeployed troops, representing approximately half of those who were in the military during the same time period but did not deploy. Random sampling was based on gender and unit component (active duty, reserve, National Guard); women and reserve/National Guard were oversampled. The sample of 30,000 was sent a 16-page self-administered, structured health questionnaire, followed up with three reminders and a phone call for remaining nonresponders at 6 months [27]. The NHS questionnaire included questions on demographic and military characteristics, somatic and psychological symptoms, functional limitations, chronic conditions, self-reported health status, medical care utilization (such as hospitalizations and physician contacts), smoking, and substance use. Many of the survey questions came from the 
National Health Interview Survey to allow for comparison to the general U.S. population.

Relevant environmental risk factors were also evaluated including immunization history, pyridostigmine bromide (PB) pills, smoke from oil well fires, diesel, and other chemical exposures. Respondents included 11,441 Gulf War veterans (75\%) and 9,476 Gulf War era (nondeployed) veterans (64\%) resulting in an overall response rate of $70 \%$. For each of our three aims we used veteran respondents to the 1995 NHS who met the criteria for either the CDC or Kansas definitions of GWI [12].

The data on female-specific health care utilization come from electronic medical records in the Veterans Health Administration Corporate Data Warehouse (CDW), which houses records for all veterans who have received healthcare at a VA facility. Mortality data for this study come from the Joint Department of Defense (DoD)- Department of Veterans Affairs Mortality Data Repository (all-cause) (MDR), a database containing cause-specific mortality information for all veterans. The MDR is a combination of multiple federal database including the National Death Index, DoD specific databases, and Veterans Health Administration files. While developed with the intent to provide a comprehensive database for military and veteran suicide research in order to better understand and prevent suicide, the MDR includes information on all deaths including specific causes of death using ICD-9 and ICD-10 codes [28].

Data for all aims were analyzed using SAS Enterprise Grid software (version 5.1, SAS Institute Inc.). This study has been reviewed and approved by the Institutional Review Board at the Syracuse VA Medical Center.

\subsection{Specific Aims}




\section{Specific Aim 1: Identify pre-war health predictors associated with meeting criteria for Gulf}

War Illness. We hypothesize that pre-war medical symptoms do not predict meeting criteria for GWI after the war.

To address this aim, we conducted a retrospective case-control study using data from the 1995 National Health Survey of Persian Gulf War Era Veterans (NHS). We applied modified CDC and Kansas criteria for GWI to deployed and non-deployed respondent data and identified those who did or did not meet the criteria for either definition. Additionally, we created a new definition of probable GWI using the recommendations of the IOM [2]. Using these two definitions of GWI, we investigated pre-war medical conditions and symptoms as risk factors for predicting probable GWI. We calculated prevalence estimates of pre-war medical conditions and symptoms stratified by probable GWI status. We performed a series of multivariable logistic regression analyses evaluating the associations between pre-war medical conditions and symptoms to probable GWI.

Specific Aim 2: Identify differences in all-cause and cause-specific mortality among veterans who do and do not meet criteria for GWI. We hypothesize that deployed veterans who meet criteria for GWI will have significantly greater risk for all-cause and cause-specific mortality.

As in the first aim, respondent identifiers and probable GWI status come from the NHS. Veteran identifiers were matched to mortality data from the MDR. We calculated crude all-cause and cause-specific mortality rates stratified by probable GWI classification. Next, we calculate ageand gender-adjusted all-cause and cause-specific mortality hazard ratios using Cox proportional hazard models comparing veterans who did and did not report GWI symptomology. 
Specific Aim 3: Identify differences in risk for reproductive disorders among women who do and do not meet criteria for GWI. We hypothesize that women who were deployed to the Persian Gulf War who met criteria for GWI will have higher incidence for reproductive disorders.

Data for this aim come from respondents to the NHS limited to those who self-reported as women on the survey. This cohort of women veterans was matched to the VA medical record database to identify all International Classification of Disease (ICD) codes in inpatient, outpatient, emergency department, and fee-for-service medical records related to femalespecific health conditions (e.g., endometriosis, spontaneous abortions, etc). We calculated incidence estimates of female-specific medical conditions among women who did and did not meet the criteria for GWI according to the CDC and Kansas definitions. Next, we calculated indirectly age-adjusted standardized incident rate ratios and adjusted hazard ratios using Cox proportional hazard models adjusting for race/ethnicity and age group. 


\section{References}

1. Freedman, L. and E. Karsh, The Gulf conflict, 1990-1991: Diplomacy and war in the new world order. 1993: Princeton University Press.

2. Committee on the Development of a Consensus Case Definition for Chronic Multisymptom Illness in - Gulf War, V., P. Board on the Health of Select, and M. Institute of, in Chronic Multisymptom IIIness in Gulf War Veterans: Case Definitions Reexamined. 2014, National Academies Press (US). Copyright 2014 by the National Academy of Sciences. All rights reserved.: Washington (DC).

3. Haley, R.W., T.L. Kurt, and J. Hom, Is there a Gulf War Syndrome? Searching for syndromes by factor analysis of symptoms. Jama, 1997. 277(3): p. 215-22.

4. Haley, R.W., G.D. Luk, and F. Petty, Use of structural equation modeling to test the construct validity of a case definition of Gulf War syndrome: invariance over developmental and validation samples, service branches and publicity. Psychiatry Res, 2001. 102(2): p. 175-200.

5. Fukuda, K., et al., Chronic multisymptom illness affecting Air Force veterans of the Gulf War. Jama, 1998. 280(11): p. 981-8.

6. Bourdette, D.N., et al., Symptom factor analysis, clinical findings, and functional status in a population-based case control study of Gulf War unexplained illness. J Occup Environ Med, 2001. 43(12): p. 1026-40.

7. Steele, L., Prevalence and patterns of Gulf War illness in Kansas veterans: association of symptoms with characteristics of person, place, and time of military service. Am J Epidemiol, 2000. 152(10): p. 992-1002.

8. Kang, H.K., et al., Health of US veterans of 1991 Gulf War: a follow-up survey in 10 years. J Occup Environ Med, 2009. 51(4): p. 401-10.

9. Ismail, K., et al., Is there a Gulf War syndrome? Lancet, 1999. 353(9148): p. 179-82.

10. Shapiro, S.E., M.R. Lasarev, and L. McCauley, Factor analysis of Gulf War illness: what does it add to our understanding of possible health effects of deployment? Am J Epidemiol, 2002. 156(6): p. 578-85.

11. Ismail, K. and G. Lewis, Multi-symptom illnesses, unexplained illness and Gulf War Syndrome. Philos Trans R Soc Lond B Biol Sci, 2006. 361(1468): p. 543-51.

12. Dursa, E., et al., Gulf War Illness in the 1991 Gulf war and Gulf era veteran population: an application of the centers for disease control and prevention and Kansas case definitions to historical data. Journal of Military and Veterans Health, 2018. 26(2): p. 43.

13. White, R.F., et al., Recent research on Gulf War illness and other health problems in veterans of the 1991 Gulf War: Effects of toxicant exposures during deployment. Cortex, 2016. 74: p. 449-75.

14. Gwini, S.M., et al., Increased symptom reporting persists in 1990-1991 Gulf War veterans 20 years post deployment. Am J Ind Med, 2015. 58(12): p. 1246-54.

15. Yancey, J.R. and S.M. Thomas, Chronic fatigue syndrome: diagnosis and treatment. Am Fam Physician, 2012. 86(8): p. 741-6.

16. Committee on the Diagnostic Criteria for Myalgic Encephalomyelitis/Chronic Fatigue, S., P. Board on the Health of Select, and M. Institute of, The National Academies Collection: Reports funded by National Institutes of Health, in Beyond Myalgic 
Encephalomyelitis/Chronic Fatigue Syndrome: Redefining an Illness. 2015, National Academies Press (US). Copyright 2015 by the National Academy of Sciences. All rights reserved.: Washington (DC).

17. Christley, Y., T. Duffy, and C.R. Martin, A review of the definitional criteria for chronic fatigue syndrome. J Eval Clin Pract, 2012. 18(1): p. 25-31.

18. Clauw, D.J., Fibromyalgia: a clinical review. Jama, 2014. 311(15): p. 1547-55.

19. Chey, W.D., J. Kurlander, and S. Eswaran, Irritable bowel syndrome: a clinical review. Jama, 2015. 313(9): p. 949-58.

20. Riedl, A., et al., Somatic comorbidities of irritable bowel syndrome: a systematic analysis. J Psychosom Res, 2008. 64(6): p. 573-82.

21. Jones, E., et al., Post-combat syndromes from the Boer war to the Gulf war: a cluster analysis of their nature and attribution. Bmj, 2002. 324(7333): p. 321-4.

22. Hyams, K.C., F.S. Wignall, and R. Roswell, War syndromes and their evaluation: from the U.S. Civil War to the Persian Gulf War. Ann Intern Med, 1996. 125(5): p. 398-405.

23. McAndrew, L.M., et al., Iraq and Afghanistan Veterans report symptoms consistent with chronic multisymptom illness one year after deployment. J Rehabil Res Dev, 2016. 53(1): p. 59-70.

24. Smith, T.C., et al., Chronic multisymptom illness: a comparison of Iraq and Afghanistan deployers with veterans of the 1991 Gulf War. Am J Epidemiol, 2014. 180(12): p. 117687.

25. Institute of Medicine, D.o.H.P.a.D.P., Committee on Health Effects Associated with Exposures during the Gulf War:, Gulf War and Health, Vol 1, Depleted Uranium, Pyridostigmine Bromide, Sarin, Vaccines. 2000, Institute of Medicine, National Academy Press: Washington, DC.

26. Blanchard, M.S., et al., Chronic multisymptom illness complex in Gulf War I veterans 10 years later. Am J Epidemiol, 2006. 163(1): p. 66-75.

27. Kemp, J. and R.M. Bossarte, Surveillance of suicide and suicide attempts among veterans: addressing a national imperative, in Am J Public Health. 2012. p. e4-5. 


\section{Table1: Summary of GWI Publications}

\begin{tabular}{|c|c|c|c|c|c|}
\hline Brief desciption & Cotition & $\begin{array}{l}\text { Propesed } \\
\text { Gwillose } \\
\text { defirition } \\
\text { dereloped }\end{array}$ & $\begin{array}{c}\text { Symptinn- } \\
\text { bersed } \\
\text { study }\end{array}$ & $\begin{array}{c}\text { Factor } \\
\text { antysis } \\
\text { used" }\end{array}$ & $\begin{array}{l}\text { Custers } \\
\text { amblysis } \\
\text { used" }\end{array}$ \\
\hline \multicolumn{6}{|l|}{ Populdation besed sturfies } \\
\hline VA stungy & Kang et al., 2000, 2009 & $\mathbf{x}$ & $\mathbf{x}$ & $\mathbf{x}$ & \\
\hline lowa study & lowa Persian Gulf Study Group, 1997; Doetheling et al., 2000 & & $\mathbf{x}$ & $\mathbf{x}$ & \\
\hline Oregon and Washington Veteran Sturies & Mocandey et al., 1999; Borrdette et al., 2001; Stordach et al, 2000; Spenoer et al., 1998 & $\mathbf{x}$ & $\mathbf{x}$ & $\mathbf{x}$ & \\
\hline Kansas & Stede, 2000 & $\mathbf{x}$ & $\mathbf{x}$ & & \\
\hline Canadian Veteran Study & Goss Gilroy the, 1998 & & $\mathbf{x}$ & & \\
\hline \multicolumn{6}{|l|}{ United Kingdom Veteran Studies: } \\
\hline Uriversity of Lmodon Veteran Stufies & Unwin et al., 1999; lsmal et al. 1999; & & $\mathbf{x}$ & & \\
\hline Uriversity of Manchester Veteran Study & Cherry et al., 2001 & & $\mathbf{x}$ & $\mathbf{x}$ & $\mathbf{x}$ \\
\hline London Scthod of theiene and Trupical Medicine Veteran Study & Maoonodie et al., 2003; Simmons et al., 2004 & & $\mathbf{x}$ & & \\
\hline Guy's, King's, and St. Thomas's Schods of Medioine Sturies & Everitt et al., 2002 & & & & $\mathbf{x}$ \\
\hline \multicolumn{6}{|l|}{ Studies in other countries: } \\
\hline Darish Peacekeper Stufies & Istwey et al, 1999 & & $\mathbf{x}$ & & \\
\hline Australian Veteran Studies & Keball et al., 2004; Futhes et al. 2004 & & $\mathbf{x}$ & $\mathbf{x}$ & \\
\hline French Military Study & Sabamon et al. 2006 & & $\mathbf{x}$ & & \\
\hline CDC and UK Combined & Niserhaum et al, 2004 & & & $\mathbf{x}$ & \\
\hline \multicolumn{6}{|l|}{ MWTitay unit based studies } \\
\hline Hawaii and Penrsylvaria Active-Duty and Reserve Study & Stretrh et al, 1995 & & $\mathbf{x}$ & & \\
\hline Ft. Deveris and New Orleans Cohort Studes & Proctor et al., 1998; Wolfe et al, 1998 & & $\mathbf{x}$ & & \\
\hline Seabee Reserve Battalion Sturies & Haley et al., 1997; Gray et al, 1999; Gray et al., 2002; Haley et al, 2001; Kruke et al., 2000; tarnaoutuine et al., 21 & & $\mathbf{x}$ & $\mathbf{x}$ & \\
\hline Perrmsytvania Air National Guard Study & Fulanda et al., 1998 & $\mathbf{x}$ & $\mathbf{x}$ & $\mathbf{x}$ & \\
\hline Air Farce Wamen's Study & Piece, 1997 & & $\mathbf{x}$ & & \\
\hline \multicolumn{6}{|l|}{ Registy sturfes } \\
\hline Department of Deferse Registry Studies & Joseph of at, 1997, Kroenke ot a, 1998; Roy of al, 1998; Frickson of a, 1998 & & $\mathbf{x}$ & & \\
\hline Department of Veterans Affuirs Registry Sturdes & Escdante and Fischbarh, 1998; Hallman ot al, 2003; Oralinci et al, 2006 & & $\mathbf{x}$ & $\mathbf{x}$ & $x$ \\
\hline United Kingdom Regit ty Shudy & Coker et al, 1999, Lee ot al, 2001, 2002 & & $\mathbf{x}$ & & \\
\hline
\end{tabular}

a. Detaiks in Chater 3 of $10 \mathrm{M} 2014$

h Detaik in Chapter 4 of IOM 2014 
Chapter 2

Aim 1 Manuscript 


\title{
Predicting Gulf War Illness Using Pre-War Medical Conditions
}

\begin{abstract}
Introduction: Though a validated and universally accepted case definition still does not exist, presumptive Gulf War Illness (GWI) remains a significant health concern for many Gulf War veterans. Pre-war health conditions of Gulf War veterans are mostly unexplored and could aid in developing a more accurate case definition of GWI. The objective of this study was to investigate pre-war predictors of Gulf War Illness (GWI) using survey data from a populationbased sample of Gulf War veterans.
\end{abstract}

Methods: Using two definitions of GWI (CDC/Kansas combined and a newly developed 3domain definition), we calculated a series of multivariable logistic regression models to identify correlates of pre-war medical characteristics and GWI. Predictors were grouped in the following categories: pain, dermatologic, genitourinary, gastrointestinal, neurological, cardiac, respiratory, and inflammation.

Results: All predictor group variables included in the respective models were significantly associated with the 3-domain and CDC/Kansas measures of GWI.

Conclusion: In this study, meeting criteria for GWI in 1995, using either the CDC/Kansas version or 3-domain definition was predicted by all pre-war medical conditions considered in this analysis. Results from this study suggest pre-war factors are associated with increased risk for meeting criteria for GWI. Subsequent studies should consider the reliability of measures used to 
classify GWI and the possibility that pre-war factors may be associated with increased vulnerability for GWI or symptoms of similarly presenting disorders. 


\section{Introduction}

An estimated $25-50 \%$ of veterans who served in the 1990-1991 Persian Gulf War reported experiencing a syndrome of medical conditions after return from deployment, commonly referred to as Gulf War Illness (GWI) [1-3]. GWI is characterized by clusters of medical symptoms including fatigue, pain, dermatological and cognitive symptoms, and disorders of the respiratory, neurological, and gastrointestinal systems, which have been included in various efforts to classify GWI since the mid-1990's [4]. While veterans with GWI continue to report symptoms consistent with this syndrome 30 years post-war, no definitive case definition exists, creating a challenge for categorization of disease status and assessment of treatment options [4].

Historical studies and reports have shown similar clusters of symptoms occurring among veterans from all United States (U.S.) military conflicts since the Civil War, as well as military conflicts in other countries [5-8]. The high prevalence of symptoms consistent with syndromic illness among deployed veterans of the 1990-1991 Gulf War makes GWI a disorder unique to this population of veterans $[6,9,10]$.

To understand the increased symptom reporting and related conditions among Gulf War veterans, it is important to acknowledge the baseline risk of related medical symptoms in the general U.S. population. An epidemiologic study published in 1993 reported the most common medical conditions in the United States were joint pain (37\% prevalence), back pain (32\% prevalence), headaches (24.9\% prevalence), and fatigue (24\% prevalence); all symptoms 
included in currently-accepted classifications of GWI [11]. Importantly, one of the earliest and most widely used measures of GWI [2] reported an excess burden of a specific cluster of conditions, theoretically associated with deployment to the 1990-1991 Persian Gulf War, ranging from $25-30 \%$.

Shortly after the 1990-1991 Gulf War, researchers attempted to classify distinct groupings of symptoms and achieve consensus on a common definition of GWI, a difficult task given the myriad of conditions being reported, as well as differences in sampling and study design [12, 13]. In 2014, the Institute of Medicine (IOM) published a systematic review of existing GWI case definitions and ultimately determined no published case definition accurately captures the groups of symptoms and diagnoses consistently reported in studies of this population [4]. In addition to recommending continued efforts towards developing a case definition for GWI, IOM endorsed the use of two existing definitions that they felt most closely captured GWI symptoms in the published literature: the definition developed by the Centers for Disease Control and Prevention (CDC) [14] and the definition developed by Steele, referred to commonly as the Kansas definition [2]. Neither of these case definitions have been validated or tested for reliability [4].

A recent publication classified veteran respondents as meeting criteria for $\mathrm{GWI}$ according to the CDC and Kansas definitions using historical data from the Department of Veterans Affairs' population-based National Health Survey of Persian Gulf War Era Veterans (NHS) [1]. This study estimated $40-50 \%$ of deployed veterans met the criteria for GWI according to these definitions. 
Additionally, this study estimated a relatively high prevalence (17\%) of probable GWI cases in non-deployed veterans using these same case definitions, a finding consistent with prior research studies [3]. In the absence of an empirically-supported explanation, the paradoxically high prevalence of non-deployed veterans meeting criteria for a condition thought to be related to deployment to a particular region and conflict raises questions about both the reliability and validity of existing assessments and resulting estimates of disease burden generated by their use. Several studies have demonstrated overlap of symptoms of GWI with symptoms included in other established syndromic disorders, including chronic fatigue syndrome, irritable bowel syndrome, and fibromyalgia, further complicating efforts to identify characteristics uniquely associated with GWI $[2,15-18]$.

Multiple studies have investigated the relationship between prevalence of GWI symptoms and wartime exposures of the 1990-1991 Persian Gulf War, including oil well fire smoke, nerve agents at a munitions depot (Khamisiyah), pyridostigmine bromide (PB, an anti-nerve agent), vaccinations, and depleted uranium (used for tank armor and bullets), however results from these studies are inconclusive. A 1997 survey of Gulf War veterans found that those who reported exposures to PB, oil well fire smoke, tent heaters during deployment, anthrax vaccination, and chemical odors were more likely to meet criteria for the CDC definition of GWI compared to those without those exposures [19]. However, a case-control study of Kansas-area veterans found no increased risk for meeting the criteria for GWI among veterans who reported exposure to oil well fire smoke [20]. This same study reported increased risk for meeting GWI criteria among veterans who reported wearing uniforms treated with pesticides compared to 
those without, but no increased risk among veterans reporting other pesticide exposures [20]. They also found increased risk for meeting criteria for GWI among veterans who reported taking PB pills compared to those who did not [20]. A review by the IOM reported inadequate evidence to establish an association between multiple vaccinations and chronic health outcomes [21]. Using data from the NHS, researchers reported few differences in health outcomes between veterans reporting exposure to potential sarin and cyclosarin nerve agents (Khamisiyah), though GWI criteria was not assessed in this study [22]. A cross-sectional study found increased risk for separate GWI symptoms among veterans with self-reported exposure to pesticides during Gulf War deployment, though this study also did not investigate those meeting all criteria for GWI [23]. Finally, a cross-sectional study of Air Force veterans reported increased risk for CDC's definition of GWI among those self-reporting exposure to PB and pesticides [24].

The lack of in-theater measurement of these exposures has made classification of these exposures difficult, relying instead on veteran self-report and environmental modeling of exposure to airborne chemicals and smoke [21]. Additionally, research on environmental exposures is complicated by multiple and varied exposures experienced by those deployed to areas of conflict. Many studies reporting the relationships between wartime exposures and GWI lack generalizability due to small sample sizes and limited or specific groups of veterans sampled. Various definitions of GWI have been used in these studies, making comparisons across studies problematic. Studies of veterans who deployed to Iraq and Afghanistan in support of Operation Iraqi Freedom (OIF) and/or Operation Enduring Freedom (OEF) report 
high prevalence of veterans meeting the criteria for $\mathrm{GWI}[25,26]$, an indication that GWI may not have been caused by a unique exposure or experience during the 1990-1991 Gulf War.

To date, studies investigating pre-war predictors of GWI are limited. A follow-up study using a subset of respondents to the NHS reported an association between pre-war anxiety and depression and chronic multi-symptom illness (a term previously used to refer to GWI) in both deployed and non-deployed veterans of the Gulf War era [27]. This is in an indication that, to some extent, those meeting criteria for GWI had some pre-war health differences compared to those without probable GWI, and further studies should explore additional pre-war health conditions. Cross-sectional data from the 1995-1997 NHS study provides a unique opportunity to utilize responses to pre-war medical condition questions collected approximately five years post-war as predictors of early onset GWI [28].

Investigating the associations between pre-war medical conditions and symptoms consistent with definitions of GWI may help researchers understand if certain veterans were likely to develop GWI-like illness regardless of deployment status and may help researchers refine currently accepted definitions of GWI. The objective of this study was to determine which, if any, pre-war medical conditions predict meeting criteria for GWI using survey data from a representative sample of Gulf War veterans. Additionally, this study also compares the prevalence and risk of pre-war medical condition predictors among a newly developed, 3domain definition of GWI derived from a review of criteria reported by existing studies (CDC/Kansas) $[2,4,14]$. 


\section{Methods}

Measures:

Data for this study came from the 1995-1997 National Health Survey of Persian Gulf War Era Veterans (NHS) [28]. This population-based study collected health and military exposure data from a stratified random sample of 15,000 deployed Gulf War veterans and 15,000 nondeployed veterans using a 16-page mailed survey with telephone follow-up for non-responders. Deployed veterans were sampled from all 693,826 Gulf War veterans deployed between August 1, 1990 and March 1, 1991, as determined by the Department of Defense's Defense Manpower Data Center. Fifteen thousand non-deployed veterans were sampled from 800,690 veterans, representing half of those who served in the military during the same time period but did not deploy to the 1990-1991 Persian Gulf War. The samples were stratified by gender, unit component (active duty, National Guard, Reserves), and branch of service (Air Force, Army, Navy, Marine Corps). A detailed description of study design and methods is described in a previous publication [29]. Analyses included in this study were limited to deployed veterans.

\section{Gulf War Illness definitions:}

We used two definitions of GWI as outcome measures for these analyses, based on results from an existing 2014 IOM systematic review of all GWI scientific research publications. The IOM concluded after reviewing the existing published GWI classification methods that no complete or ideal case definition currently exists in the published literature. The definition developed by the Centers for Disease Control and Prevention (CDC) [14] and the definition developed by 
Steele, referred to commonly as the Kansas [2] definition, were recommended by the IOM as the best options for classifying GWI. The first definition of GWI used in our analyses is a combination of the CDC and Kansas definitions of GWI. Details on how the Kansas and CDC definitions were modified using the NHS survey data are available in a previous publication [1]. Briefly, to meet criteria for the Kansas definition of GWI the veteran must have reported a condition occurring for the first time during or after the Gulf War in three of the following six domains: fatigue, pain, neurological/mood/cognition, gastrointestinal, respiratory, and skin. Consistent with previous use, respondents were excluded for self-reported history of cancer, diabetes, heart disease, liver disease, or stroke, or overnight hospital stays for mental health disorders. To meet criteria for the CDC definition, the veteran must have reported conditions in two of three domains: fatigue, mood or cognition, and musculoskeletal. There were no exclusion criteria for the CDC definition. For these analyses, the Kansas and CDC definitions of GWI were combined into a variable referred to as "CDC/Kansas GWI." Survey respondents meeting either the CDC or Kansas definition were considered GWI cases.

In the IOM's 2014 systematic review, they identified three groups of symptoms that appear routinely in all existing attempts at classifying GWI (24 studies on symptoms including five studies that attempt to classify GWI): fatigue, pain/musculoskeletal, and neurocognitive dysfunction [4]. While the CDC and Kansas definitions are the most frequently used classification methods, neither of these definitions have been validated and both were developed using limited samples. Due to the extensive information on medical conditions and symptoms available from the NHS survey, we developed a new definition of GWI conforming to 
the three domains identified by the IOM as being present in all existing efforts [4]. Deployed NHS respondents were classified as a "3-domain GWI" case if they had at least one during- or post-war symptom in each of the three domains: fatigue, pain, and neurocognitive dysfunction. In contrast to the CDC/Kansas GWI definition, the 3-domain GWI definition used symptoms to define cases rather than diagnosable medical conditions. Veterans reporting overnight hospital stays for psychoses were excluded (ICD-9 295-299). A sensitivity analysis was conducted to compare the 3-domain GWI definition to the CDC/Kansas GWI (Supplement 1). Supplement 2 displays the frequency counts of the medical symptoms and conditions for each domain, stratified by GWI definition.

\section{Predictors:}

Two survey questions on the NHS included lists of medical conditions and diseases with response options to indicate if the condition first occurred before, during, or after the 19901991 Persian Gulf War. Conditions that were included in either the CDC/Kansas GWI or the 3domain GWI definitions were excluded as potential predictors for that definition, resulting in two sets of predictors, one specific to each definition. To be considered a predictor, the respondent must have indicated initial symptoms or conditions with a date of onset before the war. Survey respondents with a missing response for any predictor variable were excluded from the final analytic database. A variable indicating the number of predictors was created for inclusion in regression models with levels $0,1,2,3,4$ and 5 or greater.

Predictor groups: 
Predictor variables were collapsed into grouped categories based on body systems. An exploratory factor analysis was conducted, though there was no evidence of factor groupings. For the $\mathrm{CDC} /$ Kansas definition the predictor groups were pain, genitourinary, neurological, and inflammation. The predictor groups used for the 3-domain definition of GWI include pain, dermatologic, genitourinary, gastrointestinal, neurological, cardiac, respiratory, and inflammation.

Demographic and other health status variables:

Demographic variables included age group in 1991 (17-22, 23-32, 33+), gender (men vs. women), and race/ethnicity (white, non-Hispanic vs. other). Smoking status questions were combined into one variable with levels "never smoked," "former smoker," "current smoker," representing smoking status at the time of survey completion. Questions about alcohol consumption were combined into a single variable with levels "never drank," "former drinker, "current drinker."

Statistical analyses:

Survey weights were applied to account for stratified sampling design and oversampling of women and National Guard/reservists [28]. Frequency counts, weighted percentages, and Wald chi-square estimates of demographic variables, smoking history, and drinking history were stratified by GWI definition. We calculated gender- and GWI definition-stratified frequency counts, weighted percentages, and Wald chi-square values for conditions included in the $\mathrm{CDC} /$ Kansas GWI and 3-domain GWI definition domains and predictor variables. 
A series of weighted, multivariable logistic regression models were created to calculate risk of both definitions of GWI based on pre-war medical conditions. Model one includes only the demographic and health history variables for each GWI definition. Model two includes all demographic and health history variables plus the count of predictor variable for each GWI definition. Model three includes all definition-specific potential predictor groups, plus demographics and health history variables. For model four, 12 separate regression models were created for each individual predictor variable, controlling for demographics, health history variables, and count of predictors. Model five is the full multivariable model with all statistically significant predictor groups, demographics, health history variables, and count of predictors.

Two additional sets of models were developed to investigate interactions. Model six includes separate multivariate logistic regression models, one for each predictor group, with the inclusion of a multiplicative interaction term for each predictor group and gender, plus demographic, health history, and count of predictor covariates. Model seven includes additive interaction models, one for each predictor group plus every other predictor group, for each GWI definition.

For all multivariable logistic regression models, predictor variables were entered as ordinal level variables with the reference group set as "no condition," producing weighted, adjusted odds ratios for two time periods (conditions reported before or during the war compared to after the 
war). Data were analyzed using SAS Enterprise Grid software (version 5.1, SAS Institute, Inc.). Alpha was set at 0.05 for all analyses.

\section{Results}

The total analytic subsample included 6,178 deployed veterans. Frequency counts, weighted percentages and Wald chi-squares and p-values of demographic and health risk factors for the 3-domain and CDC/Kansas GWI definitions are presented in Table 1 . Overall, $29.37 \%$ of deployed group met criteria for new GWI compared to $51.68 \%$ who met criteria for CDC/Kansas definition of GWI. Women represented approximately $7 \%$ of both definitions of GWI. The distribution of demographic characteristics and health history variables were similar for both definitions. Table 2 displays the overlap in positive $(29.16 \%)$ and negative $(48.11 \%)$ cases for both the 3-domain and CDC/Kansas definitions of GWI. Table 3 presents the prevalence of individual and grouped predictor variables by GWI definition. The prevalence of predictors was similar across shared predictor groups. For respondents meeting criteria for the 3-domain definition of GWI, approximately $30 \%$ had a pre-war respiratory condition.

Findings from multivariable logistic regression models for predictor groups stratified by GWI definitions are shown in Table 4. In Model One, which only includes demographics and smoking and drinking history, women were more likely than men to meet the criteria for both definitions of GWI (adjusted odds ratio $[\mathrm{aOR}]=1.44,95 \%$ confidence interval $[\mathrm{Cl}]=1.20,1.74$ for 3-domain GWI; aOR = 1.75, 95\% Cl = 1.46, 2.11 for CDC/Kansas GWI). Veterans reporting non-white race/ethnicity were more likely to meet the criteria for both definitions of GWI 
compared to those identifying as white $(\mathrm{aOR}=1.31,95 \% \mathrm{Cl}=1.10,1.56$ for 3-domain $\mathrm{GWI}$; aOR $=1.37,95 \% \mathrm{Cl}=1.16,1.62$ for $\mathrm{CDC} /$ Kansas $\mathrm{GWI})$. Current smokers were significantly more likely to meet GWI criteria for both definitions compared to those who reported never smoking (aOR $=1.67,95 \% \mathrm{Cl}=1.42,1.97$ for 3-domain $\mathrm{GWI}$; $\mathrm{aOR}=1.81,95 \% \mathrm{Cl}=1.56,2.11$ for $\mathrm{CDC} /$ Kansas $\mathrm{GWI}$ ). For the $\mathrm{CDC} /$ Kansas definition of $\mathrm{GWI}$, those in the youngest age group were at greater risk for meeting GWI criteria compared to those in the oldest age group $(\mathrm{aOR}=0.74,95 \% \mathrm{Cl}=$ $0.61,0.88)$ and former drinkers were at greater risk compared to those who reported never drinking $(\mathrm{aOR}=1.62,95 \% \mathrm{Cl}=1.15,2.29)$.

Model Two includes the count of predictor variables in addition to the covariates included in Model One. For 3-domain GWI, each increase in the count of predictor variables was associated with an $11 \%$ increased risk of meeting $\mathrm{GWI}$ criteria $(\mathrm{aOR}=1.11,95 \% \mathrm{Cl}=1.06,1.16)$. For the CDC/Kansas GWI definition, increasing levels of predictors increased risk by $63 \%$ for meeting GWI criteria $(\mathrm{aOR}=1.63,95 \% \mathrm{Cl}=1.42,1.87)$.

Model Three includes a set of 12 multivariable models with predictor groups in addition to demographic and health history covariates. All predictor groups were associated with a 2- to 3fold increased risk for 3-domain GWI compared to those without the pre-war conditions. Similarly, with CDC/Kansas GWI each predictor group was associated with 2- to 3.3-fold increased risk for meeting $\mathrm{CDC} /$ Kansas requirements for GWI. 
Model Four is another set of 12 models (labeled $a-h$ ), which included all covariates listed in Model Three with the addition a count of predictor variables. All predictor group variables remained statistically significant even when controlling for the count of predictors, for both GWI definitions. The count of predictors was marginally statistically significant for the 3-domain GWI outcome for all predictor groups variables except cardiovascular disease. For the $\mathrm{CDC} /$ Kansas GWI outcome, the count of predictor variables was associated with an increased risk of $38-48 \%$ per additional condition.

Model Five is the full model with all statistically significant predictors identified in Models 1- 4, demographics, health history variables, and a count of individual predictors. For both GWI definitions, all predictor group variables were statistically significant. The count of predictors was not statistically significant for either the 3-domain $(\mathrm{aOR}=1.01,95 \% \mathrm{Cl}=0.95,1.08)$ or $\mathrm{CDC} /$ Kansas $(\mathrm{aOR}=1.05,95 \% \mathrm{Cl}=0.90,1.22)$ definition of $\mathrm{GWI}$.

Supplement 3 shows the results of the multiplicative (Model Six) and additive (Model Seven) interaction models. The only multiplicative interaction that was statistically significant was the interaction of gender by inflammation for the $\mathrm{CDC} /$ Kansas $\mathrm{GWI}$ outcome $(\mathrm{aOR}=1.36,95 \% \mathrm{Cl}=$ $1.05,1.75)$. All additive interactions were statistically significant.

\section{Conclusion}

Results from these analyses demonstrate that GWI can be explained by pre-war medical conditions and symptoms. Deployed Gulf War veterans reporting pre-war medical conditions 
considered in this analysis were significantly more likely to meet criteria for GWI according to the CDC or Kansas definitions, as well as a more restrictive 3-domain definition, compared to those who did not have pre-war conditions. These findings remained statistically significant when controlling for multiple categories of pre-war medical conditions and an overall count of the number of pre-war conditions, demographic characteristics and health risk behaviors.

To our knowledge this is only the second study to investigate pre-war predictors of probable GWI among veterans of the 1990-1991 Gulf War. The previous study found that pre-war depression and anxiety predicted GWI [27]. These findings indicate a difference in pre-war mental health status among those who later met criteria for GWI. Our findings add to the scant research on baseline, pre-war differences among those who develop GWI symptoms; there is now evidence to show both mental health and medical conditions are associated with increased risk for GWI. Development of a refined definition for GWI should consider the possible influence of pre-war mental health and medical conditions.

As part of these analyses we had the unique opportunity to construct a case definition limited to the three domains recommended by the IOM (fatigue, pain/musculoskeletal, and neurocognitive dysfunction) using 1995-1997 survey data from the NHS, a population-based survey of deployed and non-deployed Gulf War veterans [4]. Development of a 3-domain version of defining GWI is supported by the IOM's review of all published studies attempting to define GWI. We were able to capitalize on existing survey data from early after the war to develop a version aligned with the IOM's suggested ideal case definition. While the CDC 
definition of GWI also uses three domains, one marked difference is the lack of mood disorders in our neurocognitive domain. Using this new definition, $29 \%$ of deployed Gulf War veterans met the criteria for GWI, compared to nearly $52 \%$ of deployed veterans meeting the criteria for the CDC or Kansas versions of GWI. While our analyses were limited to deployed and therefore not presented in the results, in the non-deployed respondent group, only $8 \%$ met the criteria for 3-domain GWI while nearly $24 \%$ met the criteria for CDC/Kansas GWI. We hypothesize that the 3-domain version represents a definition of GWI with greater specificity compared to either the CDC or Kansas definitions. Results from this study suggest that the 3-domain definition of GWI may more accurately capture true cases compared to the $C D C /$ Kansas definition; although a gold standard remains elusive.

There are some weaknesses to this study including potential differential recall bias on selfreported survey data among deployed and non-deployed veterans as well as those who were feeling ill compared to those not experiencing post-war medical symptoms. Our application of the CDC and Kansas definitions of GWI, the new 3-domain GWI definition, and the pre-war medical condition predictors were limited by the questions included on the survey. Large numbers of missing values were a limitation when selecting predictor variables. Additionally, we were unable to determine if survey respondents who did not meet criteria for $C D C /$ Kansas GWI or 3-domain GWI at the time the survey was administered later met those criteria. This study has several strengths including the population-based cohort, large overall response rate of $70 \%$, and timeliness of survey administration [28]. To our knowledge, no other populationbased surveys exist for the Gulf War veteran population. 
These findings suggest that some veterans deployed in support of the Gulf War may have had an underlying vulnerability for GWI prior to deployment associated with existing medical conditions or that some undetermined portion of veterans currently classified as meeting criteria for GWI may be more accurately classified with another syndrome-based disorder. The pursuit of a case definition for GWI continues and this study indicates the importance of inclusion of pre-war medical conditions when developing an updated case definition. The use of the 3-domain version of a GWI definition demonstrates a possible improvement in specificity and should be investigated further. 


\section{References}

1. Dursa, E., et al., Gulf War Illness in the 1991 Gulf war and Gulf era veteran population: an application of the centers for disease control and prevention and Kansas case definitions to historical data. Journal of Military and Veterans Health, 2018. 26(2): p. 43.

2. Steele, L., Prevalence and patterns of Gulf War illness in Kansas veterans: association of symptoms with characteristics of person, place, and time of military service. Am J Epidemiol, 2000. 152(10): p. 992-1002.

3. White, R.F., et al., Recent research on Gulf War illness and other health problems in veterans of the 1991 Gulf War: Effects of toxicant exposures during deployment. Cortex, 2016. 74: p. 449-75.

4. Committee on the Development of a Consensus Case Definition for Chronic Multisymptom Illness in - Gulf War, V., P. Board on the Health of Select, and M. Institute of, in Chronic Multisymptom Illness in Gulf War Veterans: Case Definitions Reexamined. 2014, National Academies Press (US). Copyright 2014 by the National Academy of Sciences. All rights reserved.: Washington (DC).

5. Jones, E., et al., Post-combat syndromes from the Boer war to the Gulf war: a cluster analysis of their nature and attribution. Bmj, 2002. 324(7333): p. 321-4.

6. Research, K.s.C.f.M.H., King's Centre for Military Health Research: A fifteen year report. 2010.

7. Engel, C.C., Jr., Post-war syndromes: illustrating the impact of the social psyche on notions of risk, responsibility, reason, and remedy. J Am Acad Psychoanal Dyn Psychiatry, 2004. 32(2): p. 321-34; discussion 335-43.

8. Hyams, K.C., F.S. Wignall, and R. Roswell, War syndromes and their evaluation: from the U.S. Civil War to the Persian Gulf War. Ann Intern Med, 1996. 125(5): p. 398-405.

9. Unwin, C., et al., Health of UK servicemen who served in Persian Gulf War. Lancet, 1999. 353(9148): p. 169-78.

10. Gwini, S.M., et al., Increased symptom reporting persists in 1990-1991 Gulf War veterans 20 years post deployment. Am J Ind Med, 2015. 58(12): p. 1246-54.

11. Kroenke, K. and R.K. Price, Symptoms in the community. Prevalence, classification, and psychiatric comorbidity. Arch Intern Med, 1993. 153(21): p. 2474-80.

12. Committee on Gulf War and Health, V.U.o.H.E.o.S.i.t.G.W., et al., in Gulf War and Health: Volume 10: Update of Health Effects of Serving in the Gulf War, 2016, D. CorySlechta and R. Wedge, Editors. 2016, National Academies Press (US). Copyright 2016 by the National Academy of Sciences. All rights reserved.: Washington (DC).

13. Hotopf, M. and S. Wessely, Can epidemiology clear the fog of war? Lessons from the 1990-91 Gulf War. Int J Epidemiol, 2005. 34(4): p. 791-800.

14. Fukuda, K., et al., Chronic multisymptom illness affecting Air Force veterans of the Gulf War. Jama, 1998. 280(11): p. 981-8.

15. Kang, H.K., et al., Health of US veterans of 1991 Gulf War: a follow-up survey in 10 years. J Occup Environ Med, 2009. 51(4): p. 401-10.

16. Ismail, K., et al., Chronic fatigue syndrome and related disorders in UK veterans of the Gulf War 1990-1991: results from a two-phase cohort study. Psychol Med, 2008. 38(7): p. 953-61. 
17. Hyams, K.C., Developing case definitions for symptom-based conditions: the problem of specificity. Epidemiol Rev, 1998. 20(2): p. 148-56.

18. Thomas, H.V., et al., Systematic review of multi-symptom conditions in Gulf War veterans. Psychol Med, 2006. 36(6): p. 735-47.

19. Wolfe, J., et al., Risk factors for multisymptom illness in US Army veterans of the Gulf War. J Occup Environ Med, 2002. 44(3): p. 271-81.

20. Steele, L., et al., Complex factors in the etiology of Gulf War illness: wartime exposures and risk factors in veteran subgroups. Environ Health Perspect, 2012. 120(1): p. 112-8.

21. Institute of Medicine, D.o.H.P.a.D.P., Committee on Health Effects Associated with Exposures during the Gulf War:, Gulf War and Health, Vol 1, Depleted Uranium, Pyridostigmine Bromide, Sarin, Vaccines. . 2000, Institute of Medicine, National Academy Press: Washington, DC.

22. Mahan, C.M., et al., Health effects in Army Gulf War veterans possibly exposed to chemical munitions destruction at Khamisiyah, Iraq: Part I. Morbidity associated with potential exposure. Mil Med, 2005. 170(11): p. 935-44.

23. Haley, R.W. and T.L. Kurt, Self-reported exposure to neurotoxic chemical combinations in the Gulf War. A cross-sectional epidemiologic study. Jama, 1997. 277(3): p. 231-7.

24. Nisenbaum, R., et al., Deployment stressors and a chronic multisymptom illness among Gulf War veterans. J Nerv Ment Dis, 2000. 188(5): p. 259-66.

25. McAndrew, L.M., et al., Iraq and Afghanistan Veterans report symptoms consistent with chronic multisymptom illness one year after deployment. J Rehabil Res Dev, 2016. 53(1): p. 59-70.

26. Smith, T.C., et al., Chronic multisymptom illness: a comparison of Iraq and Afghanistan deployers with veterans of the 1991 Gulf War. Am J Epidemiol, 2014. 180(12): p. 117687.

27. Blanchard, M.S., et al., Chronic multisymptom illness complex in Gulf War I veterans 10 years later. Am J Epidemiol, 2006. 163(1): p. 66-75.

28. Kang, H.K., et al., IIlnesses among United States veterans of the Gulf War: a populationbased survey of 30,000 veterans. J Occup Environ Med, 2000. 42(5): p. 491-501.

29. Barth, S.K., et al., Neurological mortality among U.S. veterans of the Persian Gulf War: 13-year follow-up. Am J Ind Med, 2009. 52(9): p. 663-70. 
Table 1: Frequency counts and weighted percentages of demographic and health risk factors among deployed respondents to the 1995 Gulf War Survey, stratified by Gulf War Illness (GWI) definition

New GWI (3 domain/probable) ( $n=2100,29.37 \%$ )

\begin{tabular}{|c|c|c|c|c|c|}
\hline & \multicolumn{3}{|c|}{ Yes } & \multicolumn{2}{|c|}{ Wald Chi-square } \\
\hline & $\mathbf{n}$ & Row \% & Column \% & $x^{2}$ & p-value \\
\hline \multicolumn{6}{|l|}{ Gender } \\
\hline Men & 1684 & 28.97 & 92.70 & 10.39 & 0.001 \\
\hline Women & 416 & 35.63 & 7.30 & & \\
\hline \multicolumn{6}{|l|}{ Age group } \\
\hline 3944 (17-22 in 1991) & 436 & 30.19 & 25.93 & 13.69 & 0.001 \\
\hline $45-54(23-32$ in 1991) & 932 & 26.81 & 46.66 & & \\
\hline $55+(33+$ in 1991) & 732 & 34.02 & 27.41 & & \\
\hline \multicolumn{6}{|l|}{ Race/ethnicity } \\
\hline White & 1524 & 28.18 & 71.37 & 6.04 & 0.01 \\
\hline Other & 576 & 32.80 & 28.63 & & \\
\hline \multicolumn{6}{|l|}{ Smoking status } \\
\hline Current smoker & 1075 & 35.22 & 53.25 & 42.5 & $<.000$ \\
\hline Former & 71 & 21.84 & 3.41 & & \\
\hline Never smoked & 954 & 24.95 & 43.34 & & \\
\hline \multicolumn{6}{|l|}{ Drinking status } \\
\hline Current drinker & 1612 & 28.85 & 79.93 & 7.77 & 0.0 \\
\hline Former & 323 & 34.70 & 15.04 & & \\
\hline Never drank & 165 & 25.07 & 5.03 & & \\
\hline
\end{tabular}

\begin{tabular}{l|ccc} 
Never drank & 165 & 25.07 & 5.03 \\
\hline & GWI (CDC/Kansas) $(n=3515,51.68 \%)$
\end{tabular}

\begin{tabular}{|c|c|c|c|c|c|}
\hline & \multicolumn{3}{|c|}{ Yes } & \multicolumn{2}{|c|}{ Wald Chi-square } \\
\hline & $\mathbf{n}$ & Row \% & Column \% & $x^{2}$ & p-value \\
\hline \multicolumn{6}{|l|}{ Gender } \\
\hline Men & 2826 & 50.97 & 92.70 & 28.45 & $<.0001$ \\
\hline Women & 689 & 62.73 & 7.30 & & \\
\hline \multicolumn{6}{|l|}{ Age group } \\
\hline $39-44(17-22$ in 1991) & 777 & 56.42 & 27.54 & 14.86 & 0.0006 \\
\hline $45-54(23-32$ in 1991) & 1624 & 48.41 & 47.88 & & \\
\hline $55+(33+$ in 1991$)$ & 1114 & 53.68 & 24.58 & & \\
\hline \multicolumn{6}{|l|}{ Race/ethnicity } \\
\hline White & 2556 & 50.01 & 71.97 & 10.14 & 0.0015 \\
\hline Other & 959 & 56.51 & 28.03 & & \\
\hline \multicolumn{6}{|l|}{ Smoking status } \\
\hline Current smoker & 1691 & 59.76 & 51.34 & 67.25 & $<.0001$ \\
\hline Former & 136 & 40.71 & 3.61 & & \\
\hline Never smoked & 1688 & 45.63 & 45.05 & & \\
\hline \multicolumn{6}{|l|}{ Drinking status } \\
\hline Current drinker & 2720 & 51.21 & 80.64 & 11.81 & 0.0027 \\
\hline Former & 521 & 58.11 & 14.32 & & \\
\hline Never drank & 274 & 44.17 & 5.04 & & \\
\hline
\end{tabular}


Table 2: Frequency counts and weighted percentages of overlap between new and old GWI variables

\begin{tabular}{|r|r|r}
\hline & \multicolumn{2}{|c|}{$\begin{array}{r}\text { New GWI (3 domain/probable) } \\
(\mathrm{n}=2100,29.37 \%)\end{array}$} \\
\hline $\begin{array}{r}\text { GWI (CDC/Kansas) } \\
(\mathrm{n}=3515,51.68 \%)\end{array}$ & $\mathrm{Y}$ & $\mathrm{N}$ \\
\hline $\mathrm{Y}$ & $2090(29.16 \%)$ & $1425(22.52 \%)$ \\
\hline $\mathrm{N}$ & $10(0.21 \%)$ & $2653(48.11 \%)$ \\
\hline
\end{tabular}


Table 3: Frequency counts and weighted percentages of predictor variables and groups by GWI definition

\begin{tabular}{|c|c|c|c|c|}
\hline \multirow[b]{2}{*}{ Predictor Variables } & \multicolumn{2}{|c|}{$\begin{array}{c}\text { New GWI (3 domain/probable) } \\
\text { (n=2100,29.37\% ) }\end{array}$} & \multicolumn{2}{|c|}{ GWI (CDC/Kansas) (n=3515, 51.68\%) } \\
\hline & n & $\boldsymbol{X}_{0}$ & $n$ & \% \\
\hline Pain & 293 & 16.46 & 302 & 9.82 \\
\hline arthritis of ary kind & 117 & 6.67 & 181 & 5.96 \\
\hline lumbago & 98 & 5.47 & 150 & 4.94 \\
\hline back pain or spasms & 157 & 9.03 & & \\
\hline Demotologic & 205 & 8.77 & 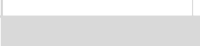 & \\
\hline eczema or psoriasis & 32 & 0.94 & & \\
\hline derm atitis or any other skin trouble & 60 & 2.49 & & \\
\hline any disease of the hair or scalp, induding hair loss & 71 & 3.78 & & \\
\hline skin rashes & 40 & 162 & & \\
\hline any hair loss & 96 & 4.39 & & \\
\hline Genitowinary & 74 & 3.67 & 91 & 2.36 \\
\hline cirrhosis of liver & 2 & 0.04 & 3 & 0.1 \\
\hline hepatitis & 13 & 0.96 & 18 & 0.72 \\
\hline any other liver trouble & 4 & 0.17 & 6 & 0.11 \\
\hline any disease of genital organs & 12 & 1.1 & 22 & 0.95 \\
\hline frequent bladder infections & 8 & 0.14 & 11 & 0.11 \\
\hline frequent or painful urination & 26 & 1.11 & 42 & 1.04 \\
\hline painful sexual intercourse & 11 & 0.21 & 16 & 0.22 \\
\hline impotence or other sexual problems & 10 & 0.28 & 15 & 0.28 \\
\hline Gastrointestinal & 300 & 14.92 & & \\
\hline gastritis (irritation of the stomach) & 78 & 3.64 & & \\
\hline enteritis (irritation of the intestine) & 15 & 0.94 & & \\
\hline colitis (irritation of the colon) & 15 & 0.35 & & \\
\hline frequent diarrhea & 17 & 0.91 & & \\
\hline been nauseous & 58 & 3.15 & & \\
\hline been vomiting & 40 & 2.62 & & \\
\hline stomach or abdominal pain & 58 & 2.88 & & \\
\hline reflux, heartburn, or indigestion & 125 & 5.82 & & \\
\hline diarrhea & 62 & 3.4 & & \\
\hline constipation & 71 & 3.68 & & \\
\hline Neurologicad & 289 & 16.44 & 509 & 16.5 \\
\hline migraines & 62 & 3.44 & 118 & 3.65 \\
\hline loss of hearing or ringing in your ears & 154 & 9.32 & 268 & 9.11 \\
\hline a fever or chills & 58 & 3.57 & 103 & 3.41 \\
\hline problems with sweating (not due to exercise) & 50 & 2.81 & 79 & 2.53 \\
\hline Candiac & 175 & 9.28 & 52 & 1.72 \\
\hline coronary heart disease & 5 & 0.29 & & \\
\hline hypertension & 66 & 3.03 & & \\
\hline stroke or cerebral-vascular accident & 2 & 0.14 & & \\
\hline tachycardia & 27 & 1.31 & & \\
\hline any tightness in your chest & 31 & 1.31 & & \\
\hline irregular heartbeat & 47 & 2.48 & & \\
\hline swelling of both feet or andes & 37 & 2.52 & 52 & 1.72 \\
\hline Respirotory & 619 & 30.48 & & \\
\hline sinus trouble & 293 & 14.02 & & \\
\hline bronchitis & 86 & 3.8 & & \\
\hline asthma & 44 & 1.76 & & \\
\hline other lung condition & 8 & 0.52 & & \\
\hline wheezing in your chest & 63 & 3.2 & & \\
\hline a runny nose or congestion of your nose or sinuses & 342 & 16.96 & & \\
\hline a sore throat, hoarse voice, or other throat problems & 149 & 7.77 & & \\
\hline trouble swallowing & 36 & 2.15 & & \\
\hline problems with coughin & 89 & 5.31 & & \\
\hline difficulty in breathing or shortness of breath & 43 & 2.16 & & \\
\hline Inflommotion & 152 & 8.21 & 253 & 8.01 \\
\hline problems with your mouth, gums or teeth & 100 & 5.73 & 161 & 5.24 \\
\hline problems with swollen glands (lymph nodes) in your neck and/or armpits & 54 & 2.96 & 93 & 2.89 \\
\hline wounds that are slow to heal & 4 & 0.17 & 11 & 0.37 \\
\hline
\end{tabular}




\begin{tabular}{|c|c|c|c|c|c|c|c|c|c|c|c|c|}
\hline \multicolumn{13}{|c|}{ Table 4: Multivariable logistic regression models for grouped predictor terms by GWI definitions } \\
\hline & \multirow{2}{*}{\multicolumn{2}{|c|}{$\begin{array}{l}\text { Np pretictor groups, demographics only } \\
\text { Model } 1^{*}\end{array}$}} & \multirow{2}{*}{\multicolumn{2}{|c|}{$\begin{array}{l}\text { No predictor groups, with demographics } \\
\text { and tount of presictors } \\
\text { Model } 2^{4}\end{array}$}} & \multirow{2}{*}{\multicolumn{2}{|c|}{$\begin{array}{l}\text { One predictor group per model with } \\
\text { demagraphics, no tount of presictors } \\
\text { Moddl } 3^{3}\end{array}$}} & \multirow{2}{*}{\multicolumn{2}{|c|}{$\begin{array}{l}\text { One predictor group per model with } \\
\text { demographits and trount of predictors } \\
\text { Modcl 4_a }\end{array}$}} & \multirow{2}{*}{\multicolumn{2}{|c|}{$\begin{array}{l}\text { One predictor group per model with } \\
\text { dembgraphics and count of predictors } \\
\text { Modcl } 4 \_b\end{array}$}} & \multirow{2}{*}{\multicolumn{2}{|c|}{$\begin{array}{l}\text { One predictor group per model with } \\
\text { demographics and count of predictors } \\
\text { Modcl } 4 c\end{array}$}} \\
\hline & & & & & & & & & & & & \\
\hline & $\begin{array}{c}\text { Now GWI (3 } \\
\text { domain/Probable }) \\
\text { \{n=2100, 29.37\% }\}\end{array}$ & $\begin{array}{l}\text { GWI (COC/Kansas) } \\
(\mathrm{n}=3515,51.68 \%)\end{array}$ & $\begin{array}{c}\text { Now GWI \{3 } \\
\text { domain/probable }\} \\
\{\mathrm{n}=2100,29.37 \%\}\end{array}$ & $\begin{array}{l}\text { 6W/ }\{C D C / \text { kansas }) \\
(n=3515,51.68 \%)\end{array}$ & $\begin{array}{l}\text { Ncw GWI (3 } \\
\text { domain/probable) } \\
\text { (n=2100, 29.37\%) }\end{array}$ & $\begin{array}{l}\text { GWI (COC/Kansas) } \\
(\mathrm{n}=3515,51.68 \%)\end{array}$ & $\begin{array}{l}\text { Now GWI (3 } \\
\text { domain/probable }) \\
\{n=2100,29.37 \%\}\end{array}$ & $\begin{array}{l}\text { GWI \{CDC/Kansas) } \\
(\mathrm{n}=3515,51.68 \%\}\end{array}$ & $\begin{array}{l}\text { New GWI (3) } \\
\text { dornain/probable\}) } \\
(n=2100,29.37 \%)\end{array}$ & $\begin{array}{l}G W \mid\{C D C / \text { Kansas }\} \\
(n=3515,51.68 \% \%\end{array}$ & $\begin{array}{l}\text { New GWl }\{3 \\
\text { dornain/probable } \\
(\mathrm{n}=2100,29.37 \%)\end{array}$ & $\begin{array}{l}\text { GWW (COC/Kansas) } \\
(\mathrm{n}=3515,51.68 \%)\end{array}$ \\
\hline & aOR $\{95 \% \mathrm{Cl}\}$ & $\mathrm{aOR}(95 \% \mathrm{Cl})$ & $a O R\{\{95 \% \mathrm{Cl}\}$ & aOR $(95 \% \mathrm{Cl})$ & aOR $(95 \% \mathrm{Cl})$ & $\mathrm{aOR}(95 \% \mathrm{Cl})$ & $a O R(95 \% C l)$ & $\mathrm{aOR}(95 \% \mathrm{Cl})$ & aOR $\{95 \% \mathrm{Cl}\}$ & $\mathrm{AOR}(95 \% \mathrm{Cl})$ & aOR $\{95 \% \mathrm{Cl})$ & $\mathrm{aOR}\{95 \% \mathrm{Cl}\})$ \\
\hline \multicolumn{13}{|l|}{ Grouped predictor variables } \\
\hline Pain & & & & & $2.81(2.57,3.08)$ & $2.55(2.28,2.86)$ & $2.80(2.55,3.07)$ & $2.41(2.17,2.69)$ & & & & \\
\hline Germatologic & & & & & $2.19(2.00,2.39)$ & & 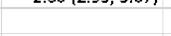 & $2.9(2.16,1,000)$ & $2.17(1.99,2.38)$ & & & \\
\hline Genitourinary & & & & & $2.58(2.33,2.85)$ & $3.12(2.72,3.57)$ & & & & & $2.55(2.31,2.82)$ & $2.99(2.62,3.42)$ \\
\hline Gastrointestinal & & & & & $2.73(2.48,3.00)$ & & & & & & & \\
\hline Neurological & & & & & $3.06(2.78,3.37)$ & $3.35(3.04,3.69)$ & & & & & & \\
\hline Cardiac & & & & & $2.92(2.66,3.20)$ & & & & & & & \\
\hline Respiratory & & & & & $2.76(2.49,3.06)$ & & & & & & & \\
\hline Inflammation & & & & & $2.36(2.16,2.58)$ & $2.65(2.39,2.93)$ & & & & & & \\
\hline & & & & & & & & & & & & \\
\hline \multicolumn{13}{|l|}{ Demogrophics and health history } \\
\hline \multicolumn{13}{|l|}{ Age group } \\
\hline $45-54$ vs $39-44$ & $0.86\{0.71,1.05\}$ & $0.74(0.61,0.88)$ & $0.85(0.70,1.03\})$ & $0.70(0.58,0.84)$ & & & $0.93(0.75,1.15)$ & $0.69(0.57,0.83)$ & $0.87\{0.71,1.07\}$ & & $0.87\{0.71,1.07\}$ & $0.71(0.59,0.86)$ \\
\hline $55+$ us 39-44 & $1.19\{0.96,1.48\}$ & $0.90(0.73,1.10)$ & $1.12\{1.06,1.16\}$ & $0.79(0.64,0.97)$ & & & $1.20\{0.95,1.53\}$ & $0.68(0.54,0.84)$ & $1.26\{0.99,1.59)$ & & $1.07\{0.85,1.35\}$ & $0.74(0.60,0.92)$ \\
\hline Gender (Women us Men) & $1.44(1.20,1.74)$ & $1.75(1.46,2.11)$ & $1.42\{1.18,1.71\}$ & $1.73\{1.44,2.09\}$ & & & $1.41\{1.15,1.74\}$ & $1.80(1.48,2.20)$ & $1.38\{1.13,1.59\}$ & & $1.22\{0.99,1.50\}$ & $1.53(1.25,1.87)$ \\
\hline Race/ethricity (Other vs white) & $1.31(1.10,1.56)$ & $1.37(1.16,1.62)$ & $1.36\{1.14,1.63\}$ & $1.42(1.21,1.70)$ & & & $1.19\{0.98,1.44\}$ & $1.32(1.10,1.58)$ & $1.20\{0.99,1.46\}$ & & $1.18\{0.97,1.42\}$ & $1.27(1.06,1.52)$ \\
\hline \multicolumn{13}{|l|}{ 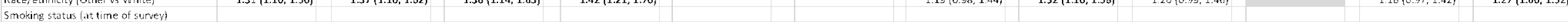 } \\
\hline Current smoker vs Nover smoled & $1.67(1.42,1.97)$ & $1.81(1.56,2.11)$ & $1.63\{1.39,1.92\}$ & $1.72(1.48,2.01\}$ & & & $1.50(1.25,1.79)$ & $1.72(1.46,2.01)$ & $1.54(1.29,1.82)$ & & $1.51(1.27,1.80)$ & $1.65(1.40,1.94)$ \\
\hline Former smoker us Never smoked & $0.78\{0.52,1.17\}$ & $0.75(0.53,1.07)$ & $0.77\{0.52,1.15\}$ & $0.74\{0.52,1.04\}$ & & & $0.65\{0.42,0.99\}$ & $0.60(0.40,0.89\}$ & $0.84\{0.55,1.28\}$ & & $0.86(0.58,1.30\}$ & $0.84(0.58,1.20\}$ \\
\hline \multicolumn{13}{|l|}{ Drinking status (at time of survey) } \\
\hline Current drinker vs Never drank & $1.11(0.80,1.54)$ & $1.20\{0.90,1.61\}$ & $1.11\{0.80,1.54\}$ & $1.23\{0.91,1.65\}$ & & & $1.00\{0.70,1.42\}$ & $1.10\{0.80,1.51\}$ & $1.45\{0.97,2.15\}$ & & $1.02\{0.71,1.45\}$ & $1.15(0.84,1.58\}$ \\
\hline Former drinker us Never drank & $1.44(0.99,2.09)$ & $1.62(1.15,2.29)$ & $1.44\{0.99,2.10\}$ & $1.65(1.17,2.34)$ & & & $1.33(0.89,2.98\}$ & $1.52(1.06,2.20)$ & $1.09\{0.77,1.55\}$ & & $1.31\{0.88,1.95\}$ & $1.53(0.84,1.58)$ \\
\hline Count of predictors $(0,1,2,3,4,5+\}$ & & & $1.11\{1.06,1.16\}$ & $1.63(1.42,1.87)$ & & & $1.06\{1.01,1.12\}$ & $1.42(1.24,1.64\}$ & $1.07(1.02,1.12)$ & & $1.06(1.01,1.12)$ & $1.48(1.28,1.71\}$ \\
\hline Mutliyariable model chi-square & $x z=10.27, p<.0001$ & $x 2=16.35, p<.0001$ & $x z=10.92, p<.0001$ & $x z=19.32, p<0001$ & & & $x^{2}=59.78, p<.0001$ & $x z=41.68, p<0001$ & $x z=39,79, p<.0001$ & & $x z=44.97, p<.0001$ & $x z=43.08, p<0001$ \\
\hline
\end{tabular}




\begin{tabular}{|c|c|c|c|c|c|c|c|c|c|c|c|c|}
\hline & \multicolumn{2}{|c|}{$\begin{array}{l}\text { One predictor group per model with } \\
\text { demographics and counl of predicl lors } \\
\text { Model 4_d }\end{array}$} & \multicolumn{2}{|c|}{$\begin{array}{l}\text { One predictor group per model with } \\
\text { demographics and counh of prediclors } \\
\text { Modcl } 4 \text { _c }\end{array}$} & \multicolumn{2}{|c|}{$\begin{array}{l}\text { One predictor group per model with } \\
\text { demographics and counl of prediclors } \\
\text { Madel } 4 \text { f }\end{array}$} & \multicolumn{2}{|c|}{$\begin{array}{l}\text { One predictor group per model with } \\
\text { demographics and count of prediclors } \\
\text { Model } 4 \text { _E }\end{array}$} & \multicolumn{2}{|c|}{$\begin{array}{l}\text { One predictor group per model with } \\
\text { demographics and count of prediclors } \\
\text { Modcl 4_h }\end{array}$} & \multicolumn{2}{|c|}{$\begin{array}{l}\text { All statistically significant predictor groups } \\
\text { with demographics and count of predictors } \\
\text { Model } 5\end{array}$} \\
\hline & $\begin{array}{l}\text { New GW/ (3 } \\
\text { dumain/probate) } \\
(n=2100,29.37 \%)\end{array}$ & 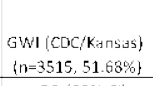 & $\begin{array}{l}\text { New GWI (3 } \\
\text { domuin/probable) } \\
(n=2100,29.37 \% \text { ) }\end{array}$ & $\begin{array}{c}\text { GWI (COC/Kansus\}) } \\
(n=3515,51.68 \%)\end{array}$ & $\begin{array}{l}\text { New GWI (3) } \\
\text { domain/probable) } \\
\text { (n=2100,29.37\%) }\end{array}$ & $\begin{array}{l}G W \mid(C D C / K a n s a s) \\
{[n=3515,51.68 \%)}\end{array}$ & $\begin{array}{c}\text { New GWI \{3 } \\
\text { dumain/probablet } \\
\text { \{n=2100, 29.37\%) }\end{array}$ & 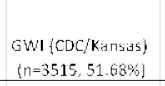 & 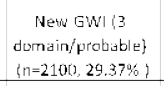 & $\begin{array}{l}\text { GWW }\{\text { COC/Kansas\}) } \\
(n=3515,51.68 \%)\end{array}$ & $\begin{array}{l}\text { New GWW (3 } \\
\text { domiain/probable) } \\
\text { (n=2100, 29.37\%) }\end{array}$ & $\begin{array}{l}\text { GWI (COC/Ransiss) } \\
(n=3515,51.68 \%)\end{array}$ \\
\hline & $\mathrm{aOR}\{95 \% \mathrm{Cl}\}$ & aOR $\{95 \% \mathrm{Cl}\}$ & $\mathrm{aOR}(95 \% \mathrm{Cl})$ & $\mathrm{aOR}\{95 \% \mathrm{Cl}\}$ & $\mathrm{aOR}\{95 \% \mathrm{Cl}\}$ & aOR $\{95 \% \mathrm{Cl}\}$ & JOR $\{95 \% \mathrm{Cl}\}$ & aOR $\{95 \%$ cll & aOR $\{95 \% \mathrm{Cl}\}$ & $\mathrm{aOR}\{95 \% \mathrm{Cl}\}$ & aOR $\{95 \% \mathrm{Cl}\}$ & aOR $\{95 \% \mathrm{Cl}\}$ \\
\hline \multicolumn{13}{|l|}{ Grouped preditctor variatiles } \\
\hline Pain & & & & & & & & & & & $1.82(1.62,2.04\}$ & $2.01(1.75,2.31\}$ \\
\hline Dermatologic & & & & & & & & & & & $1.32(1.18,1.49\}$ & \\
\hline Genitourinary & & & & & & & & & & & $1.49\{1.31,1.69\}$ & $2.26(1.95,2.62\}$ \\
\hline Gastrointestinal & $2.72(2.47,2.99)$ & & & & & & & & & & $1.43(1.27,1.62)$ & \\
\hline Neurological & & & $3.06(2.78,3.37)$ & $3.22(2.94,3.55)$ & & & & & & & $1.81[1.60,2.04\}$ & $2.72(2.44,3.02)$ \\
\hline Cardiac & & & & & $2.90(2.64,3.17)$ & & & & & & $1.75(1.56,1.97)$ & 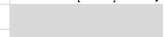 \\
\hline Respiratary & & & & & & & $2.89\{2.59,3.24\}$ & & & & $1.40\{1.21,1.61\}$ & \\
\hline Inflammation & & & & & & & & & $2.35(2.15,2.56)$ & $2.54(2.31,2.81)$ & $1.41(1.26,1.58)$ & $1.96(1.75,2.20\}$ \\
\hline \multicolumn{13}{|l|}{ Demographics and health history } \\
\hline Age group & & & & & & & & & & & & \\
\hline $45-54$ vs $39-44$ & $0.91(0.74,1.13)$ & & $1.01\{0.81,1.25\}$ & $0.79(0.65,0.98\}$ & $0.78(0.63,0.97)$ & & $0.89\{0.72,1.10\}$ & & $0.87(0.70,1.07\}$ & $0.71\{0.58,0.86\}$ & $0.97(0.75,1.25)$ & $0.80(0.64,0.99)$ \\
\hline $55+4539-44$ & $1.33(1.04,1.69)$ & & $1.31(1.02,1.67)$ & $0.86\{0.68,1.09\}$ & $0.96\{0.75,1.22\}$ & & $1.24(0.98,1.57\}$ & & $1.21\{0.95,1.53\}$ & $0.82(0.66,1.02)$ & $1.31(0.97,1.76)$ & $0.77(0.60,1.00)$ \\
\hline Gender (Women ys Men) & $1.25\{1.01,1.54\}$ & & $1.23\{0.99,1.52\}$ & $1.62(1,30,2.02\}$ & $1.24\{1.01,1.52\}$ & & $1.26\{1.03,1.54\}$ & & $1.28\{1.05,1.55\}$ & $1.62\{1.34,1.98\}$ & $1.03\{080,1.34\}$ & $1.50(1.18,1.90)$ \\
\hline Race/ethnicity (Other us white) & $1.28(1.05,1.55)$ & & $1.28(1.05,1.56)$ & $1.40(1.15,1.69)$ & $1.21(0.99,1.47)$ & & $1.29(1.06,1.57)$ & & $1.30\{1.08,1.58\}$ & $1.38\{1.15,1.66\}$ & $0.94(0.73,1.20\}$ & $1.22\{0.98,1.52\}$ \\
\hline \multicolumn{13}{|l|}{ Smoking status (at time of survey) } \\
\hline Current smoker vs Never smaked & $1.42(1.19,1.70)$ & & $1.40(1.17,1.68)$ & $1.53\{1.29,1.82\}$ & $1.48(1.23,1.77)$ & & $1.51\{1.27,1.80\}$ & & $1.43\{1.20,1.70\}$ & $1.55\{1.32,1.83\}$ & $1.12\{0.90,1.39\}$ & $1.40(1.16,1.69)$ \\
\hline Former smoker vs Never smoked & 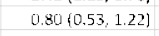 & & $0.78\{0.50,1.22\}$ & $0.72(0.49,1.06)$ & $0.72(0.45,1.14)$ & & $0.87(0.57,1.32\})$ & & $0.80(0.52,1.23\})$ & $0.76\{0.52,1.11\}$ & $0.79(0.49,1.26)$ & $0.67\{0.44,1.02\}$ \\
\hline \multicolumn{13}{|l|}{ Drinking status (at time of survey) } \\
\hline Current drinker vs Never drank & $1.14\{0.80,1.63\}$ & & $1.05\{0.73,1.51\}$ & $1.19(0.86,1.64)$ & $1.26\{0.87,1.83\}$ & & $1.06\{0.75,1.50\}$ & & $1.12\{0.79,1.57\}$ & $1.26\{0.93,1.71\}$ & $1.11(0.69,1.80)$ & $1.07(0.75,1.53)$ \\
\hline Former drinker vs Never drank & $1.51\{1.00,2.28\}$ & & $1.43\{0.95,2.17\}$ & $1.70(1.16,2.49)$ & $1.57(1.03,2.39)$ & & $1.36\{0.91,2.03\}$ & & $1.46\{0.99,2.16\}$ & $1.72(1.20,2.47)$ & $1.47(0.87,2.50)$ & $1.62(1.06,2.49)$ \\
\hline Count of predictors $(0,1,2,3,4,5+\}$ & $1.06(1.01,1.11)$ & & $1.08(1.03,1.14\}$ & $1.38\{1.21,1.59\}$ & $1.05\{0.99,1.10\}$ & & $1.14\{1.09,1.20\}$ & & $1.08\{1.02,1.14\}$ & $1.43(1.24,1.65)$ & $1.01(0.95,1.08)$ & $\mathbf{1 . 0 5}\{0.90,1.22\}$ \\
\hline Mutliyariable model chi-square & $x z=54.96, \beta<.0001$ & & $x z=65.89, p<.0001$ & $x 2=75.12, p<.0001$ & $x z=64.36, p<0001$ & & $x z=49.00, p<.0001$ & & $x z=46.81, p<.0001$ & $x z=50.69, p<00001$ & $x z=53.41, p<0001$ & $x z=39.77,0<.0001$ \\
\hline
\end{tabular}


Supplement 1: Frequency counts and weighted percentages of during- or post-war medical conditions included in GWI domains, stratified by gender

\begin{tabular}{|c|c|c|c|c|c|c|c|}
\hline \multirow[b]{3}{*}{ Survey question } & \multirow[b]{3}{*}{ Description } & \multicolumn{6}{|c|}{ New GWI (3 domain/probable) ( $\mathrm{n}=2100,29.37 \%$ ) } \\
\hline & & \multicolumn{2}{|c|}{ Men $(n=1684)$} & \multicolumn{2}{|c|}{$\begin{array}{l}\text { Women } \\
(n=416)\end{array}$} & \multicolumn{2}{|c|}{ Wald Chi-square } \\
\hline & & $\mathbf{n}$ & $\%$ & $\mathbf{n}$ & $\%$ & $x^{2}$ & p-value \\
\hline \multicolumn{8}{|l|}{ Fatigue } \\
\hline q19_25 & Excessive fatigue & 1377 & 78.70 & 364 & 87.62 & 11.69 & 0.0006 \\
\hline q19_26 & Fatigue lasting $>24$ hours & 797 & 44.29 & 226 & 55.26 & 8.70 & 0.0032 \\
\hline q19_40 & Excessive sleepiness during the day & 1003 & 59.12 & 231 & 52.82 & 2.90 & 0.0900 \\
\hline q19_41 & Awaken feeling tired after full night of sleep & 1458 & 88.75 & 326 & 78.78 & 9.79 & 0.0018 \\
\hline \multicolumn{8}{|c|}{ Pain and musculoskeletal } \\
\hline q08_3 & Any disease of muscles or tendons & 216 & 11.48 & 64 & 18.91 & 5.82 & 0.0159 \\
\hline q19_16 & Generalized musde aching or cramps & 1110 & 65.91 & 296 & 74.33 & 6.41 & 0.0114 \\
\hline q19_17 & Joint aching or pain & 1380 & 85.61 & 309 & 82.49 & 1.39 & 0.2381 \\
\hline q19_19 & Swelling in any joints & 576 & 35.37 & 145 & 40.26 & 1.67 & 0.1971 \\
\hline q19_20 & Tendency to bruise or bleed easily & 352 & 20.46 & 143 & 36.29 & 19.11 & $<.0001$ \\
\hline q19_24 & Sudden loss of strength & 737 & 40.04 & 164 & 40.80 & 0.04 & 0.8376 \\
\hline \multicolumn{8}{|l|}{ Neurocognitive } \\
\hline q08_18 & Repeated seizures, comvulsions, blakcouts & 85 & 4.64 & 17 & 5.81 & 0.48 & 0.4879 \\
\hline q08_19 & Recurrent headaches & 903 & 56.20 & 269 & 71.51 & 17.73 & $<.0001$ \\
\hline q08_21 & Neuralgia or neuritis & 151 & 7.86 & 29 & 8.97 & 0.19 & 0.6662 \\
\hline q19_2 & Blurred vision, not improved with glasses & 501 & 29.35 & 128 & 32.28 & 0.72 & 0.3957 \\
\hline q19_18 & Numbness or tingling sensation in hands or feet & 1037 & 62.48 & 238 & 60.94 & 0.18 & 0.6700 \\
\hline q19_23 & Loss of balance or dizziness & 736 & 42.56 & 216 & 55.17 & 11.27 & 0.0008 \\
\hline q19_44 & Tremors/shaking & 433 & 24.23 & 94 & 23.42 & 0.07 & 0.7886 \\
\hline q19_46 & Difficulty with speech & 358 & 21.09 & 89 & 19.19 & 0.48 & 0.4898 \\
\hline q19_47 & Difficulty with concentrating, reasoning, or memory loss & 1170 & 68.26 & 287 & 65.20 & 0.70 & 0.4014 \\
\hline \multirow[b]{3}{*}{ Sunkey question } & & \multicolumn{6}{|c|}{ GWI (CDC/Kansas) $(\mathrm{n}=3515,51.68 \%)$} \\
\hline & \multirow[b]{2}{*}{ Description } & \multicolumn{2}{|c|}{ Men $(n=2826)$} & \multicolumn{2}{|c|}{$\begin{array}{l}\text { Women } \\
(n=689)\end{array}$} & \multicolumn{2}{|c|}{ Wald Chi-square } \\
\hline & & $\mathbf{n}$ & $\%$ & $\mathbf{n}$ & $\%$ & $x^{2}$ & p-value \\
\hline \multicolumn{8}{|c|}{ Neurological/mood/cognition } \\
\hline q19_1 & Any headaches & 1594 & 65.40 & 445 & 75.27 & 12.65 & 0.0004 \\
\hline q19_2 & Blurred vision, not improved with glasses & 618 & 21.81 & 159 & 22.74 & 0.16 & 0.6918 \\
\hline q19_18 & Numbness or tingling sensation in hands or feet & 1310 & 47.25 & 304 & 46.60 & 0.05 & 0.8226 \\
\hline q19_23 & A loss of balance or dizziness & 878 & 29.25 & 258 & 38.62 & 11.52 & 0.0007 \\
\hline q19_42 & Been anxious, irritable or upset & $17 / 8$ & 65.35 & 445 & 69.01 & 1.80 & 0.1802 \\
\hline q19_43 & Been depressed or blue & 1463 & 52.17 & 409 & 61.30 & 10.07 & 0.0015 \\
\hline q19_44 & Tremors/shaking & 504 & 16.26 & 106 & 15.76 & 0.06 & 0.7998 \\
\hline q19_46 & Difficulty with speech & 413 & 14.61 & 99 & 12.05 & 2.16 & 0.1416 \\
\hline q19_47 & Difficulty concentrating & 1514 & 51.55 & 378 & 50.73 & 0.08 & 0.7739 \\
\hline q19_48 & Sensitivity to chemicals & 537 & 17.80 & 185 & 31.00 & 22.51 & $<.0001$ \\
\hline Respiratory & & & & & & & \\
\hline q19_4 & Wheezing in your chest & 869 & 30.32 & 185 & 26.65 & 1.95 & 0.1752 \\
\hline q19_10 & Problems with coughing & 884 & 30.87 & 210 & 29.79 & 0.18 & $0.6 / 48$ \\
\hline q19_11 & Difficulty in breathing or shortness or breath & 1038 & 36.24 & 246 & 35.67 & 0.04 & 0.8349 \\
\hline Musculoskeletal & & & & & & & \\
\hline q19_14 & Back pain or spasms & 1412 & 56.02 & 319 & 50.26 & 3.81 & 0.0510 \\
\hline q19_16 & Generalized musde aching or cramps & 1336 & 46.65 & 353 & 50.61 & 1.88 & 0.1709 \\
\hline q19_17 & Joint aching or pain & 1756 & 64.37 & 379 & 58.55 & 4.08 & 0.0435 \\
\hline Dermatological & & & & & & & \\
\hline q19_21 & Any hair loss & 1082 & 36.19 & 266 & 37.56 & 0.26 & 0.6116 \\
\hline Gastrointestinal & & & & & & & \\
\hline q19_27 & Been nauseous & $6 / 2$ & 22.52 & 285 & 41.69 & 45.34 & $<.0001$ \\
\hline q19_29 & Stomach or abdominal pain & 854 & 29.84 & 291 & 44.38 & 25.60 & $<.0001$ \\
\hline q19_31 & Diamhea & 1163 & 41.42 & 246 & 36.63 & 2.95 & 0.0862 \\
\hline Fatigue & & & & & & & \\
\hline q19_25 & Felt excessive fatigue (not due to exercise) & 1848 & 61.14 & 497 & 69.61 & 9.76 & 0.0018 \\
\hline q19_26 & Problems with fatigue lasting more than $\mathbf{2 4}$ hours after exertion & & & & & & \\
\hline q19_39 & Difficulty in getting to sleep or staying asleep & 1600 & 56.56 & 355 & 53.72 & 1.00 & 0.3171 \\
\hline q19_41 & Awaken feeling tired and worn out after a full night of sleep & 2029 & 73.32 & 459 & $6 / .57$ & 4.46 & 0.0347 \\
\hline
\end{tabular}


Supplement 2: Sensitivty and specificty analyses of 3domain GWI compared to CDC/Kansas GWI definitions

Sensitivity and specificity of Kansas GWI variable compared to 3 domain GWI, deployed only

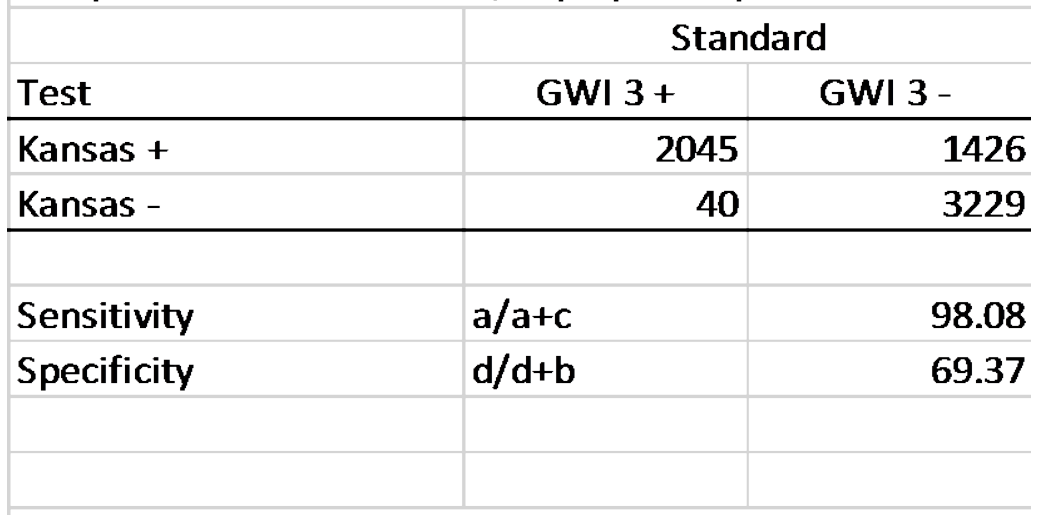

Sensitivity and specificity of CDC GWI variable compared to 3 domain GWI; deployed only

\begin{tabular}{|c|c|c|}
\hline \multirow[b]{2}{*}{ Test } & \multicolumn{2}{|c|}{ Standard } \\
\hline & GWI $3+$ & GWI 3 - \\
\hline $\mathrm{CDC}+$ & 3012 & 1197 \\
\hline CDC - & 110 & 3867 \\
\hline Sensitivity & $a / a+c$ & 96.48 \\
\hline Specificity & $d / d+b$ & 76.36 \\
\hline \multicolumn{3}{|c|}{$\begin{array}{l}\text { Sensitivity and specificity of CDC/Kansas GWI variable } \\
\text { compared to } 3 \text { domain GWI; deployed only }\end{array}$} \\
\hline & \multicolumn{2}{|c|}{ Standard } \\
\hline Test & GWI $3+$ & GWI 3 - \\
\hline CDC/Kansas + & 3093 & 1850 \\
\hline CDC/Kansas - & 14 & 3005 \\
\hline Sensitivity & $a / a+c$ & 99.55 \\
\hline Specificity & $d / d+b$ & 61.89 \\
\hline
\end{tabular}


Chapter 3

Aim 2 Manuscript 


\title{
Mortality among Veterans with Early-Onset Gulf War Illness: a 25-Year Follow-Up
}

\author{
Abstract \\ Introduction: Several previous studies have described mortality outcomes among Gulf War \\ veterans, however, no known studies to date have investigated patterns of mortality among \\ veterans meeting criteria for Gulf War Illness. The purpose of this study is to compare all-cause \\ and cause-specific mortality rates of Persian Gulf War veterans who did and did not meet \\ criteria for GWI.
}

Methods: This study used veteran respondent data from the 1995-1997 National Health Survey of Gulf War Veterans matched to the Department of Veterans Affairs-Department of Defense Mortality Data Repository database to determine vital status and underlying causes of death from 2000-2017. Prevalence estimates and rates of all-cause and cause-specific mortality for survey respondents meeting criteria for $\mathrm{GWI}$ as defined by the $\mathrm{CDC}$ and Kansas definitions were compared to those who did not meet these criteria, stratified by status of deployment to the 1990-1991 Gulf War (deployed and non-deployed). Indirectly age- and gender-adjusted standardized mortality rate ratios and adjusted hazard ratios were calculated for comparisons between deployed and non-deployed veterans with and without symptoms meeting criteria for GWI.

Results: Deployed veterans meeting criteria for GWI in 1995-1997 were at increased risk for cause-specific mortality due to malignant neoplasms, circulatory system disorders, and digestive system disorders, and had greater risk for overall mortality compared to deployed 
veterans who did not meet criteria for GWI. However, when compared to non-deployed veterans with probable GWI, deployed veterans with probable GWI had decreased overall mortality risk and decreased risk for mortality due to diseases of the circulatory system.

Conclusion: To the best of our knowledge, this is the first study to assess mortality status and cause-specific risk of death among veterans meeting criteria for GWI. These results may aid in development of a more precise definition of GWI. 


\section{Introduction}

The mortality status and characteristics of veterans deployed to the 1990-1991 Persian Gulf War have been reported in several publications, though research on mortality findings specific to veterans with probable Gulf War Illness (GWI) is lacking [1-3]. Previous studies have shown that deployment to the Gulf War is not associated with overall increased risk of death compared to those who served in the military during the same time period but did not deploy to the Persian Gulf region, though overall mortality risk is $15 \%$ greater among females when stratified by gender [1].

Several studies have reported increased risk of death due to external causes among deployed Gulf War veterans compared to veterans who were not deployed to the 1990-1991 Gulf War (non-deployed) [1,3]. One population-based study of veterans who served in the Gulf War found an increased risk of death due to brain cancer among a subgroup of deployed veterans with suspected exposure to sarin gas at the explosion of the Khamisiyah munitions cache or oil well fire smoke [2], though risk for brain cancer mortality dissipated over time [4]. In a 13-year follow-up study, Army Gulf War veterans thought to have exposure at Khamisiyah were three times more likely to die from cirrhosis of the liver compared to Army veterans who did not deploy [1]. Compared to the U.S population, female deployed Gulf War veterans were 60\% more likely to die by suicide, while male veterans were less likely when compared to males in the U.S. population at 13-years post-war follow-up [1]. 
Significant numbers of veterans returning from service in the 1990-1991 Gulf War reported a difficult to diagnose syndrome of illnesses characterized by various combinations of neurological and cognitive disorders, pain, fatigue, musculoskeletal issues, gastrointestinal problems, and respiratory illnesses [5]. This group of conditions, currently referred to as GWI, is estimated to occur in $25-40 \%$ of veterans who deployed to the 1990-1991 Persian Gulf War [6] [12]. While no universal case definition exists, two definitions are commonly used to define GWI and supported by recommendations from a 2014 Institute of Medicine (IOM) report [5]: 1) a definition developed by Fukuda, et al. [7], commonly referred to as the Centers for Disease Control (CDC) definition; and 2) a definition developed by Steele [8], commonly referred to as the Kansas definition.

Criteria for the CDC definition of GWI include experiencing at least one medical condition or symptom occurring for the first time after the 1990-1991 Persian Gulf War in two of the three domains of fatigue, mood and cognitive disorders, and musculoskeletal problems; no exclusion criteria limit eligibility for GWI according to this definition [7]. To meet the criteria of GWI according to the Kansas definition, a veteran must have medical conditions occurring for the first time after the 1990-1991 Persian Gulf War in three of the following six domains: fatigue, pain, neurological/mood/cognition, gastrointestinal, respiratory, and skin disorders. Veterans experiencing serious psychiatric conditions or diagnosis of serious health conditions including cancer, diabetes, infectious disease, heart disease, stroke, liver disease, lupus, multiple sclerosis, and problems resulting from postwar injuries are excluded from eligibility for GWI according to the Kansas definition [8]. No studies have validated either the CDC or Kansas 
definitions of GWI, yet both are commonly used to determine probable GWI classification. Recently, the IOM expressed need for development of a more robust GWI case definition [5].

Given the multiple bodily systems related to and impacted by GWI, we expect to find increased risk of death due to GWI-related diseases among veterans with probable GWI compared to those without similar symptoms. A historical cohort of veterans meeting GWI criteria in the early years after the war provides a unique opportunity to investigate long-term mortality outcomes associated with GWI [6]. The purpose of this study is to characterize patterns of mortality among veterans with evidence of GWI and compare all-cause and cause-specific mortality rates to those of veterans without early evidence of GWI. We hypothesize that deployed veterans who meet criteria for GWI will have significantly greater risk for all-cause and cause-specific mortality.

\section{Methods}

Measures

Data for this study come from the 1995-1997 NHS [27] and the Joint Department of DefenseDepartment of Veterans Affairs Mortality Data Repository (MDR) [10]. Demographic variables from the NHS included age group, gender, and race/ethnicity. The NHS data was used to identify veterans meeting criteria for GWI according to both accepted definitions [7, 8]. Details about how these definitions were applied to NHS data can be found in a previous publication [6]. For these current analyses, we define probable GWI as any survey respondent meeting criteria for either the CDC or Kansas definition and negative for probable GWI as those veteran 
respondents who did not meet criteria for either definition at the time of survey completion. Since a significant number of non-deployed veteran respondents to the NHS met criteria for GWI, comparison groups for these analyses are stratified by deployment status and probable GWI status.

We included all four groups (deployed and non-deployed, with and without probable GWI) for comparisons in our analyses in order to evaluate possibility of a dose-response mortality relationship. We assessed for increased risk for death due to diseases not already included in GWI definition domains, which may indicate need for inclusion of additional conditions in an updated GWI definition. A lack of differences between these four comparison groups may be an indication of poor specificity of the CDC and/or Kansas definitions; meaning these definitions may capture large numbers of false positives.

Mortality data for these analyses come from the MDR, a database containing mortality information for all deceased veterans of military service for the years 1979-2017. The MDR is a combination of multiple federal databases including the National Death Index, Department of Defense databases, and Veterans Health Administration files. The MDR includes information on all deaths, including specific causes of death, using ICD-9 and ICD-10 codes [10] . Using social security numbers, veteran respondents to the NHS were matched to MDR records from 20002017 to determine vital status and underlying cause of death for those who were deceased. Mortality results are reported using ICD-10 classifications [11]. 


\section{Statistical analyses}

We calculated prevalence estimates and mortality rates per 1,000 person-years for respondents with and without probable GWI, stratified by status of deployment to the 1990-1991 Persian Gulf War (deployed and non-deployed). Due to small cell counts, mortality results are presented in collapsed ICD-10 categories [11]. Indirectly age- and gender-adjusted standardized mortality rate ratios and $95 \%$ confidence intervals were calculated for ICD-10 collapsed categories for comparisons between deployed and non-deployed veterans with and without symptoms meeting criteria for GWI. Cox proportional hazard models were calculated for estimating risk of death among the comparison groups, adjusted for gender, age group, and race/ethnicity. Standardized mortality rate ratios and Cox proportional hazard models were applied to seven sets of comparisons:

-Deployed compared to non-deployed (1)

-Deployed with probable GWI compared to:

Deployed without probable GWI (2)

Non-deployed without probable GWI (3)

Non-deployed with probable GWI (4)

-Non-deployed with probable GWI compared to:

Non-deployed without probable GWI (5)

Deployed without probable GWI (6)

-Deployed without probable GWI compared to non-deployed without probable GWI (7) 
Data were analyzed using SAS Enterprise Grid software (version 5.1, SAS Institute, Inc.). Alpha was set at 0.05 for all analyses.

\section{Results}

Table 1 presents mortality incidence and rates for collapsed ICD-10 groups. Within the deployed veteran group, the overall mortality rate was 3.61 per 1,000 person-years among those meeting criteria for GWI and 2.80 among those who did not meet criteria for GWI. In the non-deployed group, overall mortality was 4.49 per 1,000 person-years among those meeting criteria for GWI and 3.45 among those not meeting GWI criteria. Deaths due to malignant neoplasms (ICD-10 category C00-C97) were highest among all categories for deployed veterans with and without probable GWI (1.25 per 1,000 person years and 0.82 per 1,000 person years, respectively). The highest rate of cause-specific mortality was for diseases of the circulatory system (ICD-10 I00-199) (1.40 per 1,000 person-years) among the non-deployed group meeting criteria for GWI. Among the deployed group meeting criteria for GWI, deaths due to diseases of the nervous system (ICD-10 G00-G09) were lowest of all cause-specific death categories in this group (0.09 deaths per 1,000 person-years).

\section{Total deployed compared to total non-deployed veterans}

As shown in Table 2, deployed veterans had statistically significantly reduced risk of all-cause mortality compared to non-deployed veterans (standardized mortality ratio $(S M R)=0.89,95 \%$ confidence interval $(\mathrm{Cl})=0.85,0.99)$. When stratified by gender, female deployed veterans had a $26 \%$ reduced risk of overall mortality compared to non-deployed females $(\mathrm{SMR}=0.74,95 \% \mathrm{Cl}$ 
$=0.57,0.96)$; there was no statistically significant difference in overall mortality among males

(Table 2). When controlling for gender, age, and race/ethnicity, there was no increased risk of all-cause or cause-specific mortality among the deployed compared to non-deployed veterans (Table 3).

Deployed veterans had an increased risk of death due to accidental injury $(\mathrm{SMR}=1.48,95 \% \mathrm{Cl}=$ $1.05,2.10)$, which remained significant among males ( $S M R=1.57,95 \% \mathrm{Cl}=1.03,2.43)$ but not females when stratified by gender (Table 2). Deployed veterans had lower risk of mortality due to malignant neoplasms $(\mathrm{SMR}=0.83,95 \% \mathrm{Cl}=0.72,0.95)$ and diseases of the circulatory system $(\mathrm{SMR}=0.84,95 \% \mathrm{Cl}=0.71,0.98)$ compared to non-deployed veterans (Table 2$)$. When controlling for gender, age, and race/ethnicity in the Cox proportional hazards models, there was decreased risk for deaths due to malignant neoplasms among all deployed compared to all non-deployed veterans $(\mathrm{aHR}=0.73,95 \% \mathrm{Cl}=0.54,0.99)$ (Table 3$)$.

Deployed veterans with probable GWI compared to deployed veterans without probable GWI Deployed veterans who met criteria for GWI had a greater risk of all-cause mortality compared to deployed veterans without probable GWI $(\mathrm{SMR}=1.28,95 \% \mathrm{Cl}=1.05,1.28)$ (Table 2). This finding remained statitstically significant when controlling for gender, age, and race/ethnicity in Cox proportional hazard models $(\mathrm{aHR}=1.30,95 \% \mathrm{Cl}=1.10,1.55)$ (Table 3). When stratified by gender, female deployed veterans with probable GWI were nearly twice as likely to die from any cause compared to those without probable GWI $(\mathrm{SMR}=1.90,95 \% \mathrm{Cl}=1.42,2.53)$ (Table 2). 
Deployed males with probable GWI had $26 \%$ increased risk for all-cause mortality compared to deployed males without GWI (SMR $=1.26,95 \% \mathrm{Cl}=1.02,1.28)$ (Table 2).

Among the cause-specific mortality categories, compared to deployed veterans not meeting GWI criteria, deployed veterans with probable GWI were at increased risk for malignant neoplasms $(\mathrm{SMR}=1.53,95 \% \mathrm{Cl}=1.30,1.81)$, diseases of the circulatory system $(\mathrm{SMR}=1.51$, $95 \% \mathrm{Cl}=1.24,1.82)$, and diseases of the digestive system $(\mathrm{SMR}=3.15,95 \% \mathrm{Cl}=2.04,4.89)$ (Table 2). When controlling for all demographic covariates in the Cox proportional hazards models, these findings remain statistically significant. Deployed veterans with probable GWI were at increased risk for death due to malignant neoplasms (adjusted hazard ratio $(\mathrm{aHR})=$ $1.53,95 \% \mathrm{Cl}=1.12,2.10)$, diseases of the circulatory system $(\mathrm{aHR}=1.54,95 \% \mathrm{Cl}=1.08,2.20)$, and diseases of the digestive system $(\mathrm{aHR}=3.16,95 \% \mathrm{Cl}=1.08,2.20)$ compared to deployed veterans without probable GWI (Table 3).

Deployed veterans with probable GWI compared to non-deployed veterans without probable GWI

Compared to non-deployed veterans without probable GWI, deployed veterans with probable GWI were at increased risk for overall death when controlling for covariates $(\mathrm{aHR}=1.17,95 \% \mathrm{Cl}$ $=1.02,1.35$ ) (Table 3). Deployed veterans with probable GWI were at increased risk for death due to accidental injury $(S M R=1.98,95 \% \mathrm{Cl}=1.27,2.95)$ compared to non-deployed veterans without probable GWI (Table 2). When controlling for all demographic covariates in Cox proportional hazard models, deployed veterans with probable GWI were at increased risk for 
death due to other external causes of accidental injury (aHR $=2.21,95 \% \mathrm{Cl}=1.09,4.48$ ) and accidental poisoning by exposure to noxious substances $(\mathrm{aHR}=11.19,95 \% \mathrm{Cl}=1.43,87.62)$ compared to non-deployed without probable GWI (Table 3).

Deployed veterans with probable GWI compared to non-deployed veterans with probable GWI Among all respondents meeting criteria for GWI, deployed veterans had lower risk for all-cause mortality when compared to non-deployed veterans (SMR $=0.80,95 \% \mathrm{Cl}=0.73,0.89)$ (Table 2), $(\mathrm{aHR}=0.83,95 \% \mathrm{Cl}=0.69,0.99)($ Table 3). Veterans who were deployed with probable GWI had lower risk of death due to diseases of the circulatory system $(\mathrm{aHR}=0.71,95 \% \mathrm{Cl}=0.51$, 0.99) compared to non-deployed veterans with probable GWI (Table 3).

Among males who met the criteria for GWI, those who were deployed had greater risk of death due to neurological diseases $(\mathrm{SMR}=2.42,95 \% \mathrm{Cl}=1.21,4.83)$ (Table 2$)$ and lower risk of death due to endocrine, nutritional, and metabolic diseases $(\mathrm{SMR}=0.51,95 \% \mathrm{Cl}=0.29,0.90)$ and diseases of the circulatory system $(\mathrm{SMR}=0.70,95 \% \mathrm{Cl}=0.57,0.86)$ compared to non-deployed males (Table 2).

Non-deployed veterans with probable GWI compared to non-deployed veterans without probable GWI

Within the non-deployed group, veterans who met criteria for GWI had greater risk of death overall compared to those without probable GWI (SMR $=1.30,95 \% \mathrm{Cl}=1.12,1.51)$ (Table 2), $(\mathrm{aHR}=1.40,95 \% \mathrm{Cl}=1.17,1.68)($ Table 3$)$. Compared to non-deployed without probable GWI, 
non-deployed with probable GWI were at increased risk for accidental poisoning by and exposure to noxious substances compared to non-deployed veterans without GWI, though the confidence intervals were unreliable and skewed due to small numbers (aHR $=15.23,95 \% \mathrm{Cl}=$ 1.77, 131.22) (Table 3).

Non-deployed veterans with probable GWI compared to deployed veterans without probable GWI

Non-deployed veterans who met criteria for GWI had greater risk of death overall compared to deployed without probable GWI (SMR $=1.60,95 \% \mathrm{Cl}=1.25,1.68)$ (Table 2). This finding remained statistically significant when controlling for all demographic covariates in Cox proportional hazard models $(\mathrm{aHR}=1.57,95 \% \mathrm{Cl}=1.27,1.93)$ (Table 3$)$.

Deployed veterans without probable GWI compared to non-deployed veterans without probable GWI

Among all veterans who did not meet criteria for GWI, deployed veterans GWI had lower risk of death due to malignant neoplasms $(\mathrm{SMR}=0.63,95 \% \mathrm{Cl}=0.48,0.82)$ and diseases of the circulatory system $(\mathrm{SMR}=0.73,95 \% \mathrm{Cl}=0.54,0.98)$ compared to non-deployed (Table 2$)$. In the gender-stratified models, deployed males without probable GWI had greater risk of death due to intentional self-harm $(\mathrm{SMR}=1.95,95 \% \mathrm{Cl}=1.16,3.30)$ compared to non-deployed males without probable GWI. 


\section{Conclusion}

Overall, we found a $30 \%$ increased mortality risk among deployed veterans who met the criteria for either the CDC or Kansas definition for GWI in 1995-1997 compared to deployed veterans who did not meet criteria for probable GWI. However, among all respondents with probable GWI, deployed veterans had $17 \%$ decreased risk for overall mortality compared to nondeployed respondents. We found evidence to support our hypothesis of an increased risk for mortality among deployed veterans meeting criteria for GWI compared to the other groups given the myriad of symptoms and disorders associated with GWI. Interestingly, our results show non-deployed veterans meeting criteria for GWI to be at greater risk of overall mortality when compared to deployed veterans with GWI, deployed veterans without GWI, and nondeployed veterans without GWI.

Our results comparing all deployed to non-deployed indicated decreased risk for all-cause and cause-specific mortality due to malignant neoplasms and diseases of the circulatory system, regardless of probable GWI classification. A previous study of Gulf War era veterans found no statistically significant differences in overall mortality, mortality due to malignant neoplasms, or diseases of the circulatory when comparing deployed to non-deployed at 13 years post-war [1].

Within the deployed group, comparing those with probable GWI to those without, we found increased risk of mortality due to malignant neoplasms, diseases of the digestive system, and diseases of the circulatory system. Digestive system illnesses are included as a domain for the Kansas GWI criteria, so increased mortality related to these disorders is predictable and does 
support our hypothesis for increased risk of death due to domain related illnesses. However, increased risk of death due to malignant neoplasms and circulatory system diseases are notable as these symptoms are not included as criteria for the CDC or Kansas definition of GWI and are part of the exclusion criteria for the Kansas definition. When looking at the non-deployed group, those with probable GWI had increased risk of all-cause mortality and mortality due to diseases of the circulatory system compared to those without probable GWI, a similar finding to the same comparison in the deployed group. A possible explanation for these findings is that veterans who met the criteria for GWI are more likely to have reported pre-war medical conditions, including cardiac problems such as coronary heart disease, hypertension, and tachycardia (Aim One findings, results not published). Veterans meeting the criteria for GWI also were more likely to have reported genitourinary, pain, neurological, and respiratory disorders, which taken together could indicate poorer baseline health and increased risk for premature mortality (Aim One findings, results not published).

Among all veterans meeting criteria for probable GWI, those in the deployed group had statistically significantly reduced risk of overall mortality compared to non-deployed when controlling for gender, age, and race/ethnicity, an unexpected finding given that the deployed group experienced exposure to hazards of the Gulf War, which we speculated would put them at greater risk for poorer future health and related mortality outcomes. One possible explanation for this finding is that perhaps healthier servicemembers were chosen for Gulf War deployment. Several mortality studies of deployed and non-deployed Gulf War veterans have 
demonstrated that the deployed group was at lower risk for mortality compared to nondeployed veterans [1-3].

We found some support for our hypothesis that respondents meeting the criteria for GWI in 1995-1997 would have increased risk of domain-related cause-specific mortality compared to those without probable GWI between the years 2000-2017. Deployed males with probable GWI had increased risk of death due to nervous system diseases compared to non-deployed with probable GWI; neurological symptoms were included as domains in the Kansas definition of GWI. However, when controlling for gender, age, and race/ethnicity in Cox proportional hazard models, there was no increased risk of mortality in any comparison group. Among all comparisons, we found no increased risk of mortality due to diseases of the respiratory system when controlling for all demographic covariates, which does not support our hypothesis of greater risk for mortality due to domain-related diseases among those with probable GWI as respiratory disease is a domain included in the Kansas GWI definition. As mentioned above, we found increased risk of mortality due to digestive diseases, a domain included in the Kansas GWI definition, among the those with probable GWI compared to those without for both the non-deployed and deployed subgroups, when controlling for demographic covariates.

We found evidence for increased risk of mortality for two groups of medical conditions not directly related to the CDC or Kansas GWI definition domains - endocrine, nutritional, and metabolic diseases and circulatory system diseases. Deployed males with probable GWI had lower risk of death due to endocrine, nutritional, and metabolic diseases compared to non- 
deployed with probable GWI, a finding unsupportive of the recent interest in the expected positive relationship between metabolic syndrome and GWI $[12,13]$. While endocrine, nutritional, and metabolic diseases are correlated with obesity, a study of Gulf War deployed and non-deployed veterans in 2003-2005 did not find any differences in obesity between these two groups [14]. Results from the Millennium Cohort Study reported greater prevalence of obesity among military servicemembers and veterans who did not deploy, though this data is not limited to Gulf War veterans [15].

Our findings show increased risk for diseases of the circulatory system among deployed veterans with probable GWI versus deployed without probable GWI, and non-deployed veterans with probable GWI compared to all other groups. A recent study demonstrated that cardiac symptoms reported pre-Gulf War predicted probable GWI at 5 years post-war (Aim One findings, results not published), which could explain the increased risk for mortality due to diseases of the circulatory system. This finding may also be partially explained by the inclusion of pain as a domain for the Kansas GWI definition and musculoskeletal disorders as a domain for the CDC GWI definition. Pain is positively related to inflammation [16], which studies have shown is associated with heart disease [17]. Further research is needed to determine the relationship between endocrine, nutritional, and metabolic diseases and diseases of the circulatory system and GWI.

There are several limitations to this study. First, it is possible that some veteran respondents who did not meet criteria for either the CDC or Kansas definitions for GWI on the NHS survey in 
1995-1997 may have developed symptoms later on that would classify they as having GWI, resulting in misclassification bias. As mentioned earlier, neither the CDC nor the Kansas definition of GWI have been validated and results from analyses using these two measures may be prone to misclassification bias. Response bias may have influenced survey responses to the NHS resulting in an overestimate of veterans meeting GWI criteria. Self-reported data is at risk for recall bias, which may differ by deployment group. In this study, veterans who deployed and were experiencing health effects may have had better recall of their time period of symptom onset compared to those who were not deployed or not feeling ill. In our analyses we did not include data on environmental exposures such as potential sarin gas exposures resulting from the weapons cache destruction at Khamisiyah and oil well fire smoke. Additionally, we did not assess for mortality trends over time. Using aggregated data could result in null findings at the end of the follow up period and obscuration of significant mortality trends. These mortality data were limited to $2000-2017$ in order to look at long-term mortality follow-up of those who had probable GWI in the early years after the war, though by doing so we may have overlooked important mortality findings that occurred between 1995 and 2000; however, mortality analyses published for deployed and non-deployed Gulf War veterans within this time frame indicate low mortality overall and increased risk of death due to external causes among deployed compared to non-deployed [3]. Our mortality results are grouped by ICD-10 categories due to small numbers, which may conceal disease-specific mortality relationships associated with probable GWI. There are several strengths to this study. A population-based sampling scheme was used for the NHS, allowing survey responses to more closely represent 
the larger deployed and non-deployed population. The large number of survey respondents and $70 \%$ response rate allowed for an adequate sample size for these analyses.

To our knowledge this is the first study to report the long-term mortality status of 1990-1991 Persian Gulf War veterans who met criteria for GWI. We found that veterans with probable GWI were at greater risk of mortality overall, and specifically due to malignant neoplasms, diseases of the circulatory system, and diseases of the digestive system compared to deployed veterans not meeting GWI criteria, though mortality risk was decreased when compared to non-deployed veterans with probable GWI. Our findings of increased risk of all-cause and cause-specific mortality among non-deployed veterans with probable GWI adds to the complexity associated with attempts to define this syndrome.

Examining the long-term mortality experience of veterans with early-onset GWI aids in our understanding of the trajectory of the disorder. Veterans who are classified as having GWI should be monitored for health conditions not directly to their GWI symptoms, such as cancers, metabolic disorders, and cardiovascular disease. 


\section{References}

1. Barth, S.K., H.K. Kang, and T. Bullman, All-Cause Mortality Among US Veterans of the Persian Gulf War: 13-Year Follow-up. Public Health Rep, 2016. 131(6): p. 822-830.

2. Barth, S.K., et al., Neurological mortality among U.S. veterans of the Persian Gulf War: 13-year follow-up. Am J Ind Med, 2009. 52(9): p. 663-70.

3. Kang, H.K., et al., Mortality among US and UK veterans of the Persian Gulf War: a review. Occup Environ Med, 2002. 59(12): p. 794-9.

4. $\quad$ Barth, S.K., et al., Trends in brain cancer mortality among U.S. Gulf War veterans: 21 year follow-up. Cancer Epidemiol, 2017. 50(Pt A): p. 22-29.

5. Committee on the Development of a Consensus Case Definition for Chronic Multisymptom Illness in - Gulf War, V., P. Board on the Health of Select, and M. Institute of, in Chronic Multisymptom Illness in Gulf War Veterans: Case Definitions Reexamined. 2014, National Academies Press (US). Copyright 2014 by the National Academy of Sciences. All rights reserved.: Washington (DC).

6. Dursa, E., et al., Gulf War Illness in the 1991 Gulf war and Gulf era veteran population: an application of the centers for disease control and prevention and Kansas case definitions to historical data. Journal of Military and Veterans Health, 2018. 26(2): p. 43.

7. Fukuda, K., et al., Chronic multisymptom illness affecting Air Force veterans of the Gulf War. Jama, 1998. 280(11): p. 981-8.

8. Steele, L., Prevalence and patterns of Gulf War illness in Kansas veterans: association of symptoms with characteristics of person, place, and time of military service. Am J Epidemiol, 2000. 152(10): p. 992-1002.

9. Kang, H.K., et al., Illnesses among United States veterans of the Gulf War: a populationbased survey of 30,000 veterans. J Occup Environ Med, 2000. 42(5): p. 491-501.

10. Kemp, J. and R. Bossarte, Suicide data report: 2012. 2013: Department of Veterans Affairs, Mental Health Services, Suicide Prevention ....

11. Organization, W.H., ICD-10 : international statistical classification of diseases and related health problems. 2004, World Health Organization.

12. Blanchard, M., et al., Medical Correlates of Chronic Multisymptom IIIness in Gulf War Veterans. Am J Med, 2019. 132(4): p. 510-518.

13. Naviaux, R.K., et al., Metabolic features of Gulf War illness. PLoS One, 2019. 14(7): p. e0219531.

14. Coughlin, S.S., H.K. Kang, and C.M. Mahan, Selected Health Conditions Among Overweight, Obese, and Non-Obese Veterans of the 1991 Gulf War: Results from a Survey Conducted in 2003-2005. Open Epidemiol J, 2011. 4: p. 140-146.

15. Rush, T., C.A. LeardMann, and N.F. Crum-Cianflone, Obesity and associated adverse health outcomes among US military members and veterans: Findings from the millennium cohort study. Obesity (Silver Spring), 2016. 24(7): p. 1582-9.

16. Zhang, J.M. and J. An, Cytokines, inflammation, and pain. Int Anesthesiol Clin, 2007. 45(2): p. 27-37.

17. Danesh, J., et al., Low grade inflammation and coronary heart disease: prospective study and updated meta-analyses. Bmj, 2000. 321(7255): p. 199-204. 
Table 1: Unadjusted mortality frequency counts and rates among respondents to the 1995 Gulf War Survey, stratified by Gulf War Illness and deployment status, $2000-2017$

\begin{tabular}{|c|c|c|c|c|c|c|c|c|c|c|c|c|c|}
\hline & & \multicolumn{6}{|c|}{ Deployed } & \multicolumn{6}{|c|}{ Non-deployed } \\
\hline & & \multicolumn{3}{|c|}{ with GWI ( $n=6180)$} & \multicolumn{3}{|c|}{ w/o GWI (n=3878) } & \multicolumn{3}{|c|}{ with GWI ( $n=2200)$} & \multicolumn{3}{|c|}{ w/o GWI $(n=6688)$} \\
\hline & & $\mathbf{n}$ & $\mathbf{x}$ & $\begin{array}{c}\text { mortality } \\
\text { rate }^{*}\end{array}$ & $\mathbf{n}$ & $\mathbf{x}$ & $\begin{array}{c}\text { mortality } \\
\text { rate* }\end{array}$ & $\mathbf{n}$ & $\mathbf{x}$ & $\begin{array}{c}\text { mortality } \\
\text { rate* }\end{array}$ & $\mathbf{n}$ & $\mathbf{x}$ & $\begin{array}{c}\text { mortality } \\
\text { rate* }\end{array}$ \\
\hline \multicolumn{2}{|c|}{ Total mortality } & 392 & 6.34 & 3.61 & 192 & 4.95 & 2.80 & 173 & 7.86 & 4.49 & 405 & 6.06 & 3.45 \\
\hline \multicolumn{14}{|c|}{ ICD 10 Category } \\
\hline $000-97$ & Malignant neoplasms & 136 & 2.20 & 1.25 & 56 & 1.44 & 0.82 & 52 & 2.36 & 1.35 & 153 & 2.29 & 1.30 \\
\hline EOO-E90 & Endocrine, nutritional and metabolic diseases & 15 & 0.24 & 0.14 & 14 & 0.36 & 0.20 & 8 & 0.36 & 0.21 & 16 & 0.24 & 0.14 \\
\hline G00-G99 & Diseases of the nerwous system & 10 & 0.16 & 0.09 & 7 & 0.18 & 0.10 & 3 & 0.14 & 0.08 & 12 & 0.18 & 0.10 \\
\hline $100-199$ & Diseases of the circulatory system & 106 & 1.72 & 0.98 & 44 & 1.13 & 0.64 & 54 & 2.45 & 1.40 & 103 & 1.54 & 0.88 \\
\hline J00-J99 & Diseases of the respiratory system & 21 & 0.34 & 0.19 & 12 & 0.31 & 0.18 & 13 & 0.59 & 0.34 & 25 & 0.37 & 0.21 \\
\hline K00-K93 & Diseases of the digestive system & 20 & 0.32 & 0.18 & 4 & 0.10 & 0.06 & 8 & 0.36 & 0.21 & 17 & 0.25 & 0.14 \\
\hline V01-V99 & Transport accidents & 15 & 0.24 & 0.14 & 15 & 0.39 & 0.22 & 8 & 0.36 & 0.21 & 21 & 0.31 & 0.18 \\
\hline W00-X59 & Other extemal causes of accidental injury & 22 & 0.36 & 0.20 & 10 & 0.26 & 0.15 & 7 & 0.32 & 0.18 & 12 & 0.18 & 0.10 \\
\hline $\mathrm{X} 40-\mathrm{X} 49$ & Accidental poisoning by and exposure to noxious substances & 10 & 0.16 & 0.09 & 1 & 0.03 & 0.01 & 5 & 0.23 & 0.13 & 1 & 0.01 & 0.01 \\
\hline $\mathrm{X60-X84}$ & Intentional self harm & 14 & 0.23 & 0.13 & 14 & 0.36 & 0.20 & 8 & 0.36 & 0.21 & 15 & 0.22 & 0.13 \\
\hline
\end{tabular}

*per 1,000 person-years 
Table 2: Intrectly age- and gender-adjusted standard mortality ratios among respondents to the 1995 Guff War Survey stratified by Gudf War Illness and deployment status, 2000-2017

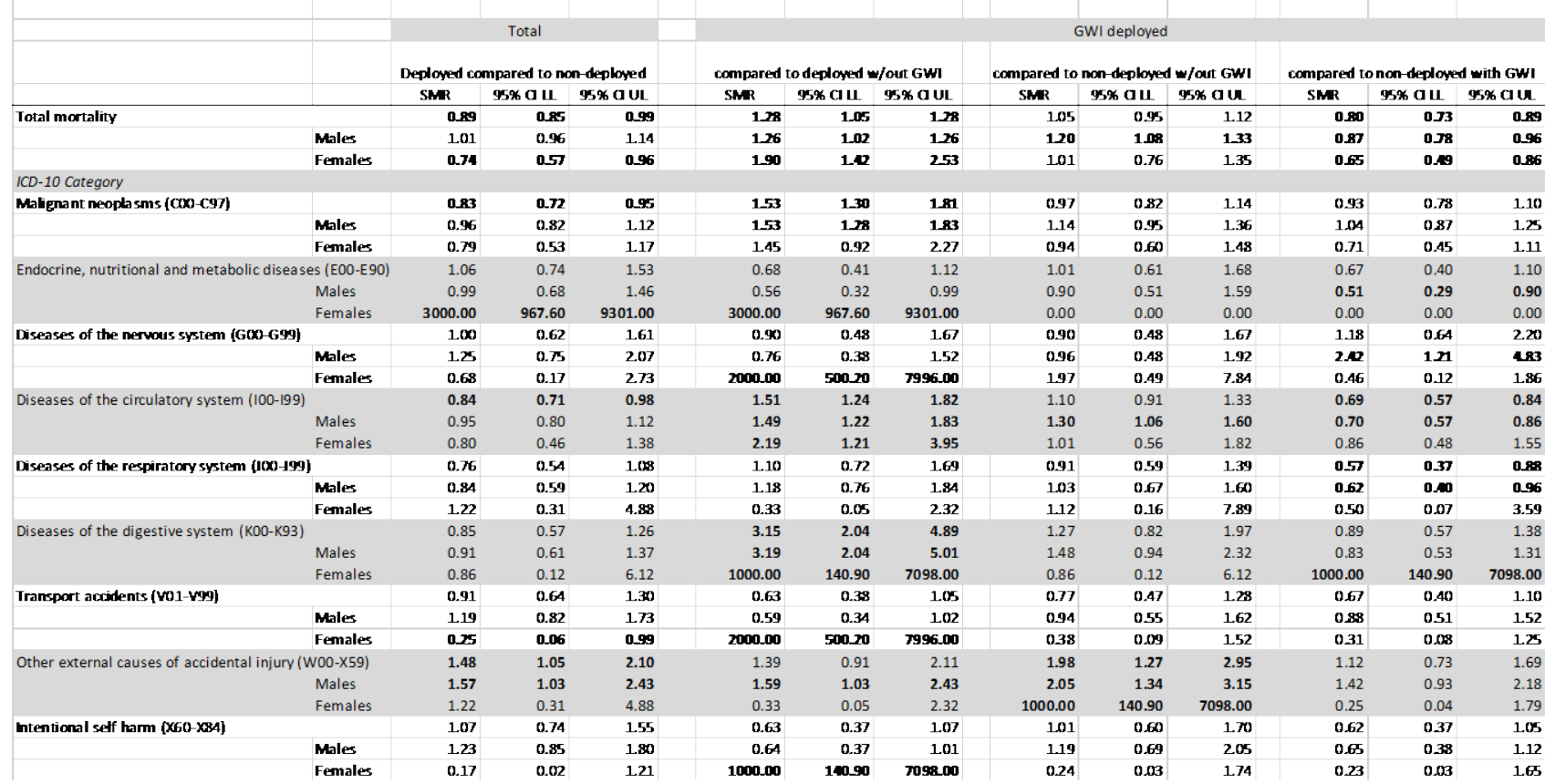




\begin{tabular}{|c|c|c|c|c|c|c|c|c|c|c|}
\hline & & \multicolumn{6}{|c|}{ GWI non-deployed } & & & \\
\hline & & \multicolumn{3}{|c|}{ compared to non-deployed w/out GWI } & \multicolumn{3}{|c|}{ compared to deployed w/out GWI } & \multicolumn{3}{|c|}{$\begin{array}{l}\text { deployed w/out GWI compared to } \\
\text { non-deployed w/out GWI }\end{array}$} \\
\hline & & SMR & 95\% व L & $95 \%$ C UL & SMR & $95 \% \mathrm{CU}$ & $95 \%$ O UL & SMR & 95\% वu & $95 \%$ Q UL \\
\hline \multicolumn{2}{|l|}{ Total mortality } & 1.30 & 1.12 & 1.51 & 1.60 & 1.25 & 1.68 & 0.81 & 0.79 & 1.03 \\
\hline & Makes & 1.36 & 1.16 & 1.61 & 1.45 & 1.10 & 1.53 & 0.95 & 0.92 & 1.21 \\
\hline & Females & 1.58 & 1.13 & 2.21 & 288 & 206 & 403 & 0.50 & 0.26 & 0.96 \\
\hline \multicolumn{11}{|l|}{ ICD-10 Category } \\
\hline \multirow[t]{3}{*}{ Malignant neoplasms (COO-C97) } & & 1.04 & 0.79 & 1.37 & 1.65 & 1.26 & 2.17 & 0.63 & 0.48 & 0.82 \\
\hline & Makes & 1.06 & 0.77 & 1.45 & 1.43 & 1.04 & 196 & 0.75 & 0.57 & 0.98 \\
\hline & Females & 1.34 & 0.78 & 2.30 & 205 & 1.19 & 3.54 & 0.66 & 0.27 & 1.58 \\
\hline \multicolumn{2}{|c|}{ Endocrine, nutritional and metabolic diseases (E00-E90) } & 1.52 & 0.76 & 3.04 & 1.02 & 0.51 & 2.03 & 1.50 & 0.89 & 2.53 \\
\hline & Males & 1.75 & 0.87 & 3.49 & 1.08 & 0.54 & 2.16 & 1.56 & 0.93 & 2.64 \\
\hline & Females & 3000.00 & 967.60 & 9301.00 & 0.00 & 0.00 & 0.00 & 0.00 & 0.00 & 0.00 \\
\hline \multicolumn{2}{|l|}{ Diseases of the nervous system (G00-G99) } & 0.76 & 0.25 & 2.36 & 0.76 & 0.25 & 2.36 & 1.00 & 0.48 & 2.10 \\
\hline & Males & 0.32 & 0.05 & 2.29 & 0.26 & 0.04 & 1.86 & 1.29 & 0.61 & 2.70 \\
\hline & Femakes & 4.12 & 102 & 16.32 & 2000.00 & 500.20 & 799600 & 0.00 & 0.00 & 0.00 \\
\hline \multirow[t]{3}{*}{ Diseases of the circulatory system (100-199) } & & 1.60 & 1.22 & 2.08 & 2.18 & 1.67 & 2.85 & 0.73 & 0.54 & 0.98 \\
\hline & Males & 1.85 & 1.40 & 2.46 & 2.13 & 1.61 & 2.83 & 0.87 & 0.64 & 1.18 \\
\hline & Females & 1.16 & 0.52 & 2.59 & 2.51 & 1.13 & 5.59 & 0.45 & 0.11 & 1.82 \\
\hline \multicolumn{2}{|c|}{ Diseases of the respiratory system (J00-J99) } & 1.58 & 0.92 & 2.73 & 1.92 & 1.12 & 3.32 & 0.82 & 0.47 & 1.45 \\
\hline & Males & 1.76 & 0.99 & 3.09 & 1.92 & 1.09 & 3.38 & 0.85 & 0.47 & 1.54 \\
\hline & Femaks & 2.21 & 0.31 & 15.77 & 0.65 & 0.09 & 4.61 & 3.41 & 0.48 & 24.48 \\
\hline \multirow[t]{3}{*}{ Diseases of the digestive system ( $\mathrm{KOO-K93)}$} & & 1.43 & 0.72 & 2.87 & 3.55 & 1.78 & 7.11 & 0.40 & 0.15 & 1.07 \\
\hline & Males & 1.77 & 0.89 & 3.55 & 3.79 & 1.90 & 7.58 & 0.46 & 0.17 & 1.22 \\
\hline & Females & 0.00 & 0.00 & 0.00 & 0.00 & 0.00 & 0.00 & 0.00 & 0.00 & 0.00 \\
\hline \multirow[t]{3}{*}{ Transport accidents (V01-V99) } & & 1.16 & 0.58 & 2.32 & 0.95 & 0.47 & 190 & 1.22 & 0.74 & 2.03 \\
\hline & Males & 1.08 & 0.45 & 2.58 & 0.71 & 0.29 & 1.70 & 1.60 & 0.97 & 2.66 \\
\hline & Females & 1.25 & 0.40 & 3.88 & 3000.00 & 967.60 & 930100 & 0.00 & 0.00 & 0.00 \\
\hline \multicolumn{2}{|c|}{ Other external causes of accidental injury (W00-X59) } & 1.78 & 0.85 & 3.73 & 1.24 & 0.59 & 2.61 & 1.43 & 0.77 & 2.66 \\
\hline & Males & 1.45 & 0.60 & 3.48 & 1.08 & 0.45 & 2.59 & 1.29 & 0.67 & 2.48 \\
\hline & Females & 2000.00 & 500.20 & 7996.00 & 1.30 & 0.32 & 5.19 & 1000.00 & 140.90 & 7098.00 \\
\hline \multirow[t]{3}{*}{ Intentional self harm (X60-X84) } & & 1.62 & 0.81 & 3.25 & 1.02 & 0.51 & 2.03 & 1.60 & 0.95 & 2.70 \\
\hline & Makes & 1.74 & 0.78 & 3.87 & 0.90 & 0.40 & 2.01 & 1.95 & 1.16 & 3.30 \\
\hline & Females & 1.04 & 0.26 & 4.17 & 2000.00 & 500.20 & 799600 & 0.00 & 0.00 & 0.00 \\
\hline
\end{tabular}




\begin{tabular}{|c|c|c|c|c|c|c|c|c|c|c|c|c|c|c|}
\hline & \multirow{2}{*}{\multicolumn{2}{|c|}{$\begin{array}{c}\text { Dephoyed compared to non- } \\
\text { deployed }\end{array}$}} & \multicolumn{6}{|c|}{ GWI Deployed } & \multicolumn{4}{|c|}{ GWI non-deployed } & & \\
\hline & & & \multicolumn{2}{|c|}{$\begin{array}{l}\text { deployed with GWI } \\
\text { compared to deyployed }\end{array}$} & \multicolumn{2}{|c|}{$\begin{array}{l}\text { oompaned to non- } \\
\text { deyployed w/out GWI }\end{array}$} & \multicolumn{2}{|c|}{$\begin{array}{l}\text { compared to non- } \\
\text { deployed with } \mathrm{GM}\end{array}$} & \multicolumn{2}{|c|}{$\begin{array}{l}\text { companed to non- } \\
\text { deployed without GWM }\end{array}$} & \multicolumn{2}{|c|}{$\begin{array}{c}\text { compared to deployed } \\
\text { without } \mathbf{G W}\end{array}$} & \multicolumn{2}{|c|}{$\begin{array}{c}\text { deployed } w / o \text { GWI to } \\
\text { non deployed } w / 0\end{array}$} \\
\hline & aHR & 95\%0 & aHR & 95\%0 & aHR & 95\%a & aHR & 95\%0 & aHR & 95\%0 & ahR & 95\%a & aHR & 95\%a \\
\hline Total mortality & 0.97 & $0.87,109$ & 1.30 & $1.10,1.5$ & 1.17 & $102,1,5$ & 0.83 & $0.69,0.99$ & 1.4 & $1.17,168$ & 1.7 & $127,1.93$ & 0.91 & $0.7,1.08$ \\
\hline \multicolumn{15}{|l|}{ CD-10 categary } \\
\hline Malignant nepplasms $(\mathrm{CO} 0-\mathrm{C97})$ & 0.93 & $0.76,1.13$ & 1.53 & $1.12,210$ & 111 & $0.88,140$ & 0.98 & $0.71,1.35$ & 111 & 081,153 & 1.54 & 105,226 & 0,3 & $0.54,0.999$ \\
\hline Endocrine, mutritional and metabolic diseases (EOO EQO) & 1.11 & $0.64,1.90$ & 0.63 & $0.30,1.31$ & 1.05 & $0.52,2.12$ & 0.67 & $0.28,1.58$ & 172 & $0.74,4.03$ & 109 & $0.46,261$ & 1.59 & $0.7,3.27$ \\
\hline Diseases of the nerwous system (GOOG G99) & 1.12 & $0.56,242$ & 0.95 & $0.36,2.52$ & 102 & $0.44,2.38$ & 1.26 & $0.35,4,60$ & 0.8 & $0.27,283$ & 0.71 & $0.18,282$ & 1.16 & 0.45294 \\
\hline Diseases of the cincuatory astem (1000199) & 0.93 & $0.74,1.16$ & 1.54 & 108,220 & 126 & $0.96,166$ & or & $0.51,0.99$ & 1.76 & 127,25 & 2.17 & $15,3,324$ & 0.84 & $0.59,1.19$ \\
\hline Diseases of the respiratory system $(100-699)$ & 0.89 & $0.56,1.41$ & 1.15 & $0.56,235$ & 1.09 & $0.61,1.5$ & 0.62 & $031,1.23$ & 1.83 & $0.94,3.59$ & 187 & $0.85,4.11$ & 0.94 & $0.47,1.86$ \\
\hline Diseases of the digestive sstem (K00-NO3) & 0.92 & $0.52,161$ & 3.16 & 108,978 & 142 & $0.74,273$ & 0899 & $0.39,202$ & 164 & $0.71,381$ & 3899 & $1.17,1296$ & 0.44 & $0.15,1.30$ \\
\hline Iranspat accidents (v01-v99) & 0.93 & $0.56,1.56$ & 0.6 & $0.32,1.34$ & 0.83 & $0.43,1.62$ & 0.67 & $0.28,1.59$ & 1.17 & $0.52,266$ & 0.99 & $0.41,236$ & $1.2 n$ & 0.632 .38 \\
\hline Other extermal causes of acoidental ingury ( $(m \times 0) \times 59$ ) & 1.58 & $0.85,280$ & 1.52 & $0.72,3.21$ & $2 \pi$ & $109, \mathbf{2} 8$ & 1.13 & $0.48,264$ & 1.95 & $0.77,4.96$ & 1.18 & $0.44,3.15$ & 148 & $0.64,3.44$ \\
\hline Accidental poisoning by and expostre to noxious sibstances ( $X 40-\times 49$ ) & 165 & $0.61,4.48$ & 6.97 & $0.89,54.59$ & 11.19 & $1.03,87.62$ & 0.72 & $0.25,2.13$ & 15,23 & $1 \pi, 131 n$ & 7.68 & $0.88,67.23$ & 145 & $0.09,22,78$ \\
\hline Intentional seff harm (X60-X34) & 1.04 & $0.62,1.80$ & 0.72 & $0.34,1.50$ & 0.98 & $0.47,2.88$ & 0.59 & $0.25,141$ & 1.53 & $0.65,3.63$ & 1.16 & $0.48,278$ & 1.55 & $0 . \overline{3.22}$ \\
\hline
\end{tabular}

'Alifusted for gender, race/ethnioty, and age enoup 
Chapter 4

Aim 3 Manuscript 


\title{
Assessing the risk of female-specific medical conditions among women with Gulf War Illness
}

\begin{abstract}
Introduction: Women comprise approximately $7 \%$ of the deployed Gulf War veteran cohort yet research has shown that women have higher prevalence of Gulf War Illness (GWI) compared to men. While several studies have demonstrated increased risk for female-related medical conditions and adverse reproductive outcomes among women deployed to the Gulf War, research on female-specific health outcomes specifically related to GWI is sparse. The objective of this study is to assess the incidence and risk of female-specific medical conditions among Gulf War veterans with and without probable GWI.
\end{abstract}

Methods: Deployed and non-deployed female veterans were identified using data from the National Health Survey of Persian Gulf War Era Veterans, a population-based survey conducted in 1995-1997. Respondents were classified as meeting criteria for GWI according to the CDC and Kansas definitions and were matched to Department of Veterans Affairs electronic medical records. Visits related to female-specific ICD-9 diagnoses were analyzed. We calculated incidence, indirectly age-adjusted standardized incident rate ratios, and adjusted hazard ratios using Cox proportional hazard models adjusting for race/ethnicity and age group.

Results: Deployed women meeting criteria for either the CDC or Kansas definition of GWI in 1995 were at increased risk for disorders of the breast and female genital tract compared to non-deployed women who did not meet GWI criteria. Within the deployed group, women 
meeting criteria for GWI had increased risk for disorders of the female genital tract compared to those not meeting GWI criteria.

Conclusion: Our findings show that there may be increased risk for female-specific medical conditions among women who were deployed who met the criteria for GWI in 1995, however additional research is needed to evaluate possible relationships between female-specific and reproductive health outcomes and GWI. 


\section{Introduction}

Approximately 37,000 women servicemembers were deployed to the 1990-1991 Gulf War, the largest deployment of women at the time, comprising nearly $7 \%$ of the total deployed population [1]. A recent systematic review of epidemiologic studies on the health of Gulf War veterans reported inconsistent findings in the limited published literature regarding the health of women who deployed to the Gulf War [2]. Several studies have demonstrated that women who deployed in support of the Gulf War were at increased risk for or reported high prevalence of Gulf War Illness (GWI) symptomology, the signature illness of the Gulf War $[3,4]$; however, research on female-specific health outcomes related to $\mathrm{GWI}$ is sparse $[2,5]$. Some studies have reported inconclusive evidence that women Gulf War veterans were at increased risk for reproductive issues and other health conditions [4, 6-12].

Research studies have demonstrated increased health concerns among women who were deployed to the Gulf War in comparison to deployed men or non-deployed women. United States (U.S.) Air Force Women who deployed to the Gulf War were more likely to report skin rashes, coughing, unintentional weight loss, insomnia, depression, and memory problems two to three years post Persian Gulf War deployment when compared to women who deployed to other areas [13]. In a follow-up study of this same cohort, women deployed to the Persian Gulf War reported more health problems, such as fatigue, joint pain, muscle pain or stiffness, irritability, flu-like symptoms, and skin rash, compared to women deployed elsewhere [14]. A survey of United Kingdom Air Force veterans reported that women had increased prevalence and risk for some health conditions, including headaches, fatigue, pain, and loss of 
concentration compared to women not deployed and women deployed to Bosnia [4]. A study completed 5 years post-war reported increased risk for outpatient medical visits and inpatient hospital stays among deployed Gulf War women compared to deployed men [15]. A population-based cross-sectional survey conducted in 2012-2014 reported increased risk for migraines, irritable bowel syndrome, gastritis, endocrine disorders, asthma, tachycardia, fibromyalgia, repeat bladder infections, and genital organ diseases among female deployed Gulf War veterans when compared to male deployed veterans [16].

A few research studies have focused on female-specific health concerns among Gulf War veterans, though results are inconsistent. A 1997 literature review and review of Gulf War Health Registries of Gulf War investigated women's health concerns and reported no significant increased health risks [12]. Among the female-specific health conditions included in a survey of United Kingdom Air Force veterans, deployed Gulf War women had greater risk of premenstrual tension, period problems, yeast infections, and subfertility compared to women who deployed to Bosnia [4]. A review study of reproductive outcomes among Gulf War women did not find evidence for increased gynecological issues in deployed females compared to non-deployed females [10].

Due to concerns about the potential for associations between negative reproductive health outcomes and numerous environmental exposures during the Gulf War, several studies have focused on birth defects, miscarriages, and fertility problems among deployed women veterans. Results from a survey of United Kingdom (U.K.) Air Force veterans reported that Gulf 
War deployed women had greater risk for miscarriage compared to women who did not deploy

[4]. Results of a cross-sectional survey that collected data 5 years after the Gulf War demonstrated higher prevalence of miscarriages in deployed females compared to their nondeployed counterparts, though the risk was not statistically significant [11]. A cross-sectional survey conducted between 1998-2001 of Gulf War veterans from the U.K. reported no increased risk for miscarriage among deployed females compared to female veterans who did not deploy [9]. Review of the research on miscarriages in female deployed veterans found some, though inconclusive, evidence of an association [10].

A 2006 review article summarizing the literature on Gulf War service and reproductive health reported there was no consistent evidence for an association between deployment and birth defects or fetal deaths, though results were limited by the small number of female study participants [10]. One study found no increased risk for birth defects in babies born between 1998 and 2004 to men and women who deployed to the Gulf War compared to those who did not deploy [6]. This same study reported increased risk for birth defects among deployed women compared to non-deployed women [11]. One study found increased risk for spontaneous abortions and ectopic pregnancies among deployed Gulf War women compared to non-deployed women [8]. A study of birth certificates of babies born to Gulf War deployed and non-deployed women found increased risk for hypospadias among babies born post-war to deployed Gulf War women compared to non-deployed [7]. However, many studies on fertility among Gulf War women lacked statistical power for reaching conclusions [10]. 
Several research studies indicate that women veterans who deployed in support of the Gulf War are more likely to meet the criteria for GWI compared to non-deployed women or deployed men, though the reason for this difference is unknown. GWI, a syndromic disorder, is the most concerning health outcome of the 1990-1991 Gulf War. Research studies have identified common groups of symptoms occurring disproportionately in veterans of the Gulf War compared to those who weren't deployed, including fatigue, pain, neurological and cognitive disorders, respiratory disorders, gastrointestinal issues, and dermatologic concerns. A recent study that calculated prevalence of probable GWI using data from a 1995-1997 population-based survey of Gulf War veterans reported the prevalence among women at 44$58 \%$ compared to $40-49 \%$ among men, depending on the definition of GWI used [17]. The Millennium Cohort Study reported increased odds of chronic GWI among women who deployed to the Gulf War compared to men, measured between years 2001-2008 [18]. A study of Gulf War deployed Army servicemembers reported that $60 \%$ of women met the criteria for GWI, and women were at increased risk for probable GWI compared to men [19]. Women veterans from the United Kingdom Air Force deployed to the Gulf War had a greater than two-fold increased risk for meeting the CDC definition of GWI compared to women deployed to Bosnia and women who did not deploy [4]. There is some evidence that women deployed to the more recent conflicts, Operation Enduring Freedom/Operation Iraqi Freedom, were at increased risk for reporting medical conditions consistent with GWI compared to deployed men [20]. Research has shown that women are at greater risk for syndromic disorders, such as chronic fatigue syndrome, fibromyalgia, and irritable bowel syndrome compared to men, which may also explain the increased prevalence of GWI among women[21-25]. 
Given the findings from previous studies indicating that women are disproportionately impacted by GWI as well as the numerous studies indicating possible increased risk for femalespecific health concerns and reproductive outcomes among women who deployed to the Gulf War, we hypothesize that women who were deployed to the Persian Gulf War who met criteria for GWI will have higher incidence for reproductive disorders. In this study we assessed the risk for female-specific medical conditions using Department of Veterans Affairs (VA) medical record data from 2000-2014 among female Gulf War veterans who presented with symptoms consistent with GWI in 1995-1997 compared to those without GWI symptomology. The objective of this study is to assess the incidence of female-specific medical conditions among Gulf War veterans meeting criteria of GWI compared to those who do not meet GWI criteria.

\section{Methods}

Women veterans included in this study were identified using respondent data from the 19951997 National Health Survey of Persian Gulf War Era Veterans (NHS) [26], a population-based health survey of 15,000 veterans deployed to the 1990-1991 Gulf War and a comparison group of 15,000 non-deployed veterans. Women were oversampled by $20 \%$. The response rate was approximately $70 \%$, resulting in 20,917 respondents, of which $20 \%$ were women $(n=4,208)$. Detailed information regarding the NHS has been reported previously [26].

\section{Measures}


Gender, age (grouped based on age at end of follow-up), and race/ethnicity (white, nonHispanic vs. other) were self-reported on the NHS. Deployment status was determined by the Department of Defense's Defense Manpower Data Center, which provided military servicemember identities for the NHS cohort.

For this study GWI status was determined by applying existing definition criteria to responses to medical conditions and symptoms on the NHS. In 2014, the Institute of Medicine (IOM) reviewed all published studies attempting to define GWI [27]. They concluded that an ideal case definition has yet to be developed and tested, and recommended use of two existing definitions: the definition developed by the Centers for Disease Control and Prevention, known as the CDC definition [28], and another version developed using a Kansas-based veteran cohort, referred to as the Kansas definition of GWI [29]. Neither of these definitions have been validated or tested for reliability [27]. Recently, the criteria for determining a GWI case using the CDC and Kansas versions were applied to the historical NHS data. Detailed information about these methods are available in a previous publication [17]. In the NHS study, $43.9 \%$ of deployed women met the criteria for the Kansas definition of GWI while $58.2 \%$ met the criteria for GWI according to the CDC definition [17]. For this current study, female veterans who met the criteria for either the CDC or the Kansas definitions for GWI were classified as positive for probable GWI, while those who did not meet either criteria were classified as negative [28, 29].

Social security numbers of female veterans who were not missing a CDC or Kansas GWI classification $(n=3,988)$ were matched to the VA Corporate Data Warehouse, the electronic 
medical record database for years 2000 through 2014 including inpatient, outpatient, emergency department visits, and fee for service files. Of the female NHS respondents, $51 \%$ ( $n=$ 2,049 ) had at least one VA medical record. For these analyses, we limited records to the earliest occurrence of female-specific medical conditions for each social security number using ICD-9 codes [30].

\section{Statistical Analyses}

We calculated incidence, person years at risk, crude incidence rates per 1,000 person-years, and indirectly age-adjusted standardized incidence rates per 1,000 person-years of femalespecific medical conditions stratified by deployed veterans with and without GWI, and nondeployed veterans without GWI. Indirectly age-adjusted standardized incidence rate ratios (SIR) and 95\% confidence intervals $(\mathrm{CI})$ for female-related medical conditions were calculated for collapsed ICD-9 categories and expanded three-digit ICD-9 codes with sufficient numbers of cases. Person-years were counted starting with the veteran's first visit. Veterans were censored from the denominator if deceased or if two years lapsed without an additional medical visit. Cox proportional hazard models controlling for race/ethnicity and age group were used to calculate adjusted hazard ratios (aHR) and 95\% confidence intervals ( $\mathrm{Cl}$ ) for female-specific medical conditions for collapsed ICD-9 categories and selected three-digit ICD-9 codes with sufficient number of cases.

Three sets of comparisons were made for each analyses: deployed with GWI compared to nondeployed without GWI, deployed with GWI compared to deployed without GWI, and deployed 
without GWI compared to non-deployed without GWI, the latter to get a sense of the underlying or baseline rates of female medical conditions in the deployed group compared to the non-deployed group. Data were analyzed using SAS Enterprise Grid software (version 5.1, SAS Institute, Inc.). Alpha was set at 0.05 for all analyses.

\section{Results}

Table 1 presents the incidence, crude incidence rate ratios per 1,000 person-years, and indirectly age-adjusted standardized incident rate ratios (SIR) of female-specific ICD-9 categories (disorders of breast; inflammatory disease of female pelvic organs; other disorders of female genital tract; complications of pregnancy, childbirth, and the puerperium; certain conditions originating in the perinatal period) among female veteran respondents to the NHS stratified by deployment and GWI status. The conditions with the greatest incidence rates were disorders of the breast (ICD-9 610-612) and other disorders of the female genital tract (ICD-9 617-629) for each deployment and GWI category. Deployed women meeting criteria for GWI were more likely to report a disorder of the breast $(\mathrm{SIR}=1.23,95 \% \mathrm{Cl}=1.08,1.40)$ and other disorders of the female genital tract $(\mathrm{SIR}=1.28,95 \% \mathrm{Cl}=1.17,1.41)$ compared to non-deployed women without GWI. Compared to deployed women not meeting the criteria for GWI, deployed women with GWI had $27 \%$ increased risk for a disorder of the female genital tract (SIR $=1.27,95 \% \mathrm{Cl}=1.16,1.39)$.

Table 2 presents incidence, crude incident rate ratios, and indirectly age-adjusted standardized incidence rate ratios for expanded ICD-9 categories. For all three stratification groups, incidence 
was greatest for ICD-9 627, menopausal and postmenopausal disorders. Compared to nondeployed women who did not meet the criteria for GWI, deployed women who met the criteria for GWI in 1995 were more likely to have a VA medical visit for other disorders of the breast $(\mathrm{SIR}=1.18,95 \% \mathrm{Cl}=1.03,1.36) ;$ inflammatory disease of cervix, vagina, and vulva $(\mathrm{SIR}=1.20$, $95 \% \mathrm{Cl}=1.04,1.39)$; genital prolapse $(\mathrm{SIR}=1.53,95 \% \mathrm{Cl}=1.09,2.16)$; noninflammatory disorders of cervix $(\mathrm{SIR}=1.38,95 \% \mathrm{Cl}=1.07,1.77)$; noninflammatory disorders of vagina $(\mathrm{SIR}=$ $1.91,95 \% \mathrm{Cl}=1.56,2.34)$; pain and other symptoms associated with female genital organs (SIR $=1.24,95 \% \mathrm{Cl}=1.07,1.45)$; disorders of menstruation and other abnormal bleeding from female genital tract $(\mathrm{SIR}=1.24,95 \% \mathrm{Cl}=1.09,1.42)$; menopausal and postmenopausal disorders $(\mathrm{SIR}=1.39,95 \% \mathrm{Cl}=1.23,1.58)$. Deployed women meeting $\mathrm{GWI}$ criteria were at increased risk for the following medical conditions compared to deployed women without GWI symptoms: inflammatory disease of cervix, vagina, and vulva $(\mathrm{SIR}=1.22,95 \% \mathrm{Cl}=1.05,1.41)$; endometriosis $(\mathrm{SIR}=1.82,95 \% \mathrm{Cl}=1.31,2.58)$; noninflammatory disorders of ovary, fallopian tube, and broad ligament $(\mathrm{SIR}=1.62,95 \% \mathrm{Cl}=1.27,2.06)$; noninflammatory disorders of vagina $(\mathrm{SIR}=1.67,95 \% \mathrm{Cl}=1.36,2.04) ;$ pain and other symptoms associated with female genital organs $(\mathrm{SIR}=1.19,95 \% \mathrm{Cl}=1.03,1.37) ;$ disorders of menstruation and other abnormal bleeding from female genital tract $(\mathrm{SIR}=1.53,95 \% \mathrm{Cl}=1.33,1.75)$.

Deployed veterans who met the criteria for GWI in 1995 were also at increased risk for several female specific medical conditions compared to deployed veterans who did not meet criteria for GWI (Table 2). Deployed veterans who met the criteria for GWI were at increased risk for inflammatory disease of cervix, vagina, and vulva $(\mathrm{SIR}=1.22,95 \% \mathrm{Cl}=1.05,1.41)$; 
endometriosis $(\mathrm{SIR}=1.82,95 \% \mathrm{Cl}=1.31,2.58)$; genital prolapse $(\mathrm{SIR}=1.42,95 \% \mathrm{Cl}=1.01$, 1.99); noninflammatory disorders of ovary fallopian tube and broad ligament $(\mathrm{SIR}=1.62,95 \% \mathrm{Cl}$ $=1.27,2.06)$; noninflammatory disorders of vagina $(\mathrm{SIR}=1.67,95 \% \mathrm{Cl}=1.36,2.04)$; pain and other symptoms associated with female genital organs $(\mathrm{SIR}=1.19,95 \% \mathrm{Cl}=1.03,1.37)$; and disorders of menstruation and other abnormal bleeding from female genital tract $(S I R=1.53$, $95 \% \mathrm{Cl}=1.33,1.75)$. When comparing deployed and non-deployed veterans without probable GWI, women who were deployed were at decreased risk for noninflammatory disorders of ovary, fallopian tube, and broad ligament $(\mathrm{SIR}=0.53,95 \% \mathrm{Cl}=0.33,0.97)$. Deployed women who did not meet criteria for GWI were at increased risk for noninflammatory disorders of vagina $(\mathrm{SIR}=1.76,95 \% \mathrm{Cl}=1.21,2.55)$ and menopausal and postmenopausal disorders $(\mathrm{SIR}=$ $1.30,95 \% \mathrm{Cl}=1.04,1.63)$ compared to non-deployed who did not meet the criteria for GWI. Incidence estimates were too small for calculating SIRs for the expanded list of conditions in the complications of pregnancy, childbirth, and the puerperium ICD-9 category.

Table 3 presents the adjusted hazard ratios (aHR) resulting from Cox proportional hazards models which control for age and race/ethnicity for the collapsed ICD-9 groups of femalespecific medical conditions. The only statistically significant result was an increased risk for disorders of the female genital tract for deployed veterans who met the criteria for GWI when compared to non-deployed veterans who did not meet the criteria for $\mathrm{GWI}(\mathrm{aHR}=1.24,95 \% \mathrm{Cl}$ $=1.06,1.47$ ). 
Table 4 shows adjusted hazard ratios for the expanded list of ICD-9 codes for the other disorders of female genital tract category. Deployed veterans who met the criteria for GWI had a marginally significant increased risk for menopausal and postmenopausal disorders compared to non-deployed veterans who did not meet criteria for GWI when controlling for age and race/ethnicity (aHR=1.26, $95 \% \mathrm{Cl}=1.002,1.59)$. Among those without $\mathrm{GWI}$ symptoms, deployed women were at $44 \%$ increased risk for disorders of menstruation and other abnormal bleeding from female genital tract compared to non-deployed, controlling for age and race/ethnicity $(\mathrm{aHR}=1.44,95 \% \mathrm{Cl}=1.04,1.98)$.

\section{Conclusion}

Results of our study show that women veterans who were deployed in service of the 1990-1991 Gulf War who met the criteria for GWI were at increased risk for some female-specific medical conditions at 9 to 24 years follow-up. Deployed women meeting criteria for either the CDC or Kansas definition of GWI in 1995 were at increased risk for disorders of the breast and female genital tract compared to non-deployed women who did not meet GWI criteria. Within the deployed group, women meeting the criteria for GWI had increased risk for disorders of the female genital tract compared to those not meeting GWI criteria.

To our knowledge, this is the first study to look at female-specific health outcomes among women meeting criteria for GWI. Results of previous research studies on female-specific disorders among women deployed to the Gulf War have been inconsistent or underpowered, with one study reporting increased risk for female-specific issues in a specific group of deployed 
women from the U.K. [4], and another study of U.S. women showing no increased risk for gynecological issues [10]. Our results indicate deployed women without GWI criteria had no increased risk in female-specific disorders compared to non-deployed without GWI. However, our results indicate deployed women meeting criteria for GWI had increased risk for femalespecific disorders compared to both comparison groups: non-deployed women meeting criteria for GWI and deployed women without GWI symptoms.

Previous research studies on reproductive issues among deployed women veterans showed some increased risk for negative reproductive outcomes, including birth defects and miscarriages, among deployed Gulf War women. Our findings do not support this finding, though the number of visits for services related to complications of pregnancy, childbirth, and the puerperium (ICD-9 630-679) and conditions originating in the perinatal period (ICD-9 760779) were small, and standardized incidence rate ratios and adjusted hazard ratios could not be calculated.

Our findings indicate that women who met the criteria for GWI in 1995 experienced increased risk for some female-specific disorders approximately 9 to 24 years after the Gulf War. These findings indicate that women who served in the Gulf War may have experienced exposures during deployment that could have put them at risk for increased female-specific health conditions in addition to probable GWI symptoms. 
Studies of deployed women indicate women frequently experience gynecologic disorders during deployment, often due to vaginal or urinary infections and menstrual disorders [31]. Conditions during deployment are associated with these disorders, such as heat, infrastructure, and unsanitary environments [31]. A study of women military servicemembers who deployed to the 1990-1991 Gulf War or other conflicts reported a change in feminine hygiene and menstrual management practices between normal life and deployment [32]. A survey of deployed women found that $30 \%$ experienced vaginal infections and $18 \%$ experienced urinary tract infections [33].

Compared to their male counterparts, female military servicemembers are at increased risk for experiencing military sexual trauma (MST), which is sexual assault or harassment experienced during military service. Results of a population-based veteran survey reported $41 \%$ of women and $4 \%$ of men met the criteria for MST [34]. Women who deployed or experienced combat are at increased risk for military sexual trauma [35]. One study reported an association between MST and liver disease among VA patients [36]. A study of women veterans reported increased risk for reproductive and gynecological symptoms and urological issues, chronic fatigue, breast disease, gastrointestinal, and cardiovascular disorders among those who reported MST compared to those who did not [37].

Female-specific disorders can be caused by diseases of organs that effect the reproductive system, including the thyroid, kidney, and liver [38]. Disorders of the genitourinary system were found to be pre-war predictors of GWI in a previous study (Aim 1 results, data not published). It 
is possible that some women may have had pre-war health conditions related to femalespecific disorders that would have made them more likely to experience GWI symptoms.

Alternatively, meeting the criteria for GWI could be related to these increased female-related health conditions. There is additional complexity in determining the relationship between GWI symptomology and female-specific disorders due to the lack of a definitive case definition for GWI. In their 2014 report, the IOM concluded that three domains of symptoms were commonly found in all published attempts at GWI case definitions (fatigue, pain, and neurocognitive dysfunction), with three additional domains found in all symptom-based studies (respiratory, dermatologic, and gastrointestinal symptoms). While the CDC and Kansas versions of GWI definitions are recommended as appropriate for research use [27], it is possible that these two definitions are affected by low specificity due to the inclusion of additional and different domains other than those concluded as most common by the IOM.

For our study, we identified women respondents on the survey who met criteria for either the CDC or Kansas definitions, which included conditions such as headaches, joint pain, stomach or abdominal pain, and excessive fatigue. It is possible that women who met these criteria may have had increased risk for female-related health disorders due to an association between female-related health outcomes and conditions included in the GWI domains. The lack of a definitive case definition likely contributes to the inconsistent findings of female-specific health outcomes related to Gulf War deployment and GWI. 
There are some limitations to this study. Survey results may be impacted by recall bias; ill veterans may have been more likely to respond to the survey compared to veterans who were not experiencing negative health. Additionally, not all veterans, regardless of deployment status, are eligible for VA care, so medical records are limited to those that are eligible who decided to use the VA medical system for health care. Some veterans may have deployed to subsequent conflicts resulting in additional exposures. Additionally, some veterans who were classified as not meeting GWI criteria in 1995 may have met the criteria for GWI in subsequent years, resulting in potential misclassification of probable GWI status for the current study.

There are several strengths to this study. The NHS is a population-based survey that oversampled women by $20 \%$ with a $70 \%$ response rate [26]. Due to the inclusion of a lengthy list of medical conditions and symptoms, we were able to classify respondents as meeting criteria for GWI according to the two currently recommended definitions of GWI, the CDC and Kansas definitions. To our knowledge, this is the only existing survey available with deployed and non-deployed GW veterans with the ability to classify according to probable GWI within 5 years post-war. Additionally, we were able to match the women survey respondents to electronic VA medical records.

In conclusion, we found an increased risk for some female-related medical conditions in 2000 through 2014 among deployed women veterans who met criteria for either the CDC or Kansas definitions of GWI. Specifically, these medical issues were mostly related to disorders of the female genital tract. We found no increased risk for complications from pregnancy among 
deployed women with probable GWI. Our study findings underscore the need for an updated and validated GWI definition. Without knowing the specificity of the CDC and Kansas definitions of GWI, and without an alternative case definition or biomarker, we are unable to confirm GWI cases. Without being able to confirm the true cases of GWI, we cannot be confident that our findings represent a true relationship between GWI and female-specific health outcomes. Determining an accurate case definition for GWI should be a priority in order to fully understand the relationship between female-related health conditions and Gulf War deployment and GWI. 


\section{References}

1. Office, U.G.A., Women in the Military: Deployment in the Persian Gulf War. 1993, Government Printing Office: Washington, DC.

2. Coughlin, S.S., et al., A Review of Epidemiologic Studies of the Health of Gulf War Women Veterans. J Environ Health Sci, 2017. 3(2).

3. Dursa, E.K., et al., Prevalence of a positive screen for PTSD among OEF/OIF and OEF/OIFera veterans in a large population-based cohort. J Trauma Stress, 2014. 27(5): p. 542-9.

4. Unwin, C., et al., Women in the Persian Gulf: lack of gender differences in long-term health effects of service in United Kingdom Armed Forces in the 1991 Persian Gulf War. Mil Med, 2002. 167(5): p. 406-13.

5. Ansa, B.E., et al., The Gulf War Women's Health Cohort: Study Design and Protocol. Int J Environ Res Public Health, 2020. 17(7).

6. Bukowinski, A.T., et al., Birth defects in infants born in 1998-2004 to men and women serving in the U.S. military during the 1990-1991 Gulf War era. Birth Defects Res A Clin Mol Teratol, 2012. 94(9): p. 721-8.

7. Araneta, M.R., et al., Prevalence of birth defects among infants of Gulf War veterans in Arkansas, Arizona, California, Georgia, Hawaii, and lowa, 1989-1993. Birth Defects Res A Clin Mol Teratol, 2003. 67(4): p. 246-60.

8. Araneta, M.R., et al., Conception and pregnancy during the Persian Gulf War: the risk to women veterans. Ann Epidemiol, 2004. 14(2): p. 109-16.

9. Doyle, P., et al., Miscarriage, stillbirth and congenital malformation in the offspring of UK veterans of the first Gulf war. Int J Epidemiol, 2004. 33(1): p. 74-86.

10. Doyle, P., N. Maconochie, and M. Ryan, Reproductive health of Gulf War veterans. Philos Trans R Soc Lond B Biol Sci, 2006. 361(1468): p. 571-84.

11. Kang, H., et al., Pregnancy outcomes among U.S. Gulf War veterans: a population-based survey of 30,000 veterans. Ann Epidemiol, 2001. 11(7): p. 504-11.

12. Murphy, F., et al., Women in the Persian Gulf War: health care implications for active duty troops and veterans. Mil Med, 1997. 162(10): p. 656-60.

13. Pierce, P.F., Physical and emotional health of Gulf War veteran women. Aviat Space Environ Med, 1997. 68(4): p. 317-21.

14. Pierce, P.F., Monitoring the health of Persian Gulf War veteran women. Federal Nursing Service Award. Mil Med, 2005. 170(5): p. 349-54.

15. Carney, C.P., et al., Women in the Gulf War: combat experience, exposures, and subsequent health care use. Mil Med, 2003. 168(8): p. 654-61.

16. Dursa, E.K., et al., Health Status of Female and Male Gulf War and Gulf Era Veterans: A Population-Based Study. Womens Health Issues, 2019. 29 Suppl 1: p. S39-s46.

17. Dursa, E., et al., Gulf War Illness in the 1991 Gulf war and Gulf era veteran population: an application of the centers for disease control and prevention and Kansas case definitions to historical data. Journal of Military and Veterans Health, 2018. 26(2): p. 43.

18. Smith, T.C., et al., Chronic multisymptom illness: a comparison of Iraq and Afghanistan deployers with veterans of the 1991 Gulf War. Am J Epidemiol, 2014. 180(12): p. 117687. 
19. Wolfe, J., et al., Risk factors for multisymptom illness in US Army veterans of the Gulf War. J Occup Environ Med, 2002. 44(3): p. 271-81.

20. Porter, B., et al., Prevalence of Chronic Multisymptom Illness/Gulf War IIIness Over Time Among Millennium Cohort Participants, 2001 to 2016. J Occup Environ Med, 2020. 62(1): p. 4-10.

21. Jason, L.A., et al., A community-based study of chronic fatigue syndrome. Arch Intern Med, 1999. 159(18): p. 2129-37.

22. Yunus, M.B., Gender differences in fibromyalgia and other related syndromes. J Gend Specif Med, 2002. 5(2): p. 42-7.

23. Meleine, M. and J. Matricon, Gender-related differences in irritable bowel syndrome: potential mechanisms of sex hormones. World J Gastroenterol, 2014. 20(22): p. 6725-43.

24. Kim, Y.S. and N. Kim, Sex-Gender Differences in Irritable Bowel Syndrome. J Neurogastroenterol Motil, 2018. 24(4): p. 544-558.

25. Arout, C.A., et al., Gender Differences in the Prevalence of Fibromyalgia and in Concomitant Medical and Psychiatric Disorders: A National Veterans Health Administration Study. J Womens Health (Larchmt), 2018. 27(8): p. 1035-1044.

26. Kang, H.K., et al., Illnesses among United States veterans of the Gulf War: a populationbased survey of 30,000 veterans. J Occup Environ Med, 2000. 42(5): p. 491-501.

27. Committee on the Development of a Consensus Case Definition for Chronic Multisymptom Illness in - Gulf War, V., P. Board on the Health of Select, and M. Institute of, in Chronic Multisymptom Illness in Gulf War Veterans: Case Definitions Reexamined. 2014, National Academies Press (US). Copyright 2014 by the National Academy of Sciences. All rights reserved.: Washington (DC).

28. Fukuda, K., et al., Chronic multisymptom illness affecting Air Force veterans of the Gulf War. Jama, 1998. 280(11): p. 981-8.

29. Steele, L., Prevalence and patterns of Gulf War illness in Kansas veterans: association of symptoms with characteristics of person, place, and time of military service. Am J Epidemiol, 2000. 152(10): p. 992-1002.

30. Organization, W.H., ICD-10 : international statistical classification of diseases and related health problems. 2004, World Health Organization.

31. Trego, L.L., Prevention is the key to maintaining gynecologic health during deployment. J Obstet Gynecol Neonatal Nurs, 2012. 41(2): p. 283-292.

32. Czerwinski, B.S., et al., Variations in feminine hygiene practices of military women in deployed and noncombat environments. Mil Med, 2001. 166(2): p. 152-8.

33. Lowe, N.K. and N.A. Ryan-Wenger, Military women's risk factors for and symptoms of genitourinary infections during deployment. Mil Med, 2003. 168(7): p. 569-74.

34. Barth, S.K., et al., Military Sexual Trauma Among Recent Veterans: Correlates of Sexual Assault and Sexual Harassment. Am J Prev Med, 2016. 50(1): p. 77-86.

35. Leardmann, C.A., et al., Combat deployment is associated with sexual harassment or sexual assault in a large, female military cohort. Womens Health Issues, 2013. 23(4): p. e215-23.

36. Kimerling, R., et al., The Veterans Health Administration and military sexual trauma. Am J Public Health, 2007. 97(12): p. 2160-6. 
37. Frayne, S.M., et al., Medical profile of women Veterans Administration outpatients who report a history of sexual assault occurring while in the military. J Womens Health Gend Based Med, 1999. 8(6): p. 835-45.

38. Hammer, G.D. and S.J. McPhee, Pathophysiology of disease : an introduction to clinical medicine. Eighth Edition ed. 2019, New York: McGraw-Hill Education. xiv, 814 pages. 
Intirently age-athisted stantarized

incidence rate ratios comparing

Deployed with GW

( $n=265)$

Depoyed w/o GW

(n=335)

Nondeployed, w/o GW (n=532)

Wo GW

rude

cuite

incidence rate/ $1000 \mathrm{pr}$

$$
\text { Disorders of breas }
$$

Inflammatory Disease of Female Pelvic Organ

Other Disorders of Female Genital Tract

$227 \quad 37.48$

rate/ $1000 \mathrm{pr}$

$\begin{array}{ll}68 & 34.26\end{array}$

34.26
24.45
72.42

incidence

98

98
80

ate/1000 py

SR 95\% al 95\% वu

$123 \quad 108 \quad 140$

$\begin{array}{lll}123 & 108 & 140\end{array}$

24.53

125

72.42

2.65

760-779 Certain Cons O/ Pregrancy, Childbirth, And The Puerpent

$\begin{array}{rr}29 & 3.96 \\ 6 & 0.81\end{array}$

0.81

12

72.52
3.34

$\begin{array}{lll}1.14 & 0.99 & 132 \\ 128 & 117 & 141\end{array}$

\begin{tabular}{l|l|l|}
1128 & 117 & 141 \\
\hline 1.11 & 0.77 & 1.59 \\
\hline
\end{tabular}
Intirectly age-atjusted Intirectly age-actjusted standantized standartized incidence rate incidence rate ratios comparing tios companing deploped wi th deployed $w / 0$ GW/ to non-deployed GWI to dephoyed w/o GW W/OGWI

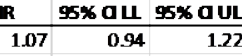
SR 95\% CL $95 \%$ Cu

\begin{tabular}{|l|l|l|l|l|l|}
\hline 1.07 & 0.94 & 1.22 & 1.14 & 0.90 & 1.44 \\
\hline 0.96 & 0.83 & 1.12 & 0.98 & 0.74 & 1.29 \\
\hline 127 & 116 & 139 & 0.99 & 0.83 & 1.18 \\
\hline 158 & 1.10 & 2.8 & 0.98 & 0.31 & 1.5 \\
\hline
\end{tabular}

$\begin{array}{lll}127 & 116 & 139 \\ 158 & 110 & 228\end{array}$

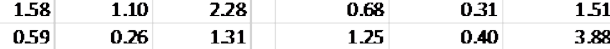




\begin{tabular}{|c|c|c|c|c|c|c|c|}
\hline \multirow[b]{2}{*}{ KD 9 Code } & \multirow[b]{2}{*}{ KD 9 Description } & \multicolumn{2}{|c|}{ Deployed with GW } & \multicolumn{2}{|c|}{ Deploped w/o GWI } & \multicolumn{2}{|c|}{ Nondeployed, w/o GW } \\
\hline & & incidence & $\begin{array}{c}\text { crude } \\
\text { incidenoe } \\
\text { rate/1000 py }\end{array}$ & incidence & $\begin{array}{c}\text { crude } \\
\text { incidence } \\
\text { rate/1000 PY }\end{array}$ & incidence & $\begin{array}{c}\text { arde } \\
\text { incidenes } \\
\text { rate/1000 Py }\end{array}$ \\
\hline $610-612$ & Disorders of breast & & & & & & \\
\hline 610 & Benign mammary dysplasios & 106 & $15-53$ & 30 & 13.96 & 51 & 15.01 \\
\hline 611 & Other disorders of breast & 191 & 30.53 & 59 & 29.33 & 85 & 26.66 \\
\hline 614-616 & Inflammatory Disease Of Femate Pehric Organs & & & & & & \\
\hline 614 & Tota-Inflammatory disease of owary fallopion tube pehwic cellular tisscee and peritoneum & 18 & 243 & 7 & 3.09 & 10 & 276 \\
\hline 615 & Total-inflammatory diseases of uterus except cervix & 3 & 0.41 & 5 & 2.17 & $\mathbf{0}$ & 0.00 \\
\hline 616 & Inflammatory disease of cervix ungina and wetwa & 174 & 27.41 & 46 & 22.32 & 74 & 22.66 \\
\hline 617-629 & Other Disorders of Femate Genitud Tract & & & & & & \\
\hline 617 & Endometriosis & 35 & 4.80 & 6 & 259 & 13 & 3.55 \\
\hline 618 & Genital prolopse & 33 & 4.51 & 7 & 3.06 & 11 & 3.05 \\
\hline 619 & Fistwa imwolving female genital tract & $\mathbf{1}$ & 0.13 & $\mathbf{0}$ & 0.00 & $\mathbf{0}$ & 0.00 \\
\hline 620 & Noninflammatory disorders of owary fallopian tube and brood ligament & 66 & 9.18 & 13 & 5.76 & 35 & 9.91 \\
\hline 621 & Disorders of uterus not elsewhere dossified & 94 & 13.25 & 28 & 12.64 & 49 & 13.68 \\
\hline 622 & Noninflammatory disorders of oervix & 60 & $\mathbf{8 . 4 0}$ & 17 & 7.73 & 21 & 5.96 \\
\hline 623 & Noninflammatory disorders of ungina & 94 & 13.25 & 28 & 12.64 & 49 & 13.68 \\
\hline 624 & Noninflammatory disorders of whwa and perineum & 10 & 1.35 & 5 & 218 & 6 & 1.65 \\
\hline 625 & Pain and other symptoms associoted with female genital organs & 184 & 28.05 & 48 & 22.95 & 73 & 21.63 \\
\hline 626 & Disorders of menstruation and other abnormal bleeding from female genital tract & 211 & 33.46 & 46 & 21.75 & 84 & 25.78 \\
\hline 627 & Menopausal and postmenopausal disorders & 253 & 40.98 & 75 & 37.87 & 104 & 32.37 \\
\hline 628 & Female infertility & 11 & 1.48 & 7 & 3.09 & $\mathbf{8}$ & 221 \\
\hline 629 & Other disorders of female genital organs & 7 & 0.94 & 3 & 1.30 & 4 & 1.10 \\
\hline $630-679$ & Complications of Aregnancy, Chitdirth, And The Averperiuen & & & & & & \\
\hline 632 & Missed ahortion & 3 & 0.40 & $\mathbf{1}$ & 0.43 & $\mathbf{0}$ & 0.00 \\
\hline 633 & Ectopic pregnoncy & 2 & 0.27 & $\mathbf{1}$ & 0.43 & $\mathbf{0}$ & 0.00 \\
\hline 634 & Spontaneous abortion & 4 & 0.54 & 2 & 0.87 & 2 & 0.55 \\
\hline 635.92 & Legally induced abortion, withoust mertion of complication, complete & $\mathbf{0}$ & 0.00 & $\mathbf{0}$ & 0.00 & $\mathbf{0}$ & 0.00 \\
\hline 637.91 & Unspecified abortion, withoust mention of complication, incomplete & $\mathbf{1}$ & 0.13 & $\mathbf{1}$ & 0.43 & $\mathbf{0}$ & 0.00 \\
\hline 640 & Hemonthoge in easty pregnoncy & 6 & 0.81 & 2 & 0.87 & $\mathbf{1}$ & 0.27 \\
\hline 641.90 & Unspecified antepartum hemorrhage, unspecified as to episode of care or not applicable & $\mathbf{0}$ & 0.00 & 1 & 0.43 & 0 & 0.00 \\
\hline 642 & Hypertension complionting pregnancy childbirth and the puerperium & $\mathbf{0}$ & 0.00 & 1 & 0.43 & $\mathbf{0}$ & 0.00 \\
\hline 643 & Excessive womiting in pregnoncy & 2 & 0.27 & $\mathbf{1}$ & 0.43 & $\mathbf{0}$ & 0.00 \\
\hline 644 & Earty or threatened labor & 3 & 0.40 & 2 & 0.87 & 3 & 0.83 \\
\hline 645 & Late pregnancy & $\mathbf{1}$ & 0.13 & $\mathbf{1}$ & 0.43 & $\mathbf{0}$ & 0.00 \\
\hline 646 & Other complications of pregnancy not elsewhere classified & 6 & 0.81 & 4 & 1.75 & $\mathbf{1}$ & 0.27 \\
\hline 647 & $\begin{array}{l}\text { Infectious and pansitic conditions in the mother classifiable elsewhere but complianting pregnancy childbinth or the } \\
\text { purperium }\end{array}$ & $\mathbf{1}$ & 0.13 & 2 & 0.87 & $\mathbf{0}$ & 0.00 \\
\hline 648 & Other arrent canditions in the mother classifiable elsewhere but complicating pregnancy childbirth or the puerperium & 9 & 1.21 & 4 & 1.75 & 4 & 1.10 \\
\hline 650. & Normal delivery & 2 & 0.27 & o & 0.00 & 2 & 0.55 \\
\hline 651.03 & Twin pregnancy, antepartum condition or complication & $\mathbf{1}$ & 0.13 & $\mathbf{0}$ & 0.00 & $\mathbf{0}$ & 0.00 \\
\hline 652.23 & Breech presentation withoust mention of version, antepartum ondition or complication & 2 & 0.27 & $\mathbf{0}$ & 0.00 & $\mathbf{0}$ & 0.00 \\
\hline 653.41 & Fetopelvic disproportion, delivered, with or without mention of antepartum condition & $\mathbf{1}$ & 0.13 & o & 0.00 & $\mathbf{0}$ & 0.00 \\
\hline 654 & Abnormality of organs and soft tissues of pehis & 7 & 0.94 & $\mathbf{1}$ & 0.43 & 3 & 0.82 \\
\hline 655 & Known or suspected fetal abnormality affecting manogement of mother & 4 & 0.54 & $\mathbf{1}$ & 0.43 & 2 & 0.55 \\
\hline 656 & Other known or suspected fetal and placental problems affecting manogement of mother & 3 & 0.40 & 3 & 1.31 & 2 & 0.55 \\
\hline 657.01 & Polytyutramnios, delivered, with or without mertion of antepartum condition & $\mathbf{0}$ & 0.00 & $\mathbf{0}$ & 0.00 & $\mathbf{1}$ & 0.27 \\
\hline 658.41 & Infection of amniotic cavity, delivered, with or without mention of antepartum condition & $\mathbf{0}$ & 0.00 & $\mathbf{1}$ & 0.43 & o & 0.00 \\
\hline 659 & Other indiontions for care or intervention related to labor and delivery not elsewhere classiffied & 8 & 1.08 & 3 & 1.31 & 3 & 0.82 \\
\hline 660.31 & $\begin{array}{l}\text { Deep transverse arrest and persistent occipitoposterior position, delivered, with or without mention of antepartum } \\
\text { condition }\end{array}$ & $\mathbf{0}$ & 0.00 & $\mathbf{1}$ & 0.43 & $\mathbf{0}$ & 0.00 \\
\hline 661 & Abnomality of forces of labor & 2 & 0.27 & $\mathbf{0}$ & 0.00 & $\mathbf{0}$ & 0.00 \\
\hline 663 & Umbilical oord compliontions dering fabor and delivery & 3 & 0.40 & 1 & 0.43 & $\mathbf{1}$ & 0.27 \\
\hline 664 & Trauma to perineum and vatua dwring defivery & 3 & 0.40 & $\mathbf{1}$ & 0.43 & $\mathbf{1}$ & 0.27 \\
\hline 665_51 & Damage to pelvic joints and ligaments, delivered, with or withont mention of antepartum condition & $\mathbf{1}$ & 0.13 & $\mathbf{0}$ & 0.00 & $\mathbf{1}$ & 0.27 \\
\hline 666.24 & Delayed and secondary postpartum hemorrhage, postpartum condition or complication & $\mathbf{0}$ & 0.00 & $\mathbf{1}$ & 0.43 & 0 & 0.00 \\
\hline $6 / 2.02$ & Pyrexia of unknown origin during the puerperium, delivered, with mention of postpartum complication & $\mathbf{0}$ & 0.00 & o & 0.00 & $\mathbf{0}$ & 0.00 \\
\hline 674 & Other and unspecified compliantions of the puerperium not elsewhere classified & 2 & 0.27 & o & 0.00 & $\mathbf{0}$ & 0.00 \\
\hline 676 & Other disorders of the breast associated with childbirth and disorders of lactation & 6 & 0.81 & $\mathbf{0}$ & 0.00 & 3 & 0.83 \\
\hline $760-779$ & Certuin Conditions Originating in The Perinatul Period & & & & & & \\
\hline 761 & Fetus or newbon affected by maternal complications of pregnancy & 3 & 0.40 & 2 & 0.87 & $\mathbf{1}$ & 0.27 \\
\hline 765 & Disorders relating to short gestation and low birthweight & $\mathbf{1}$ & 0.13 & $\mathbf{1}$ & 0.44 & 2 & 0.55 \\
\hline 766.1 & Other Theavy-for-dates" infarts & $\mathbf{1}$ & 0.13 & o & 0.00 & $\mathbf{0}$ & 0.00 \\
\hline 7717 & Congenital cytomegalowirus infection & $\mathbf{1}$ & 0.13 & $\mathbf{0}$ & 0.00 & $\mathbf{0}$ & 0.00 \\
\hline 775.4 & Hypocalcemia and hypomagnesemia of newbom & $\mathbf{0}$ & 0.00 & $\mathbf{0}$ & 0.00 & $\mathbf{1}$ & 0.27 \\
\hline
\end{tabular}




\begin{tabular}{|c|c|c|c|c|c|c|c|c|c|c|}
\hline \multirow[b]{2}{*}{ IOD 9 Code } & \multirow[b]{2}{*}{ KD 9Description } & \multicolumn{3}{|c|}{ 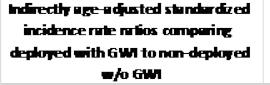 } & \multicolumn{3}{|c|}{ 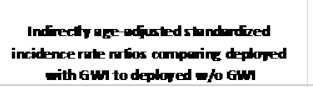 } & \multicolumn{3}{|c|}{ 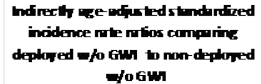 } \\
\hline & & SR & $\mathbf{s} \times \mathbf{a ~ u ^ { * }}$ & sxauk & SR & 958 all & TEX aul & Sa & 958 all & gso raul \\
\hline Gtogt2 & Disontes of theost & & & & & & & & & \\
\hline 610 & Benign manurary dbopkesies & 106 & 0.88 & 179 & $10 \mathrm{f}$ & 0.89 & 130 & 109 & 076 & 156 \\
\hline 611 & Other disonters of breast & 1.18 & 103 & 1.36 & 100 & 0.89 & 118 & 115 & ая9 & 149 \\
\hline 644-616 & 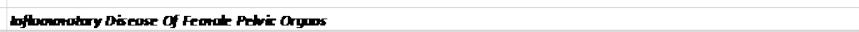 & & & & & & & & & \\
\hline 614 & 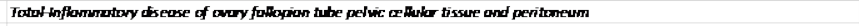 & & & & & & & & & \\
\hline 615 & 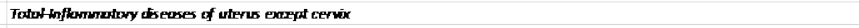 & & & & & & & & & \\
\hline 616 & inflemmetiony disecese of cervix vegina and vulvo & 120 & 104 & 1.39 & 1.2 & 1.05 & 1.41 & 098 & 073 & 131 \\
\hline 6000 & 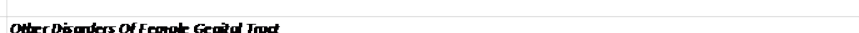 & & & & & & & & & \\
\hline $6 D$ & Endanetriesis & 173 & 0.89 & 172 & 1.82 & 1.31 & 258 & $\mathbf{a s}$ & 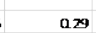 & 15 \\
\hline 618 & Gentud protopse & 1.53 & 109 & 2.16 & 1.4 & 101 & 1.99 & 100 & 051 & 25 \\
\hline 619 & Fistula imvelving femde genful truet & & & & & & & & & \\
\hline 620 & 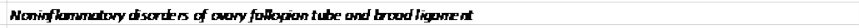 & 0.89 & 0.70 & 113 & 162 & 127 & 206 & a56 & $\mathbf{a 3 3}$ & $\mathbf{a g 9}$ \\
\hline $62 \pi$ & Disenders of utenes net else where cikssified & 096 & 0.78 & 117 & $10 \mathrm{~s}$ & 0.86 & 179 & 095 & $\alpha \in$ & 137 \\
\hline 622 & Neninflanimatory diserters of arvix & 1.38 & 107 & 17 & 105 & 0.81 & 135 & 128 & $a \times 3$ & 205 \\
\hline 623 & 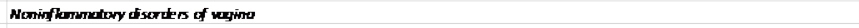 & 1.91 & 1.56 & 234 & 10 & 1.36 & 204 & 1.76 & $12 \pi$ & 255 \\
\hline 624 & Neninflamanatony disenders of wive ond perine un & & & & & & & & & \\
\hline 65 & 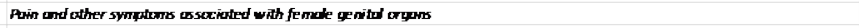 & 124 & $\mathbf{1 . 0 7}$ & 145 & 1.19 & $\mathbf{1 . 0 3}$ & 137 & 098 & 074 & 130 \\
\hline 626 & 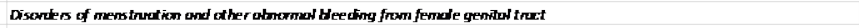 & 124 & 109 & 1.42 & 1.53 & 1.33 & 1.75 & 080 & 060 & 107 \\
\hline 62 & 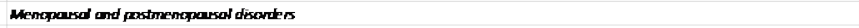 & 1.39 & 123 & 1.58 & $10 \%$ & 095 & 121 & $\mathbf{1 . 3 0}$ & 1.04 & 1.63 \\
\hline 628 & Femate infertidy & & & & & & & & & \\
\hline 620 & Other disonders of femade genitul argans & & & & & & & & & \\
\hline & & & & & & & & & & \\
\hline 630009 & 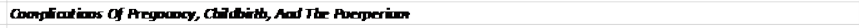 & & & & & & & & & \\
\hline 632 & Missed alortion & & & & & & & & & \\
\hline 633 & Extryocic pregnenoy & & & & & & & & & \\
\hline 6.34 & Spentaneass abertion & & & & & & & & & \\
\hline 63892 & Legally indreed abartion, without mention of canplination complete & & & & & & & & & \\
\hline 63791 & Unspecified doation, without mention of complication incomplete & & & & & & & & & \\
\hline $6 \%$ & Hementhoge in early pregnonay & & & & & & & & & \\
\hline 64190 & Unspecified antepatum henonthage, unperified as to episode of care or not applinable & & & & & & & & & \\
\hline 60 & 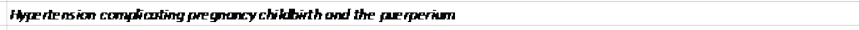 & & & & & & & & & \\
\hline 648 & Earssive vonitiong in pregnency & & & & & & & & & \\
\hline 644 & Eorly or threatrened kater & & & & & & & & & \\
\hline 6.5 & tote pregnenty & & & & & & & & & \\
\hline 696 & 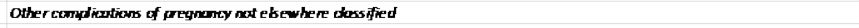 & & & & & & & & & \\
\hline 64 & 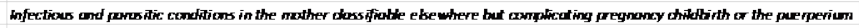 & & & & & & & & & \\
\hline 6048 & 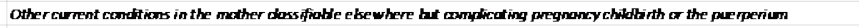 & & & & & & & & & \\
\hline 650. & Narnal delivery & & & & & & & & & \\
\hline 65108 & Twin pregnanxy, antepatun condtion ar complication & & & & & & & & & \\
\hline 6523 & Breech presentation without mention of wersion, antepatumn ambition or complination & & & & & & & & & \\
\hline 653.41 & Fetope hic disprapation, delinered, with ar without mention of antepartum condition & & & & & & & & & \\
\hline 654 & Ahnomedity of agons and seft tissuers of provis & & & & & & & & & \\
\hline 655 & 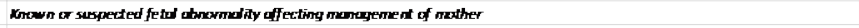 & & & & & & & & & \\
\hline 6.56 & 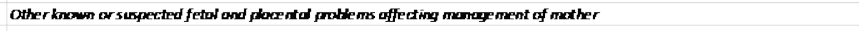 & & & & & & & & & \\
\hline $65 \% .01$ & 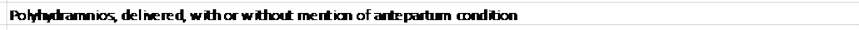 & & & & & & & & & \\
\hline 658.41 & Infection of amnictic carity, delimered, with ar without mention of antepatum conditikn & & & & & & & & & \\
\hline 659 & 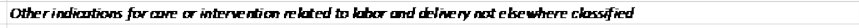 & & & & & & & & & \\
\hline 66031 & Deep trabserse arrest and persistent ocriphoposterior position, delinered, with a without mention of antepatun condition & & & & & & & & & \\
\hline 661 & Ahnowndity of forres of lather & & & & & & & & & \\
\hline 663 & 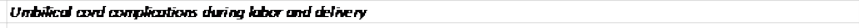 & & & & & & & & & \\
\hline 664 & Frawne to perine un and wive divring delinery & & & & & & & & & \\
\hline 66551 & Danage to pelinc joints and liganents, delivered, with or without mention of antepartun condtion & & & & & & & & & \\
\hline 666.24 & De layed and seconday postpartum hernonhage, postpartun candition or camplination & & & & & & & & & \\
\hline $6 \cap 02$ & 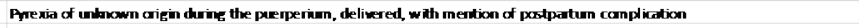 & & & & & & & & & \\
\hline 674 & Other and unspec fied anmplicutions of the parperium net ebewhere dess fied & & & & & & & & & \\
\hline $6 \pi$ & 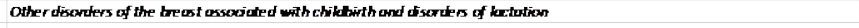 & & & & & & & & & \\
\hline 760719 & 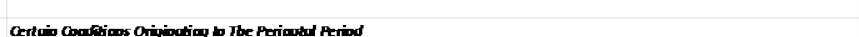 & & & & & & & & & \\
\hline 761 & 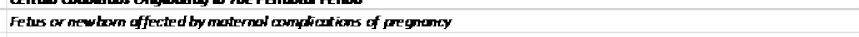 & & & & & & & & & \\
\hline 765 & Disenders rekating to shert gestution and kav birthweight & & & & & & & & & \\
\hline 766.1 & Other "hearyfor-dites" infants & & & & & & & & & \\
\hline$\pi 17$ & Congental cytonegalomis iffection & & & & & & & & & \\
\hline T3.4.4 & Hyporakern ia and Impanagnesemia of newbon & & & & & & & & & \\
\hline
\end{tabular}


Table 3: Adjusted hazard ratios and 95\% confidence intervals for collapsed female-specific ICD-9 code categories for female respondents to NHS

\begin{tabular}{|c|c|c|c|c|c|c|c|}
\hline \multirow[b]{2}{*}{ ICD 9 Code } & \multirow[b]{2}{*}{ ICD 9 Description } & \multicolumn{2}{|c|}{$\begin{array}{c}\text { Ratio (comparing } \\
\text { deployed with GWI to } \\
\text { non-deyployed w/o } \\
\text { GWI) }\end{array}$} & \multicolumn{2}{|c|}{$\begin{array}{c}\text { adjusted* Hazard Ratio } \\
\text { (comparing deployed } \\
\text { with GWI to deployed } \\
\text { w/o GWI) }\end{array}$} & \multicolumn{2}{|c|}{$\begin{array}{l}\text { adjusted* Hazard Ratio } \\
\text { (comparing deployed } \\
\text { w/o GWI to non- } \\
\text { deyployed w/o GWI) }\end{array}$} \\
\hline & & aHR & $95 \% \mathrm{~d}$ & aHR & $95 \% \mathrm{~d}$ & aHR & $95 \% \mathrm{~d}$ \\
\hline $610-612$ & Disorders of breast & 1.11 & $0.88,1.41$ & 1.11 & $0.82,1.52$ & 1.03 & $0.78,1.35$ \\
\hline $614-616$ & Inflammatory Disease Of Female Pelvic Organs & 1.08 & $0.83,1.41$ & 0.99 & $0.70,1.42$ & 1.06 & $0.77,1.45$ \\
\hline $617-629$ & Other Disorders Of Female Genital Tract & 1.24 & $1.06,1.47$ & 1.07 & $0.86,1.34$ & 1.17 & $0.96,1.43$ \\
\hline $630-679$ & Complications Of Pregnancy, Childbirth, And The Puerperium & 1.01 & $0.51,1.98$ & 0.7 & $0.26,1.88$ & 1.43 & $0.59,3.46$ \\
\hline $760-779$ & Certain Conditions Originating In The Perinatal Period & 0.74 & $0.21,266$ & 1.17 & $0.26,5.22$ & 0.57 & $0.14,2.29$ \\
\hline
\end{tabular}


Table 4: Adjusted hazard ratios and 95\% confidence intervals for individual female-specific KCD-9 codes for female respondents to NHS

\begin{tabular}{|c|c|c|c|c|c|c|c|}
\hline \multirow[b]{2}{*}{ ICD-9 Code } & \multirow[b]{2}{*}{ KD-9 Description } & \multicolumn{2}{|c|}{$\begin{array}{c}\text { adjusted* Hazard Ratio } \\
\text { (comparing deployed with } \\
\text { GWI to non deyployed w/o } \\
\text { GWI) }\end{array}$} & \multicolumn{2}{|c|}{$\begin{array}{l}\text { adjusted* Hazard Ratio } \\
\text { (comparing depkyed with } \\
\text { GWI to deployed w/o GWI) }\end{array}$} & \multicolumn{2}{|c|}{$\begin{array}{l}\text { adjusted* Hazard Ratio } \\
\text { (comparing deployed } \\
\text { w/o GWI to non- } \\
\text { deyployed w/o GWI) }\end{array}$} \\
\hline & & aHR & $95 \% 0$ & aHR & $95 \% \mathrm{a}$ & aHR & $95 \% \mathrm{a}$ \\
\hline $617-629$ & Other Disarders Of Female Genital Tract & & & & & & \\
\hline 617 & Endometriosis & 1.16 & $0.61,2.20$ & 0.66 & $0.25,1.74$ & 1.81 & $0.76,4.32$ \\
\hline 618 & Genital prolapse & 1.46 & $0.73,290$ & 0.96 & $0.37,2.48$ & 1.42 & $0.63,3.22$ \\
\hline 620 & Noninflammotory disonders of ovary fallopian tube and broad ligament & 0.76 & $0.50,1.15$ & 0.55 & $0.29,1.04$ & 1.43 & $0.79,2.59$ \\
\hline 621 & Disorders of uterus not elsewhere classified & 0.83 & $0.59,1.18$ & 0.93 & $0.58,1.48$ & 0.94 & $0.61,1.43$ \\
\hline 622 & Noninflammotory disonders of cenvix & 1.33 & $0.81,2.20$ & 1.33 & $0.70,2.53$ & 1.03 & $0.60,1.77$ \\
\hline 623 & Noninflammotory disorders of vagina & 1.22 & $0.76,1.95$ & 1.15 & $0.62,2.12$ & 1.02 & $0.61,1.72$ \\
\hline 625 & Pain and other symptoms associoted with female genital organs & 1.15 & $0.88,1.51$ & 1.01 & $0.70,1.46$ & 1.13 & $0.82,1.56$ \\
\hline 626 & Disorders of menstruation and other abnormal bleeding from female genital tract & 1.16 & $0.90,1.50$ & 0.8 & $0.55,1.14$ & 1.44 & $1.04,1.98$ \\
\hline 627 & Menoparsal and postmenoparsal disonders & 1.26 & $1.002,1.59$ & 1.27 & $0.95,1.72$ & 0.97 & $0.75,1.26$ \\
\hline
\end{tabular}

*Adjusted for race/ethnicity and age group 
Chapter 5

Discussion 


\section{Chapter 5: Discussion}

\subsection{Summary}

In the thirty years since the 1990-1991 Persian Gulf War, researchers have failed to agree on a case definition for the proposed signature health outcome related to this military conflict, a cluster of symptoms known as Gulf War Illness (GWI) [1]. The three research aims presented sought to add greater understanding of GWI by examining pre-war medical conditions as predictors of probable GWI, determining long-term mortality outcomes of veterans reporting GWI symptoms, and investigating long-term risk for female-specific health visits among women veterans with probable GWI. Additionally, because of the specificity and validity issues with the two most common GWI definitions, we proposed an alternative definition for GWI based on recommendations from the Institute of Medicine (IOM) [1].

\subsubsection{Aim 1}

Using population-based survey data collected in 1995, we discovered that deployed veterans' self-reports of pre-war medical conditions and symptoms predict meeting criteria for GWI at a later time point. For this study we used the IOM recommended CDC and Kansas definitions of GWI, as well as a newly developed 3-domain version based on the IOM systematic literature review conclusions [1-3]. The predictor groups included pain, dermatologic, genitourinary, gastrointestinal, neurological, cardiac, respiratory, and inflammation, all of which independently predicted probable GWI according to the CDC/Kansas and 3-domain definitions. When included in the same logistic regression model, all predictor groups remained statistically significant for both GWI classification methods. These results demonstrate that at least some 
veterans may have been pre-disposed to meeting GWI criteria, and that the number of pre-war medical conditions and symptoms reported by veterans was associated with increased risk for meeting GWI criteria. We conclude that pre-war predictors should be further explored and potentially included in the criteria for a GWI case definition.

\subsubsection{Aim 2}

For the second aim, we calculated mortality risk among veteran survey respondents, classified by probable GWI according to the CDC or Kansas definitions. Our findings indicate that among deployed veterans, those meeting the CDC or Kansas criteria for GWI in 1995-1997 were at increased risk for overall mortality and mortality due to malignant neoplasms, circulatory system disorders, and digestive system disorders compared to those that did not report GWI symptoms. Among veterans meeting GWI criteria, compared to non-deployed veterans, deployed veterans have decreased risk of overall mortality and mortality due to diseases of the circulatory system. It is worth noting that pre-war cardiac and gastrointestinal symptoms were predictors of GWI as reported in Aim One of this dissertation.

\subsubsection{Aim 3}

For the third aim, we focused on health outcomes of deployed female veterans who met the criteria for CDC or Kansas GWI, as research has shown that females have greater prevalence of GWI compared to males [12]. Deployed women who met the criteria for GWI in 1995-1997 were more likely to have an electronic medical record visit for breast disorders or female genital tract problems compared to women Gulf War era veterans who did not deploy and who 
did not have symptoms consistent with GWI. Among all deployed women, those meeting GWI criteria were more likely to have disorders of the female genital tract compared to those without GWI symptom criteria. The association may be partially explained by the increased risk for meeting GWI criteria among veterans who had genitourinary symptoms pre-war, as reported in Aim One.

There are some limitations to our findings, including those related to typical problems with survey data such as self-report bias and missing data. There may be misclassification bias for deployment status; some veterans may have had subsequent deployments or exposures after the time of the survey. The most critical limitation is the constraints of using the CDC and Kansas definitions of GWI to classify GWI. As mentioned previously, the studies that developed the CDC and Kansas definitions used relatively small and non-generalizable samples and resulting case definitions have not been validated [1-3]. Given the approximate $40-50 \%$ prevalence of probable GWI according to these definitions among deployed veterans, and $17 \%$ prevalence in the non-deployed group [4], it is likely that both versions have low specificity. Without knowing if the case definition of GWI used is capturing true cases of GWI and excluding non-cases, it is imprudent to make conclusions about our findings or those of other research studies that use these case definitions.

\subsection{Implications for future research}

Our studies add to the large body of literature on GWI by reporting findings on previously unknown characterization of GWI, specifically pre-war predictors, mortality outcomes, and 
female-specific health issues. These findings offer support for ongoing research towards a GWI case definition. Our proposed, 3-domain version of GWI may be an improvement over the CDC and Kansas definitions, but requires further replication studies and validity testing. Future research studies should investigate the occurrence of GWI according to the CDC and Kansas definitions, and any additional definitions of GWI that are worth pursuing, in the non-deployed veteran population and general population in order to understand the prevalence of GWI criteria in these populations and determine if this is, in fact, a unique disorder among Gulf War veterans. Ultimately, the primary research focus in the area of GWI should be determining a case definition.

\subsection{Conclusion}

Our results add to the vast literature on GWI; however, we cannot conclude from these studies that GWI is a disorder unique to deployed veterans of the 1990-1991 Persian Gulf War. We found that we were able to predict meeting the criteria for CDC or Kansas GWI with selfreported pre-war medical conditions and symptoms, which help explain our mortality and female-specific results.

Findings from these three aims do not support use of the CDC or Kansas definitions of GWI as recommended by the IOM. The IOM may have done the research and veteran community a disservice by recommending use of these two case definitions due to lack of validation or replication and overlap with other syndromic disorders. Continuing to conduct research studies based on classifying veterans as having GWI using the CDC or Kansas definitions, without 
questioning the validity of these studies, is detrimental to Gulf War veterans who are continuing to suffer from these complex symptom clusters. 


\section{References}

1. Committee on the Development of a Consensus Case Definition for Chronic Multisymptom Illness in - Gulf War, V., P. Board on the Health of Select, and M. Institute of, in Chronic Multisymptom Illness in Gulf War Veterans: Case Definitions Reexamined. 2014, National Academies Press (US), Copyright 2014 by the National Academy of Sciences. All rights reserved.: Washington (DC).

2. Fukuda, K., et al., Chronic multisymptom illness affecting Air Force veterans of the Gulf War. Jama, 1998. 280(11): p. 981-8.

3. Steele, L., Prevalence and patterns of Gulf War illness in Kansas veterans: association of symptoms with characteristics of person, place, and time of military service. Am J Epidemiol, 2000. 152(10): p. 992-1002.

4. Dursa, E., et al., Gulf War Illness in the 1991 Gulf war and Gulf era veteran population: an application of the centers for disease control and prevention and Kansas case definitions to historical data. Journal of Military and Veterans Health, 2018. 26(2): p. 43. 